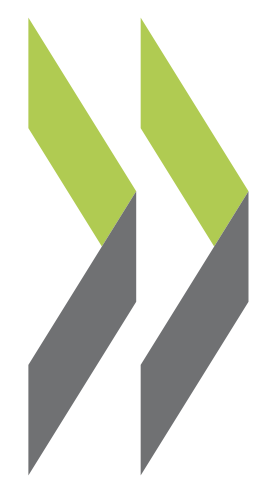

OECD Local Economic and Employment Development (LEED) Papers 2011/02

\title{
Sustainable Tourism and Local Development in Apulia Region
}

\section{Neil MacCallum,}

Thierry Baert,

Pierfelice Rosato, Stefano Barbieri 


\section{OECD LEED POLICY REVIEW}

ON:

"SUSTAINABLE TOURISM AND LOCAL DEVELOPMENT IN APULIA REGION"

A report prepared by the Local Economic and Employment Development (LEED) Programme and the Tourism Committee of the Organisation for Economic Co-operation and Development (OECD) in collaboration with Apulia Region, Italy.
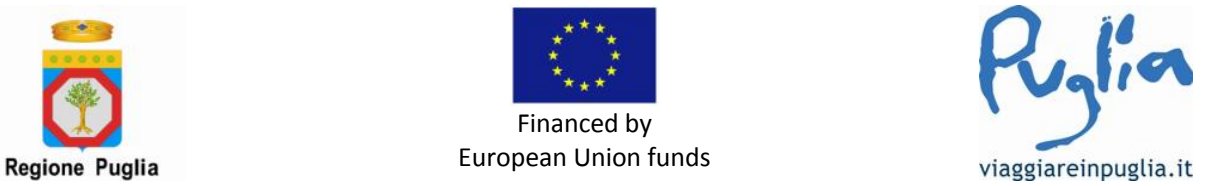



\section{AUTHORS AND PROJECT TEAM}

This report has been prepared within the project "Sustainable tourism and local development in Apulia Region" as part of the activity of the OECD's Local Economic and Employment Development (LEED) Programme on Tourism and Local Development, undertaken in cooperation with the OECD Tourism Committee. The principal authors are Neil MacCallum (Neil MacCallum Associates, UK), Thierry Baert (Senior Officer, Lille Metropolitan Agency, France) and Pierfelice Rosato (Professor, Faculty of Economics, university of Salento, Italy). Further written inputs were provided by Stefano Barbieri (OECD). The report was prepared under the supervision of Stefano Barbieri (Head of the OECD LEED Trento Centre for local development) and Alain Dupeyras (Head of the OECD Tourism Unit).

The support and the inputs of the Regional Ministry for Mediterranean Affairs, Culture and Tourism of Apulia Region, and in particular of Mr. Francesco Palumbo (Director General, Promotion of Territory, Tourism, Culture and Arts) was critical to the production of the report, as was the contribution of the representatives of regional and local authorities and other Apulian institutions and organisations who participated in meetings and provided documentation and comments. 



\section{TABLE OF CONTENTS}

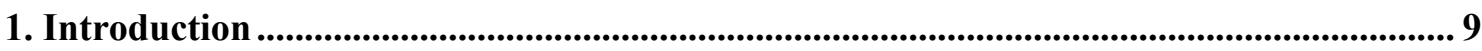

The OECD Local Economic and Employment Development Programme (LEED)

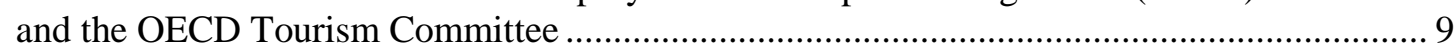

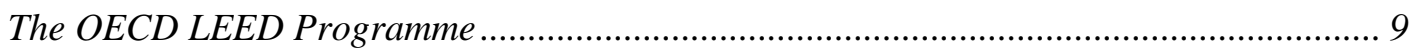

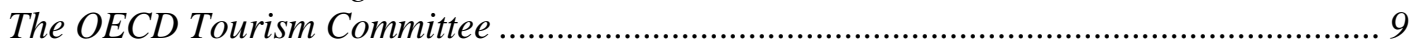

Project background, methodology and outputs ………........................................................ 10

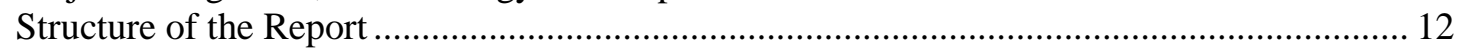

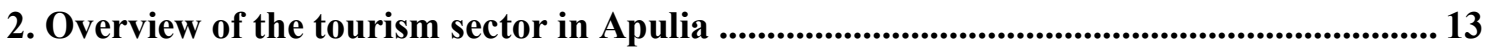

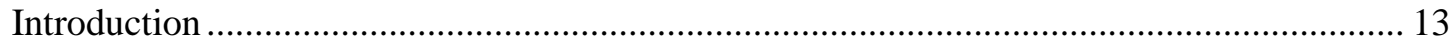

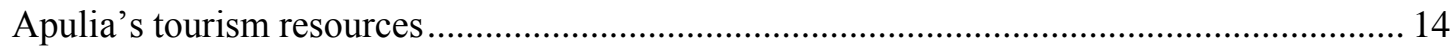

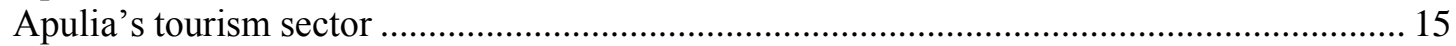

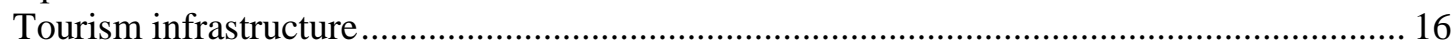

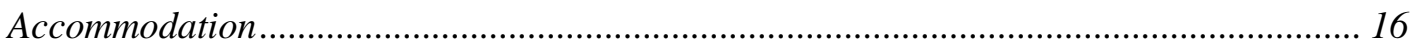



3. Overview of tourism strategy, policy and programmes in Apulia .................................... 19

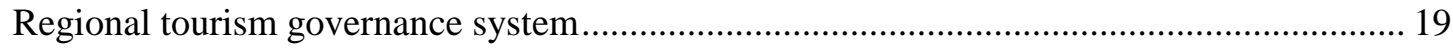

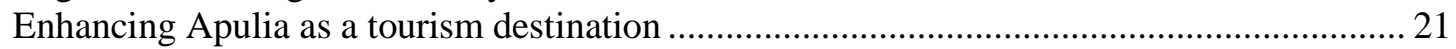

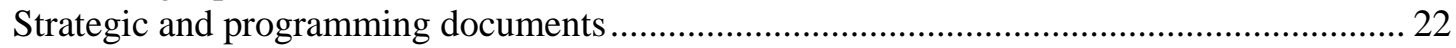

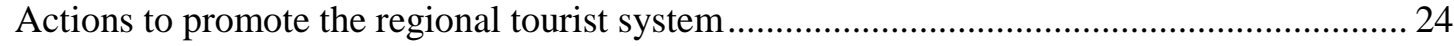

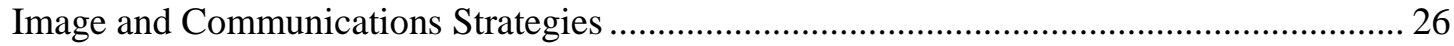

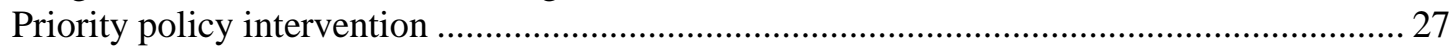

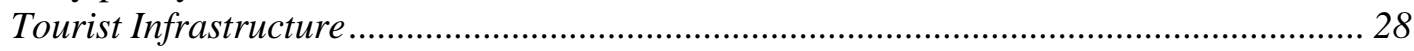

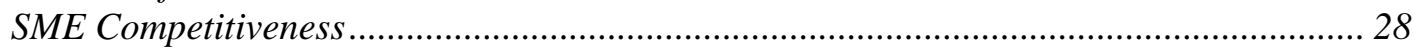

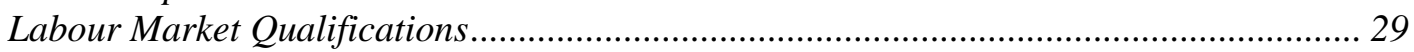



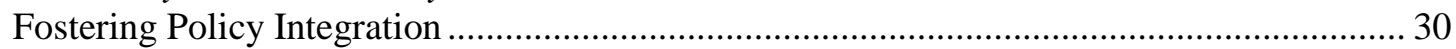

4. Challenges and requirements for establishing an integrated tourism development

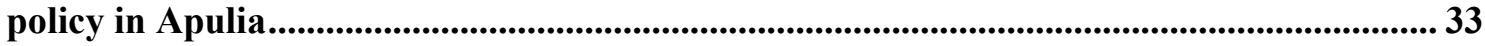

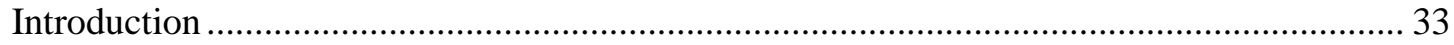

Fully integrating Tourism in the overall development strategy ............................................. 34

Importance of considering Tourism as an integrated part of local development ............... 34

Tourism, a constituent part of Apulia's current development strategy .............................. 35

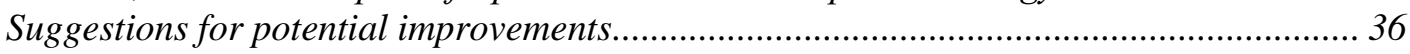

Mobilising regional resources towards tourism development ................................................. 37

Importance of mobilising all regional forces for tourism development .............................. 37

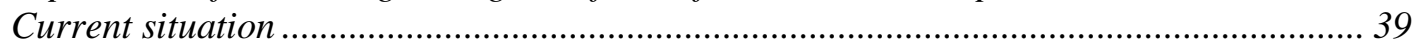

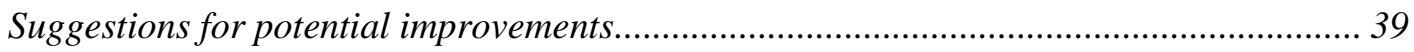

Better defining and promoting Apulia's specific tourism assets ............................................. 40 
Importance of developing a clear vision of the competitive assets ................................... 40

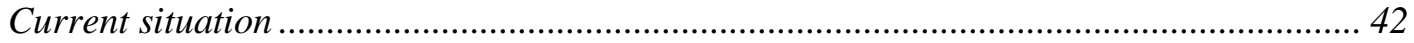

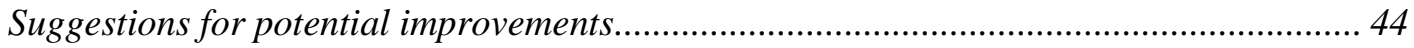

Defining tourist targets: new products for specific niches ....................................................... 47

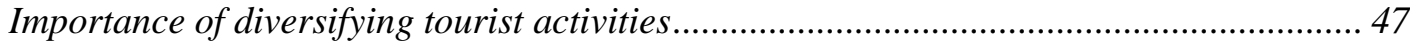

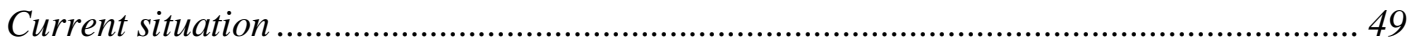

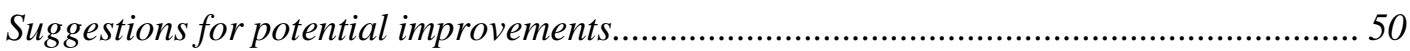



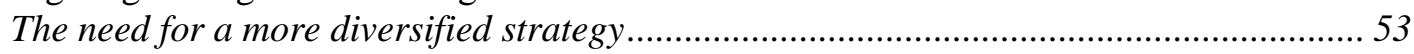





5. Training and education policies needs in the tourism sector ............................................... 57

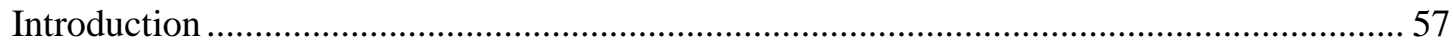

Links between tourism skills training and regional development ........................................ 58

The Importance of Human Resource Development: International Experiences .......................6 60

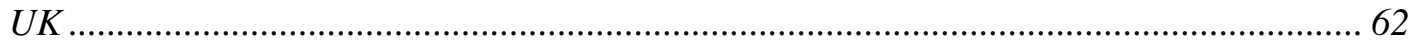

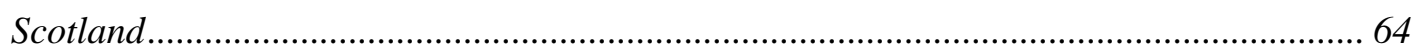

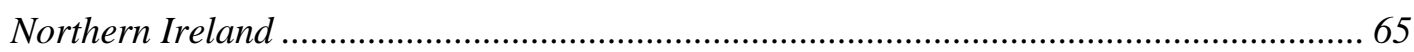

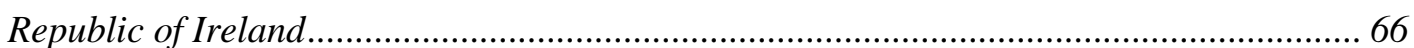

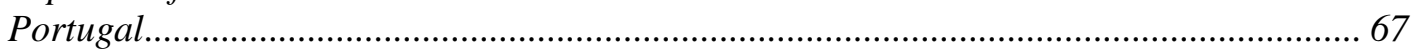

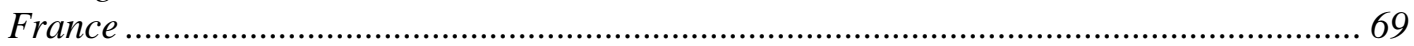

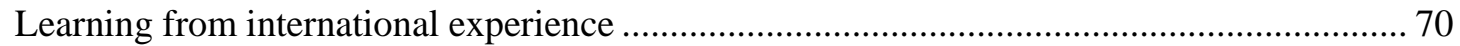

Consistent, Targeted and Themed Marketing Initiatives ................................................... 71

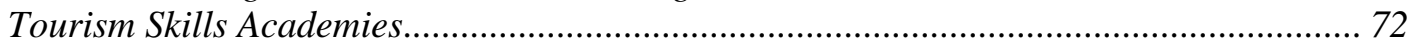

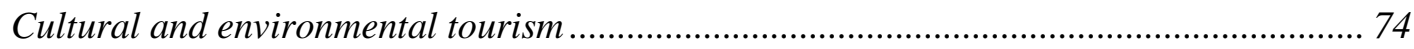



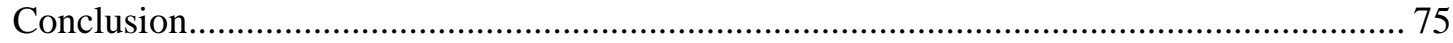

6. An Evaluation Framework for tourism development in Apulia ......................................... 77

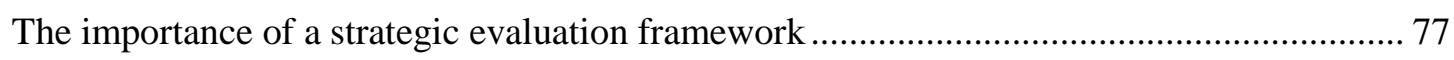

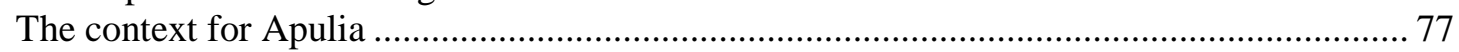

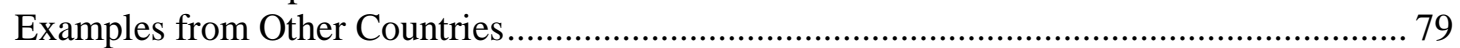

UK, England: North East England Tourism Strategy 2005-10_....................................... 79

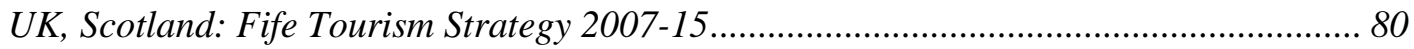

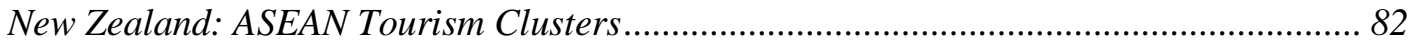

Draft Apulia Tourism Evaluation Framework ………........................................................ 82

7. Summary of analysis, recommendations and suggested actions ............................................ 86

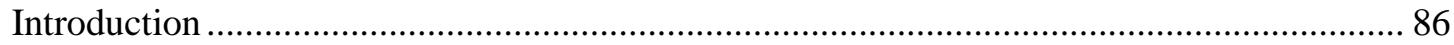

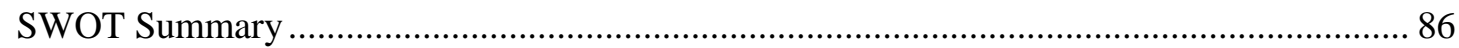

1. Better integrating tourism in the overall development strategy of the region................... 88

2. Raising participation of local citizens and private decision makers

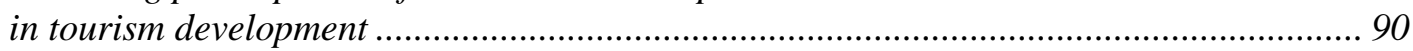

3. Better defining and promoting Apulia competitive tourism assets................................. 91

4. Improving internal mobility and external accessibility ............................................... 92

5. Better defining tourist targets: new products for specific niches .................................... 93



7. Fostering education and training for the tourism sector ............................................... 96

8. Developing an evaluation framework of tourism and local development policy ............ 98

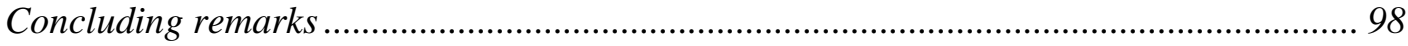




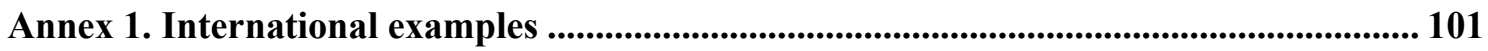

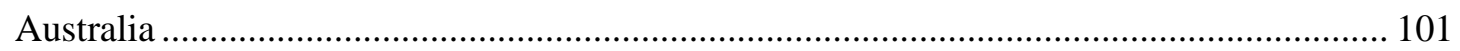



Republic of Ireland, County Laois Region .................................................................... 105

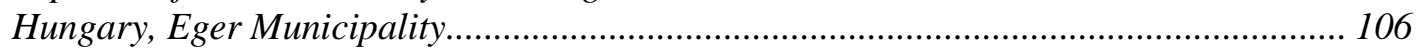

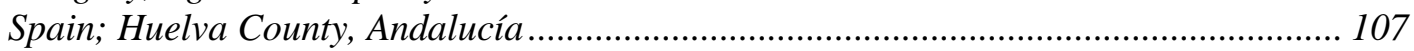

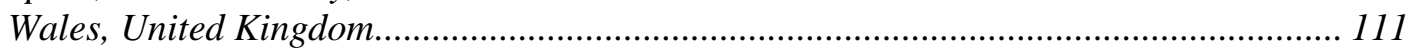

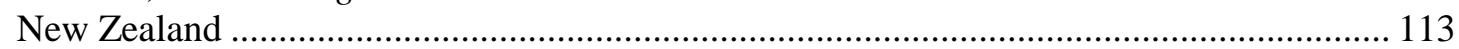

European Network of Regional Culinary Heritage .......................................................... 114

Balkans, South East Europe Cultural and Natural Heritage Routes................................... 115

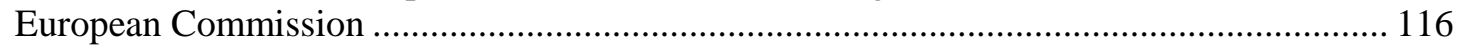

\section{Tables}

Table 1. Hungary's Operational Programmes for the period 2007-2013 ............................... 14

Table 2. Objective 1: Attract more domestic and international visitors to the region............ 80



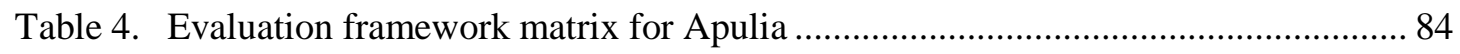



\section{Figures}

Figure 1. Sustainable Regional Tourism Destination MAnagment Framework ................ 102

Figure 2. Barossa Wine and Tourism: organisational structure ........................................ 104

\section{Boxes}

Box 1. Manchester: developing an all season tourism destination..........................................45

Box 2. Rovaniemi: creating a specific niche and marketing it worldwide .............................. 46

Box 3. The Ruhr area: developing specific and original tourism assets............................... 53

Box 4. Lille 2004: giving a positive image to a city-region and revealing its assets ............... 56 



\section{INTRODUCTION}

\section{The OECD Local Economic and Employment Development Programme (LEED) and the OECD Tourism Committee}

\section{The OECD LEED Programme}

The concept of local development is evolving rapidly. A subject of concern mainly for local authorities some years ago, local development now matters to a whole range of actors and to central governments. Governments are conscious that in a globalised economy, localities and regions compete on a world scale and must base their strategies on their local assets, knowledge, skills and other competitive advantages in order to succeed. To promote their social and economic development in an effective and sustainable way, localities and regions must pursue strategies that are cross-cutting and comprehensive, involving all relevant actors. There is a clear role for government in facilitating the emergence and development of prosperity at local level. OECD member economies look to LEED for advice on how best they can support this process in their country. They also wish that all levels and actors benefit from the exchange of know-how.

LEED is an OECD Action Programme dedicated to the identification, analysis and dissemination of innovations in local economic and employment development. The LEED Programme offers participants a uniquely active approach by providing: i) continuous monitoring and assessment of current local development practices and the diffusion of related findings; ii) analysis of initiatives, strategies and partnerships between government, business and civil society with the aim of complementing public policy and supporting local economic and social development; iii) elaboration of common methodologies and analytical frameworks for carrying out reviews and studies; and iv) a critical link both between sub-national institutions, and between the OECD and sub-national bodies, through the Partners' Club and its four Forums (the Forum on Partnerships and Local Governance, the Forum on Entrepreneurship, the Forum on Social Innovation and the Forum on Investment Strategies and Development Agencies). Integral part of LEED is the OECD LEED Trento Centre for Local Development, a specialised centre based in Trento (Italy), whose mission is to build capacity for local development in OECD member and non-member economies.

The LEED Programme is the pillar of the Centre for Entrepreneurship, SMEs and Local Development which serves three OECD bodies: the LEED Directing Committee, the Tourism Committee and the Working Party on SMEs and Entrepreneurship.

\section{The OECD Tourism Committee}

Globalisation raises permanent challenges to OECD member countries in their efforts to support the development of a competitive and sustainable tourism sector. Policies and programmes that encourage domestic and international tourism trade suppress obstacles to tourism development and improve knowledge management, promote excellence and innovation. These programmes attract and keep talent, support the access of enterprises in the global market and use resources more efficiently and innovatively to develop competitive products in the world market. 
Countries are engaged in policy and governance reforms reflecting global and local trends and structural changes in the tourism industry that lead to a new paradigm for national and international tourism that traditional tourism policies do not necessarily address. Climate change, safety and security, demographic shifts, higher energy prices, uncompetitive tourism organisations, models and products have significant impacts on travel and tourism. The policy challenge is to ensure that tourism programmes encourage a long term sustainable and competitive tourism growth for the benefits of residents, visitors and businesses. To this end, OECD members see considerable benefit in international cooperation in addressing economic and labour tourism issues, tourism policy performance and evaluation, policies harmonisation and convergence in tourism, for example for sustainable development.

In this tourism policy environment, the OECD is a recognised international player in the tourism field, notably on economic and horizontal policy issues linking tourism to related policies such the economy, trade, employment, transport, environment, local development and SMEs and Entrepreneurship. The OECD Tourism Committee acts as a forum of exchange for monitoring policies and structural changes affecting the development of international tourism and promotes a sustainable economic growth of tourism. The Tourism Committee can provide policy-makers with concrete analysis of key challenges and their economic impacts and policy responses that will shape tourism in the years to come.

\section{Project background, methodology and outputs}

Being competitive at international level is an important concern for the travel and tourism industry which operates on a global scale and market place. The improvement of competitiveness in tourism relies on a complex mix of internal and external factors. Many OECD countries and localities face a myriad of challenges and opportunities to transform their natural, historical, and cultural assets into thriving, sustainable tourism destinations, which could help support local economic growth.

This project on "Sustainable tourism and local development in Apulia region", developed by the OECD LEED Programme in collaboration with the OECD Tourism Committee, aims to assist the Regional Government of Apulia and its regional and sub-regional partners in reviewing policies and assets of the Region, so to:

- implement more effective sustainable tourism development strategies based on the valorisation of cultural, historical and natural regional assets with the aim to increase the competitiveness of Apulia as a destination and facilitate the "seasonal adjustment" of the local tourism industry;

- strengthen the value of Apulia destinations and specific visitor site propositions through the quality and the variety of tourism facilities, and;

- foster skills and capacities at local level to develop sustainable tourism and local development in an integrated way.

The project was carried out from November 2009 to September 2010, through the well established OECD peer review methodology, by an international panel composed of the OECD Secretariat and international senior experts in tourism and local development policies.

In detail, the following activities were conducted within the project review and implementation process: 
a. A steering and project working group was formed to ensure the involvement of regional key stakeholders in the implementation of the project. The steering group was led by the Regional Ministry for Mediterranean Affairs, Culture and Tourism of Apulia Region and the OECD. The working group was enlarged to local and international experts when it was considered necessary.

b. A steering group (start up) meeting was held in Apulia (Bari, 4 November 2009) to refine the work programme and agree the detailed steps and timing to be taken in the project. Discussions were also held in order to start exploring challenges and strengths related to tourism in the region and to gather relevant information for the project.

c. A fact-finding questionnaire was prepared by the OECD Secretariat and sent to Apulia as one of the principal instruments for the creation of a diagnostic. The quality of the answers was of crucial importance to the results of this review.

d. A background report, integrating and supporting answers to the above mentioned questionnaire, summarising relevant facts and documents related to tourism development in the region (such as socio-economic background, strategies and policies, programming documents, policy and business tourism structures, delivery arrangements and key challenges) was prepared by a local expert in cooperation with the regional authorities, under the OECD supervision.

e. A Review and fact finding visit was undertaken (on 14-15 December 2009) by the OECD panel in cooperation with Apulia Region to detect the strengths and weaknesses of current policy arrangements and policy development challenges. During this mission, the OECD panel met with regional and local policymakers and relevant stakeholders to gain further information and complete the questionnaire. This phase of the preparation of the report was crucial as it allowed a better understanding of the tourism issues in the region as well as provided an opportunity for discussion with policymakers and stakeholders on aspects which were not necessarily evident in written answers.

f. A draft Report was prepared by the OECD review panel based on diagnostic work undertaken, information obtained through relevant documentation and interviews with relevant stakeholders and comparisons with policies and practices followed elsewhere. The draft report set out key messages in terms of: (i) strengths and weaknesses of current approaches to tourism development in Apulia, in the light of international good practices; and (ii) practical recommendations for policy and business development according to learning models from OECD countries. The report was sent to the regional authorities for comments.

g. A seminar to present project results, to share practical approaches and initiatives and to discuss and disseminate the recommendations of the OECD was held in Apulia (Bari on 4 June 2010) with the participation of representatives of the OECD, Apulia regional government, local authorities, academic institutions and other relevant regional and local public and private organisations.

h. A final OECD report, discussing major issues related to sustainable tourism and local development in Apulia and including policy recommendations based on a comparison with OECD knowledge and international good practice, was delivered to the regional authorities on 7 October 2010. 


\section{Structure of the Report}

This document intends to provide a discussion of issues related to tourism and local development in Apulia region, an assessment of the strengths and weaknesses of current practices in related policy implementation, and recommendations and guidance on how the Apulia Government can establish and implement a successful sustainable tourism and local development strategy in the Region.

More specifically:

Chapter 2 and 3 respectively give an overview of the tourism sector in Apulia and briefly outline strategies and programmes related to tourism development currently implemented in the Region.

Chapter 4 outlines challenges for establishing an integrated tourism development policy in Apulia and related requirements concerning organisational and management arrangements.

Chapter 5 focuses on training and education policy needs in the tourism sector delivery system of the region.

Chapter 6 discuss of how to set up an evaluation framework for tourism development in Apulia.

Chapter 7 summarises the strengths, weaknesses, opportunities and threats related to tourism and local development in Apulia and points out a set of suggestions and recommendations on how the regional Government and its partners can implement more effective sustainable tourism development strategies, strengthen the quality of tourism facilities and foster skills and capacities at local level.

Finally, Annex 1 provides a more detailed description of the case studies and international examples mentioned in earlier chapters. 


\section{OVERVIEW OF THE TOURISM SECTOR IN APULIA ${ }^{1}$}

\section{Introduction}

Apulia is situated in south-east Italy and has a surface area of $19363 \mathrm{~km}^{2}$; the landscape is partly flat and partly hilly. It has the longest coastline of any Italian region, and borders on the Adriatic Sea to the east, the Ionian Sea to the south, and the neighbouring regions of Molise to the north, Basilicata and Campania to the west. The region has 4069869 inhabitants $^{2}$ and its population density of 210 per $\mathrm{km}^{2}$ makes it one of the most densely populated regions of Italy.

Apulia is recognised as one of southern Italy's most dynamic regions, and in recent years there has been a transition from an economy based predominantly on the primary sector to an economy which includes (some) big industry, an important number of SMEs, and a lively tertiary sector which supports the local economy. ${ }^{3}$ Recently the region has been opening up to new forms of international and interregional collaboration, participation and cooperation both with the nearby Mediterranean and Balkan countries, and also with areas outside Europe. The active participation of Apulia in the transEuropean corridors demonstrates the strong interest in developing and fostering networks to enhance the circulation of goods, people and ideas.

The following table outlines Apulia's economic trends in recent years (2002-2008), compared with Italy as a whole, the Centre-North, and South Italy.

\footnotetext{
${ }^{1}$ This chapter is based on the background report prepared by Prof. P. Rosato and on documents provided to the OECD team by the Regional Ministry for Mediterranean, Culture and Tourism.

${ }^{2}$ ISTAT 01/01/2007.

${ }^{3}$ The entrepreneurial vitality of Apulia is shown by the presence of over 341,000 businesses of different kinds registered for 2007.
} 
Table 1. Apulia's economic trends compared with Italy 2002-2008

\begin{tabular}{|c|c|c|c|c|c|c|c|}
\hline $\begin{array}{l}\text { Structural } \\
\text { Indicators }\end{array}$ & 2002 & 2003 & 2004 & 2005 & 2006 & 2007 & 2008 \\
\hline \multicolumn{8}{|c|}{ GDP (\%) } \\
\hline Apulia & -0.5 & -1.0 & 1.4 & 0.6 & 1.8 & 2.0 & -0.2 \\
\hline South & 0.4 & -0.3 & 0.6 & 0.3 & 1.1 & 0.7 & -1.1 \\
\hline Centre-North & 0.5 & 0.1 & 1.8 & 0.6 & 2.1 & 1.7 & -1.0 \\
\hline Italy & 0.5 & 0.0 & 1.5 & 0.6 & 1.8 & 1.5 & -1.0 \\
\hline \multicolumn{8}{|c|}{ GDP per capita (absolute values at constant prices) } \\
\hline Apulia & $14,962.2$ & $15,284.0$ & $15,702.1$ & $16,022.6$ & $16,656.6$ & $17,355.8$ & 17,955 \\
\hline South & $15,260.2$ & $15,621.5$ & $16,082.0$ & $16,501.1$ & $17,019.4$ & $17,482.8$ & 17,970 \\
\hline Centre-North & $26,781.6$ & $27,365.8$ & $28,216.4$ & $28,656.9$ & $29,475.1$ & $30,380.9$ & 30,680 \\
\hline Italy & $22,660.7$ & $23,181.3$ & $23,919.5$ & $24,372.1$ & $25,109.3$ & $25,882.1$ & 26,276 \\
\hline \multicolumn{8}{|c|}{ GDP per capita as \% of Centre-North } \\
\hline Apulia & 55.9 & 55.9 & 55.6 & 55.9 & 56.5 & 57.1 & 58.5 \\
\hline South & 57.0 & 57.1 & 57.0 & 57.6 & 57.7 & 57.5 & 58.6 \\
\hline Centre-North & 100.0 & 100.0 & 100.0 & 100.0 & 100.0 & 100.0 & 100.00 \\
\hline
\end{tabular}

Source: SVIMEZ 2009 Report on the economy of Southern Italy

\section{Apulia's tourism resources}

Apulia has a wealth of natural, cultural, environmental, architectural and social resources, including two UNESCO World Heritage sites: Frederick II of Swabia's imposing Castel del Monte, and the town centre of Alberobello with its typical "trulli", a unique legacy of local peasant culture.

Apulia has over $800 \mathrm{~km}$ of coast, 6 certified blue-flag beaches, 30 important beach resorts, 3 regional areas of excellence (Gargano, Tremiti Islands and Salento), 3 marine reserves, 250 beaches and many sea-caves. Apulia also has over 30 natural protected areas (including the National Parks of the Gargano and the High Murgia), 2 orange flags, the Itria Valley, the nature cycle path and beach trail at Torre Guaceto.

A variety of cultural resources exists in the region, including: 111 museums and art galleries (for example, the National Archaeological Museum at Taranto); a "circuit" of castles (35 open to visitors) and fortifications (coastal towers); about 100 palaces and residences; 9 historical theatres; 1042 churches including about 300 of "interest to tourists", such as cathedrals, basilicas, abbeys, cave churches, Romanesque and baroque cathedrals; Cities of Art; seven of "Italy's most beautiful villages"; 31 "historical squares"; archaeological sites and parks (eg. Lucera and Egnazia); and a large number of "historical and cultural collections" (public, private and church owned) on permanent show. In addition, there are some different historical and architectural sites, an important feature of the region: 256 courtyard houses called "trulli", 197 fortified farmsteads, underground olive oil presses, drovers' stations, towers, and many more curiosities.

Apulia also hosts many different events which enhance the historical and cultural traditions of the region, such as the Carnival at Putignano, the Daunia Carnival, the "Night of the Taranta", historical re-enactments (for example, at Oria), and literary parks. There are some nationally and internationally important events, such as the annual Itria Valley Festival. There are also some very interesting popular feasts - a tradition which has received new impetus in the last few years - accompanied by cultural activities and tourist promotions. 
In Apulia there are also important resources for religious tourism, especially S.Giovanni Rotondo, the route to San Michele, St.Nicholas' Basilica, Otranto Cathedral, the abbeys, the convents and shrines, and Holy Week events in the region.

\section{Apulia's tourism sector}

From this profile, it is apparent that tourism is one of the strategic sectors for Apulia and it is considered as a driving force for the local economy. The GDP from tourism in Apulia in 2007 (the most recent available figure) was $5 \%$ of the regional total, just a little over the national average $(4.8 \%)$, and confirmation of the increased importance of the tourism in the regional economy.

In 2007 tourists spent 4 Billion Euros, representing an increase of $2.9 \%$ from 2005. This increase is due exclusively to domestic Italian tourists as spending by foreign tourists in the region actually fell by $3 \%$ in the same period. When spending by Apulia residents outside the region is compared with non-resident spending in Apulia, the balance is positive. If tourist spending in Apulia is broken down according to types of tourist, then 55\% derives from resident tourists, $33.4 \%$ from tourists resident in other Italian regions, and $11.8 \%$ from foreign tourists. As it is evident, over 50\% of tourist spending is generated by domestic tourism, mostly due to "second homes" belonging to Apulia residents.

Apulia is an important Italian tourist destination. In the 2008 arrivals in Apulia were 2922245 and presences were 12183 376; this indicates that the region attracts a little over 3\% of the tourists who choose to holiday in Italy. Tourism in Apulia has seen significant development rates in the last ten years, with an average annual rise of 5.4\% compared with $2.0 \%$ at the national level. In particular, in 2008 Apulia actually bucked the national trend (which showed tourism decreases due to the difficult economic climate), and registered a significant increase (+6.1\%) in tourist numbers. If 2000 is taken as the reference year, the average annual growth rate is $5.4 \%$ for arrivals, and $3.9 \%$ for presences. So it is possible to state that arrivals and presences are increasing in a similar way, although they do not coincide.

Tourism in Apulia is dominated by proximity; about $16 \%$ of presences are from other Italian regions, and the regions with the biggest number of visitors to Apulia are the neighbouring regions, except for Lombardy and Veneto.

Analysis of foreign tourists shows that the inflows to Apulia have yet to reach satisfactory levels, especially in an international context. Foreign visitors are just $14.1 \%$ of the total and this is well below the average national percentage ( $40 \%$ of foreign visitors). Nor are there any encouraging signs even when data from as far back as 1998 are compared. Although there has been an increase in foreign visitors (from 1095721 in 1998 to 1713745 in 2008) the percentage of the total has actually fallen by almost one whole percent (14.1\% in 2008 versus $14.9 \%$ in 1998).

With reference to the foreign markets, Germany is consistently the leading market for both arrivals and presences; the United States' market is growing and the Japanese market is stable. The first signs of significant visitor numbers from the Eastern European markets date back to 2007, especially Russia, the Czech Republic and Poland. The numbers are still relatively low, but show a new and interesting trend. Expressed demand from the markets in nearby countries - mostly France and Switzerland - fluctuates, but remains among the leading tourist markets for Apulia.

Tourism in the region is still seasonal, much more so than in many other regions of the South. The percentages of arrivals and presences are highest in the summer, especially in the two central months of July and August. About $76.9 \%$ of annual presences were concentrated in the four summer months (June-September) of 2008; with 54.7\% in July and August. However, there is a slow, albeit not 
yet satisfactory, redistribution of presences especially due to the influence on regional tourism of short breaks outside the summer season (Easter, long weekend holidays etc.).

The average length of time tourists stay in Apulia is 4.2 days, with an inexorable tendency towards shorter stays, especially by foreign visitors.

\section{Tourism infrastructure}

\section{Accommodation}

Apulia had 3,610 accommodation facilities and 22159 beds in 2008. The number of beds in Apulia accounts for about $4.7 \%$ of the Italian total capacity. This is based on a model of hospitality in which non-hotel accommodation prevails. Apulia has 924 hotels (just $25.6 \%$ of the national total) and 2,686 non-hotel facilities. The hotels account for $36.7 \%$ of all beds. There is a prevalence of "threestar" hotels, representing about $46 \%$ of the total and $40 \%$ of beds, while "five-star" hotels account for less than $5 \%$ of the total. The gross rate of occupied hotel beds in 2007 was $22.3 \%$, much lower than the national average of $32.8 \%$.

The non-hotel tourist accommodation - including camp-sites and tourist villages - amounts to about $75 \%$ of non-hotel beds in the region, while guest houses (B\&B) are 55\% (1,129 in total) of the complementary accommodation facilities in the region, followed by 255 agri-tourism facilities accounting for $12.6 \%$ of the total.

When it comes to the average size of accommodation facilities in Apulia, there is an average of 62 beds per facility. The hotel sector in the region gives an average of 88 beds per hotel, which is well above the national average of 63 beds per hotel. Regarding the provinces, there is a significant concentration of hotel accommodation in the Provinces of Foggia (30\%) and Lecce (about 26\%), while about $50 \%$ of the complementary accommodation facilities of the Apulia are concentrated in the province of Foggia. These two provinces account for about $71 \%$ of all the accommodation facilities in the region.

Between 2000 and 2007 Apulia increased the number of accommodation facilities and beds available, with an average annual variation rate of $9.4 \%$ in 2000 and $2.1 \%$ in 2007; these levels are close to the levels in southern Italy $(+9.7 \%$ structures, $+2.6 \%$ beds), and above the Italian average $(+3.3 \%$ accommodation facilities, $+2.0 \%$ beds). Looking at the categories of accommodation facility, the number of hotels grew by $2.6 \%$, while the number of non-hotel accommodation structures rose from 815 in 2000 to 2,686 in 2008.

In addition, there is a significant sector of tourism in Apulia which does not feature in the official statistics. This involves the phenomenon of holiday homes (the so-called "second homes"). The importance of these "second homes" in Apulia is shown by some estimates from the Regional Tourist Monitor which put the real number of tourist presences at five times the official number due to the presence of "second homes".

The hospitality system in Apulia has some specific characteristics which should be highlighted in order to understand the real potential of tourism in the region and the difficulties which need to be addressed in order for further development potential to emerge.

The hotels are mainly medium-quality (3-star), and mostly situated in the various destinations along the coast. Development of hotel accommodation in Apulia has followed the logic of mediumquality beach tourism, with hotels dedicated to summer tourism and designed to open only in the 
summer months. Many of these hotels along the coast completely lack the essential services to stay open all year, for example heating. In addition, some very large tourist hotel complexes have been built along the coast - often holiday villages - directed expressly at a mass beach tourism which is not integrated with the surrounding host area. There is also low penetration of the big hotel chains - in line with the national situation - and few high-quality hotels (5-star and 5-star superior) which is not compatible with a strategy to establish a new competitive position for tourism in Apulia.

However, the last few years have seen a big increase in very typical non-hotel accommodation, which in some cases (trulli, masserie etc.) takes forms specific to Apulia. These include B\&Bs, agritourism hotels, etc. as mentioned earlier, mainly situated in the old town centres, in the countryside, and generally inland. This specific accommodation system makes it possible for Apulia to enhance its natural and cultural resources for tourism and to define a tourism destination system detached from its consolidated beach tourism.

\section{Communications and infrastructure}

\section{$\underline{\text { Ports and airports }}$}

The infrastructural system of the region hinges on three important ports and a regional airport system with 4 airports.

The articulated regional port system has three major ports with diversified functions:

- Taranto is the third Italian port in terms of traffic volume, and is a poly-functional hub for intercontinental and industrial commercial traffic;

- Bari is mainly a passenger and cruise ship terminal, in addition to being a commercial port;

- Brindisi is an important commercial and industrial port.

The Aeroporti di Apulia S.p.a. airport company belongs to Apulia Region and is responsible for integrated management of services and connections at the four airports in Apulia. Bari and Brindisi airports are international, and have flights to and from the principal Italian cities and various European and international airports. "Karol Wojtyla" Bari-Palese Airport has recently been extended and modernised, and handles 2.7 million passengers a year; Brindisi Airport has recently been renovated and handles just under a million passengers a year. Grottaglie Airport in Taranto Province is an important logistical platform for Alenia, while Foggia has a minor airport.

\section{$\underline{\text { Railways and roads }}$}

There are three railway companies operating in Apulia: Ferrovie dello Stato (882 km of rails) offers link with the whole national territory; Ferrovie Appulo Lucane (150 km of rails) cover an area in part of north-west of Apulia, connecting Puglia and Basilicata; Ferrovie del Sud Est (over $400 \mathrm{~km}$ of rails) provides links in the South-East of Apulia, where the national company is not present.

The highway and road system (77 km of highways per million of inhabitants) has some gaps in respect to national and other similar European regions (where the average is $203 \mathrm{~km}$ of highways per million of inhabitants), There are various reasons for the gaps in coverage in Apulia, including delays in constructions due to the lack of public resources, the long timing of assignments and of realisation, and the difficulties in managing complex relationships between public and private actors. In recognition of such difficulties, a five year Regional Transport Plan, the "Piano Operativo Attuativo 
2009-2013" (Regional Law 32-2007) was implemented with a decisive shift towards the sector and improving regional mobility and transportation covering all defined infrastructural (scheduled and in course) operations for all modes and means of transport. 


\section{OVERVIEW OF TOURISM STRATEGY, POLICY AND PROGRAMMES IN APULIA ${ }^{4}$}

\section{Regional tourism governance system}

The present system of governance of tourism in Apulia provides for joint efforts of different subjects: (a) the Region; (b) Tourism Promotion Offices (APT); (c) Provinces; (d) Town/City Councils.

The Region (Regional Tourist Department) has most of the tasks of programming, directing and controlling, with the purpose of ensuring a coordinated and unified presence of the image of Apulia (generally not only for tourism) in Italy and abroad. The specific and principal responsibility of the Region is to programme the development of tourism through promotion of the region and improvement of the tourism facility system, especially concerning the management of financial resources from the EU (ERDF) and Italian state (FAS).

The Tourism Promotion Agency (TPA) covers the technical-operational bodies of Apulia Region. They are present in the chief town of each province and have autonomous administration and management. Each TPA has the task of promoting its own local area and of increasing its availability by carrying out specific promotion and hospitality initiatives, either autonomously or as required by the Region. It can carry out technical-operational consultancy work to arrange for promotional programmes proposed by other public and private subjects, in keeping with Regional programming, and it also collects and processes statistical data about tourist numbers and accommodation facilities on behalf of the Region.

The legal basis for the organisation of regional tourism promotion is the Regional Law (R.L.) 28/1978 "Regional interventions for promotion of tourism in Apulia", which was last modified and supplemented in August 2005 with R.L. "Second variation to Budget for the financial year 2005" which introduced the pre-disposition of 3-year technical-financial programmes for tourism promotion and annual operative plans, and in R.L. 23 October 1996 no. 23, "Re-organisation of regional tourism administration in application of art.4 of Law 17 May 1983, no.217" and R.L. 11 February 2002 no. 1, "Regulations for application of art. 5 of Law 29 March 2001, no. 135 concerning re-organisation of Apulian tourism system”.

R.L. 11 February 2002 no.1 provided for the dissolution of the five provincial TPAs and the establishment of the RTA (Regional Tourism Agency) which took over their tasks and duties. However, this Law about the RTA has not yet been applied, so that the TPAs continue to exist under external commissioners (expiry 31.12.2009).

The Provinces mainly have the task of regulating the market by supervising the operators in the tourism sector and the management and organisation of the related activities. They also have the specific responsibility for training operators and share in programming the development of tourism in the area.

\footnotetext{
${ }^{4}$ This chapter is based on the background report prepared by Prof. P. Rosato and on documents provided to the OECD team by the Regional Ministry for tourism of Apulia.
} 
The Town and City Councils have the task of managing tourist reception services and in part also share in defining and carrying out initiatives to promote the area. The tourist reception activities are mainly carried out by signing agreements with the TPAs for the establishment and management of Tourist Information Offices (TIR) in the town or city These TIRs operate in towns and cities where tourism is important and provide information and help to tourists to enjoy their visit to Apulia's places of interest.

The present structure of governance of tourism in Apulia is at the centre of a complex reform process which is aimed at redesigning regional tourism organisation in view of the process now taking place in recognition of the Local Tourism Systems (LTSs), as provided for by the Regulations of the R.L. 11 February 2002 no. 1, and by the projected regional law - now in the discussion phase concerning reorganisation of the regional tourism system, entitled "New regulations for regional tourism organisation. Regulations regarding sector activities and programming, promotion and development of the tourism offer system."

The relevant national law (L. 135/2001) defines the local tourism systems in the following way: "homogenous or integrated tourism contexts, including areas with an integrated cultural, environmental or tourist attraction offer, including typical agricultural products or local crafts or with widespread individual or associated tourist businesses".

The Region has promoted the establishment of two distinct types of local tourism systems: the territorial tourism systems (TTS), and the product tourism systems (PTS). The TTS bring together local bodies, institutions and public administrations, professional associations, chambers of commerce and operators in homogeneous areas of a significant size. The aim is to enhance the local resources for tourism, through improved infrastructures, promotion and hospitality. The PTS are associations of public and private subjects to strengthen the competitiveness of the regional network of tourism services, and to improve the quality of the personnel working in tourism.

The Local Tourism Systems follow a Three-Year Programme of activity which must be approved by the Region and which delineates the development process which the LTS intends to undertake, and the level of agreement with Regional tourism Programming and "Vast Areas" Programming.

The Vast Areas Programming or "Area Vasta" is a new concept that does not represent a geographic entity, but the dimension of a territorial planning halfway between local and regional institutions. This definition has grown out from a process that involved private and public stakeholder discussions on the promotion and implementation of effective partnership systems and alliance networks. The operational means of territorial planning is the "Strategic Plan of Area Vasta" which defines the political project towards a sustainable development of territory in a medium to long term period. The Plan gives some guidelines proposed by Regione Puglia with particular attention on financial, economic and environmental aspects, and proposes different topics of territorial development of Area Vasta: Economics, Welfare and Culture, Environment and Territory, Mobility and Transports.

At present, the Region is evaluating 10 applications for recognition from TTSs and 5 from PTSs, which have been put forward in accordance with the regulations.

The regulations concerning re-organisation of the Regional tourism system - at present under discussion by the relevant Council commission - aim to meet some fundamental needs which have emerged during the last few years in Apulia. In particular, specific tasks and functions will be delegated to local bodies (on the basis that because of their "proximity" to citizens and tourists, this can ensure a better quality of services and performances), but at the same time the Region will retain 
the tasks of programming, directing and controlling, with specific reference to the policy of promoting the areas, which is considered to require Regional organisation.

Specifically, the regulations being studied provide some important new developments. One is the proposal to establish a Regional Destination Management Organisation (DMO) to replace the TPAs and guide the development of Destination Apulia following the guidelines and programmes of the Regional Tourism Department. In addition, there is the creation of a Tourism Programming Committee to allow the full participation of local institutions and organisations in the important decisions concerning development of the sector in the next few years.

Within the sphere of the regional information system, the Regional Tourism Monitor service will be reinforced in order to provide more extensive and more rapid information about national and international tourism trends.

The new regulations give important tasks to private operators, non-profit organisations, and organisations representing general interests; these regard participation in programming, and also the organisation and fulfilment of plans and projects to improve and strengthen the tourism facilities in Apulia. Trade unions and the business organisations have been involved in the process of formulating the regulations, in order to reach wide agreement on the final result.

The overall picture emerging from the planned reorganisation aims to ensure that each level of the regional system has clear functions: to increase the contribution of businesses and of their representative organisations, and to develop the task of the chambers of commerce and their representativeness. In addition, it aims to encourage re-training for tourism workers and to open up the job market to new professions which are particularly important in the process of modernisation, innovation and development of this sector.

\section{Enhancing Apulia as a tourism destination}

The Apulia region has recently become a more popular destination for foreign visitors. However, there are still constraints to the full development of tourism in the area. For example, the region is not matching its potential, considering its cultural and natural heritage; there is a relatively low incidence of international tourism and there is still a strong trend towards seasonal concentration of tourism flows. In this context, the regional policy on tourism aims to exploit the natural assets, culture and landscape resources of the region, transforming them to create a refined competitive advantage that will increase the attractiveness of Apulia as a destination.

The model of tourism development assumed in the Apulia region is focused on the promotion of specific local resources of the territory. The imperative is therefore to accentuate and enhance the specificity of Apulia, both in terms of natural and cultural resources and accommodations (trulli, masserizie, etc.), with the scope to encourage a highly experiential tourism, concentrated on land resources.

Furthermore, to encourage a sustainable development of tourism, it is important to qualify the tourist offer and promote the destination of Apulia. In this way, it will be possible to achieve an internationalization of tourism and overcome unbalanced seasonal flows.

This will involve the process of enhancing Apulia as a tourist destination with specific regional features revolving around four key concepts: 
1. Sustainability: The aim is to promote a territory which becomes a destination system through a process of enhancing the specificity, typicality and cultural, natural and landscape resources which characterise Apulia as a region in harmony, balance and synergy with the environment and local communities.

1. Out-of-season tourism: The strategic aim consists of enhancing forms of tourism and experiences of Apulia which are alternative and complementary to the traditional beach holiday, using a systematic process of promoting the differentiated and significant destination resources of the Region.

2. Internationalisation: Increasing Apulia's attractiveness for foreign tourists is a priority, because there is a persistent gap between the potential for penetration of the foreign markets and the numbers of foreign tourists actually registered.

3. Promotion of different "tourisms" in Apulia: The aim is to valorise the potential capacity of Apulia by creating differentiated forms of tourism offerings and complementary motives for purchasing the composite "Puglia as a product".

These goals, according to the Regional Ministry for Tourism, should be achieved through specific actions and activities that will increase the competitiveness of the region thereby enhancing the attractiveness of the territory for tourists and visitors (with a particular attention to foreign visitors).

The activities to be developed aim to:

1. strengthen the unified and integrated image of the diversified local heritage of Apulia through a marketing campaign focused on different territorial components and on the specialisation of the supply system;

2. improve specific infrastructures to support and facilitate tourist movements in the territory;

3. strengthen the regional hospitality through interventions that aim to improve tourist services making them suitable to meet the changing needs of regular and potential new customers;

4. improve the recognised qualifications levels within the human resources involved in the tourist sector focusing on the role they play in raising service standards of the overall regional system of hospitality.

\section{Strategic and programming documents}

At the European (EU) level, regional tourism policy is referred to in Priority 5 "Enhancement of natural and cultural resources for attraction and development" of the NSP - National Strategic Plan 2007. The general objective of the Priority is to valorise the local natural, cultural and landscape resources, transforming them into a competitive advantage to make the territory more attractive to tourists, to improve the quality of life for inhabitants and to promote new forms of sustainable economic development.

At the Regional level, the objectives and priorities set in the NSF are presented explicitly in the Regional Strategic Document (RSD), adopted by Regional Government Resolution 1139, 01/08/2006, which also underlines the forms of financial and programming integration for the use of EU and national funding (Underdeveloped Area Fund) in the 2007-2013 programming cycle. 
The means used to implement the unified regional policy are the OP ERDF (adopted by R.G.R. 146, 12/02/2008) and the correlated Long-Term Programme of Axis IV (approved by R.G.R. 1150, 30/06/2009) and also the Regional Action Programme (RAP) UAF approved by R.G.R. 463, $24 / 03 / 2009$.

Axis IV of the OP ERDF "Enhancement of natural and cultural resources for attraction and development" aims to make the region more attractive to tourists with environmental policies, and actions directed at goods, and cultural events and the tourism offer.

With specific reference to regional tourism policy, the Action Plan of Axis IV is organised in operational choices - essentially centred on completion of the network of infrastructures for the tourism economy, on marketing and promotion and on the development of social tourism - and the OP priorities concerning tourism.

The line of intervention of the Axis IV Action Plan which sets out the actions to carry out the aims of the Axis concerning tourism is 4.1 "Infrastructures, promotion and valorisation of the tourism economy". This line of action aims to promote the tourism economy by valorisation, qualification, diversification and promotion of the integrated tourism offer of the territorial systems, the completion and qualification of the infrastructures and territorial marketing actions with actions dedicated to completion of infrastructures supporting the tourism economy (especially tourist ports); to the development of territorial marketing and promotion, with the aim of taking Apulian tourist destinations onto the national and international markets; and finally to the creation of hospitality structures and leisure facilities for social tourism, in rural and beach contexts as well as in the old town centres.

The priority reference of the line is the Local Tourism Systems, which are in the process of achieving recognition in Apulia with the objective of integrating tourism promotion into the system of environmental and cultural features of the region and of bringing tourists and visitors out of season.

The types of action in line 4.1 of Axis IV action Plan are:

- Action 4.1.1 "Completion of infrastructures supporting the tourism economy, specifically: tourist ports; removal of barriers in major tourist sites", makes it possible to carry out activities to support the tourism offer, by adapting the structures, infrastructures and facilities in the Region. Particular importance is given to improving the tourist port system (subject of specific regional planning) and to the priority systemic interventions to enhance hospitality and availability for tourism, in order to place Apulian destinations on the national and international markets.

- Action 4.1.2 - "Enhancement and promotion of the region by development of specific marketing actions to put tourist destinations firmly on the markets" makes it possible to carry out activities to valorise and promote the Region, in order to place Apulian destinations on the national and international markets. In particular there is support for events, shows, projects and activities which provide: (a) better understanding of the territory and its special features, (b) valorisation of excellence and specialities of the territory, mostly consisting of landscape, history, architecture, culture and local traditions, (c) promotion of regional tourist destinations, itineraries and products, (d) implementation of the offer, with reference to specific targets, markets and products, (e) reinforcement of the overall image of the Region, aimed at Italian regions and foreign countries of particular interest; (f) increased hospitality capacity and the qualification of the services it requires. 
- Action 4.1.3 - "Development of residential accommodation and leisure facilities to support social tourism, in rural and beach contexts as well as in the old town centres" provides for interventions aimed at organising a territorial network of structures expressly dedicated to social tourism.

The action is carried out in line with the decisions and strategic objectives identified by the Regional Ministry for Tourism and Hotel Industry, in order to enhance the social tourism offer in Apulia, and organise it into an enhanced system.

\section{Actions to promote the regional tourist system}

The Regional Ministry for Tourism has focused recently much of its efforts in reaching a specific target considered an important prerequisite for the development of tourism in Apulia. The target consists in transforming Apulia into a prestigious tourist destination recognised and accredited in the major markets.

At the beginning of the current political administration, there was a view that Apulia region discounted a significant gap in terms of notoriety as a tourist destination due to previous marketing campaigns that focused heavily only on specific areas of the territory (i.e. Gargano, Salento, Valle d'Itria) instead of a promotion of the region as a whole. To change this situation, in recent years efforts have been made to elaborate a set of actions and activities based on communication, promotion, establishment and enhancement of the brand "Apulia".

This started with the development of an articulated programme for promoting the regional tourist system, aiming to bolster the image and position of Apulia on the various markets, to increase the numbers of incoming tourists and to diversify their targets. For this purpose, the Regional Government of Apulia has a programme of participating at the main Tourism Fairs in Italy and abroad, in line with ENIT's national annual programme.

Apulia has also been promoted by its partnership with the Apulia Film Commission Foundation in order to promote "Apulia and cinema" in Italy and abroad. The activities consisted of participation in national and international festivals, road shows and previews to bring Apulian destinations to the notice of film-goers abroad. This promotional activity with the Apulia Film Commission has also meant that film crews and both national and international cinema stakeholders have been guests in Apulia, in order to promote its image as an excellent location. The partnership with the Apulia Film Commission has made it possible - in the wake of other similar collaborations in Italy (for example, the consolidated Turin Piedmont Film Commission Foundation) - to attract increasing numbers of television and film crews to Apulia, with positive effects on the Region's image.

The Regional tourism industry has also been promoted by hospitality events and educational trips. Specific promotional projects have seen the creation and the support of hospitality initiatives for various categories. Journalists and tour operators can have a positive effect on Apulian tourism by getting to know the Region and by staying there. These activities have been aimed particularly to promote the tourist attractions of the Region and the offer from the tourism sector. The specific promotional projects for the Region have been carried out with support from the Apulian Tourist Agencies.

The competitiveness of Apulia, as a destination, has also been strengthened by cultural, artistic, sports and entertainment events. The aim is to present a rich offer of Regional events with these activities. 
These are events and initiatives (nationally or internationally important) with a promotional impact and positive effect on the image of Apulia and which can also show present Regional aspects and features, as well as products and important segments of the tourism sector. There is also a system of more Regional events planned, aimed at expanding and supplementing the Regional tourist offer with activities to welcome and entertain visitors, and also to improve the hospitality capacity of the Regional tourist system by promoting and funding "big events".

Apulia has seen the growth and consolidation of a real system of tourist and cultural events which have had a big impact on making Apulia a known and attractive destination. For example, there is the "Night of the Taranta" event in the Salento which has really helped to make the destination known and increase its appeal abroad. Apulia has also chosen to host the Charles Darwin Bicentenary Exhibition. This is a touring project based on an exhibition originally held at the American Museum of Natural History in New York, in collaboration with the Museum of Science in Boston, the Field Museum in Chicago, the Royal Ontario Museum in Toronto and the Natural History Museum in London. Bari is the third Italian stop on the exhibition tour, which registered over 120,000 visitors in Rome at the Exhibition Centre from February 12-May 3 2009. Milan had over 50,000 visitors at the Rotonda in Via Befana from June 4-25 October 2009.

Apulia Region chose to organise a great cultural event capable of attracting large numbers of tourists, as part of a wider plan of the Regional Tourism and Mediterranean Departments, intended to promote a complex of cultural and entertainment events by private operators and/or local authorities in the Region. In the last few years,

The Regional Tourism and Mediterranean Departments - responsible for cultural policies of the Regional Government - have collaborated to give institutional support to cultural event-based tourism, and have launched two specific actions.

The first is the "Single Notice Board of Tourist and Cultural Events in Apulia" and aims to select and promote the main important and interesting events in the region for tourists, on the principal reference markets. This will allow the creation of a way to promote important and attractive tourist events and also to greatly expand the overall destination offer. This will make it possible to carry out a unified promotion of all the events for tourists which take place every year in Apulia.

The second action to support cultural event-based tourism is "Puglia - location for big events" and consists of identifying forms of financial incentives to attract big cultural and entertainment events to the region. The aim is for the Region to make Apulia a choice venue for big cultural events (live shows, exhibitions etc.) by offering a packet of services to make Apulia economically competitive; for example, hospitality for the entire crew, highly qualified technical services, and provision of adequate venues for shows etc. This action aims to attract new and important cultural events to Apulia which can encourage a new influx of tourists.

The importance of such events to the development of tourism in Apulia is demonstrated by the decision to invest large amounts of EU resources for promoting tourism in a big event during the "Immacolata" holiday weekend (8 December) in 2008, an event called Puglia Night Parade. The idea was to organise a series of events at the same time in different public squares across the Region, with national and international performers able to attract significant numbers of Italian and foreign visitors outside the summer holiday season; the obvious intention was to promote out-of-season tourism in Apulia. This event was an extraordinary tourist attraction in the off-season and was an important contribution towards achieving the strategic aim of creating out-of-season tourism in the Region. 
The Regional Tourist Department wanted to consolidate the attractiveness of Apulia as an out-ofseason destination, and organised the "Puglia Show Time" event in 2009; this consisted of local entertainment events during the "Immacolata" holiday weekend, and also the promotion of Apulia as a destination in the main foreign reference markets with specific events (open theatres, cultural events etc.) in the first weekend of January, February, March and April. The aim is to encourage Italians and especially foreign tourists to visit Apulia outside the usual tourist season by organising events which enhance the specific cultural and artistic features of the Region.

The "Open Cities and Beaches 2009 and 2010" project is part of the programme of promotional events launched by the Regional Tourist Department. This is a complex programme of hospitality and promotional interventions aimed at prolonging the opening of the main public and private tourist sites, and at ensuring that visitors find their facilities improved and more available during the summer.

This range of activities are directed at consolidating and reinforcing the "hospitality culture", and include the active participation of category associations, the tertiary and business sectors, with the aim of extending opening times and days of shops and businesses. This programme approach has made it possible to improve the hospitality capacity of the Region with many of the attractions put on the web, and great benefits in terms of visitor numbers and image profile for the different Apulian tourist destinations.

\section{Image and Communications Strategies}

The different promotional programmes launched by the Department and the awareness activities involving the local communities and business system of the Region have been accompanied by some specific communication actions. These have been established as part of a system aimed at defining and conveying the image of Apulia for tourists, and this has included specific branding strategies. These should be developed to recognise the basics of tourism image making; the overall image of a tourist destination is a combination of three types of image: (a) the image created by uncontrollable information; (b) the induced image created by controllable tourist information; (c) the image resulting from the experience of people who have visited or plan to visit the destination.

The overall image has a great influence on the choices for potential tourists, on their expectations and perceptions of quality and on the filter of perceptions. This is why the creation, spread and consolidation of the image cannot be left to chance, but should follow a precise strategy of positioning and communication.

Analysis of the communication strategy is therefore aimed at identifying the induced image conveyed by the main channels of tourist communication produced by the Department, and to discover which "issues are most recurrent" in their association with tourism in Apulia - the most representative key words, the claims most used, the most important targets.

During the period 2006-2009, the Tourist and Hotel Industry Department of Apulia Region launched many institutional and promotional communication activities, using jointly different media. The official www.viaggiareinpuglia.it website is fundamental and central in the complex communication policy concerning Apulia as a tourist destination. Indeed the entire strategy for communicating about tourism in Apulia revolves around the website. The idea is to make the site the main information access point for all tourist activities in the region, and it is the point of reference for identification, connotation and validation of the Brand Apulia. Thus all events of relevance to tourism are communicated with explicit reference back to the Region's website. 
The means most used for communicating Apulia's image as a tourist destination in the last four years are: (a) press advertisements and advertising articles; (b) television advertisements and programmes; (c) tourist publications, including guides, publications, dedicated editions of specialised magazines, leaflets, posters etc.; (d) events, including fairs, forums and thematic shows; (e) internet (website, blogs and social networks); (f) various kinds of specific projects.

The Regional Department has adopted a coordinated line for the region's image to use across the whole range of published and promotional material it intends to use. This aims to ensure real coordination between the different means of communication used.

As noted above, different means of communication have been used across a four-year period, and there has been a development in the kind of communication used. This has seen a transition from "written and spoken" traditional means to innovative channels which use new technologies like the www.viaggiareinpuglia.it website (mobile section, blog, social network) which facilitates two-way communication and increases the continuous interaction between sender and target audience.

The institutional image conveyed is based on the entirety of the actions to communicate and can be categorised into four themes/values of hospitality, integration, sustainability and tourism for all. Through the themes of this image, "Destination Puglia" aims to make all local operators aware of hospitality, environmental and social sustainability of tourism, and the promotion of integrated actions. In this way Apulia is communicated as a destination which pays attention to all the local agents (operators, citizens and tourists), and is "aware" of the most important issues connected with tourism, such as accessibility and eco-sustainability.

Also, the tourist image which Apulia promotes to the outside world is of a destination that is "beautiful all year round", to be experienced 365 days a year with an out-of-season offer accommodating various types of tourism, including: (a) cinema tourism; (b) cultural; (c) food and wine; (d) religious; (e) sport; (f) thermal spas. The core image is of a destination which is sensitive to hospitality.

\section{Priority policy intervention}

The need to promote Apulia on the main target markets resulted in a significant imbalance of regional policies on tourism in the direction of actions and interventions of promotion and communication. At present, conversely, the regional government has decided to concentrate on the structural problems of local tourism with the aim of qualifying the overall supply system.

To this end, the Department for Tourism has identified four priorities to qualify the regional tourism system (with respect to which the interventions are insufficient or are in a state of planning documents not yet implemented):

1. to adjust and strengthen specific tourist infrastructures;

2. to support the competitiveness of local enterprise in order to facilitate the emergence of tourist services that can satisfy the changing needs of regular and potential customers;

3. to improve the qualifications of labour and all the human resources involved in the sector in order to increase the quality standards of the supply system;

4. to improve the internal mobility within the region and the accessibility to the destination. 


\section{Tourist Infrastructure}

A transitional programme for the strategic planning of the "Aree Vaste" has been approved recently. It identifies and allocates resources to finance specific adjustment interventions to tourist infrastructure in the region (roads, signposts, street-lighting, street furniture, marked itineraries and paths, car parks) for a total investment of 30,000,000 Euros.

\section{SME Competitiveness}

To support firms' competitiveness in the sector, the Apulia Region has defined specific rules for regional and individual schemes to help SMEs in the tourist trade. Small enterprises are helped to carry out initial investments and medium enterprises and consortiums of SMEs are helped with integrated investment projects.

The second type of support concerns aid to medium-sized enterprises and consortia of SMEs for the Integrated Investment Projects. This term means a business initiative directed towards the creation of an organic and integrated set of investments in tangible and intangible assets aimed at improving the regional tourism facilities by favouring out-of-season tourism. This involves the creation of structures, and also the recovery of buildings with a special historical-architectural value for use as hotels and the also the extension, modernisation and renovation of existing hotels in order to improve the standard of quality.

Projects which concern investments in material assets in several units must also provide for a single distinctive brand, a single integrated promotion and marketing plan, and integrated management of the tourism activities.

Connected structures are defined as structures or installations which are functionally connected with the main accommodation structure (or in the case of a consortium to a number of accommodation structures) where the activity is carried out, such as: (a) golf courses with at least 18 holes; (b) tourist ports and Flying Clubs; (c) sports facilities capable of hosting national and international competitions; (d) the first installation and/or organisation of green areas of at least 200 hectares (including the creation of cycle paths, trails, sporting trails, refreshment facilities etc.) including public property, use of which is shared with the Administration it belongs to; (e) conference centres or auditoriums with at least 2,000 seats.

Single SME or consortia which want to take advantage of this support must have had a turnover of at least 8 million Euro in the previous year.

The investment admissible must be between 2,000,000 and 20,000,000 Euro, and is entirely for installations with a weight of $35 \%$ for investments by medium-sized businesses and $45 \%$ for investments by small businesses.

The choice made by the region is to support the re-qualification and modernisation of the existing receptive structures. Financial support for new structures is restricted to those built exploiting the actual architectural heritage that is typical of Apulia (trulli, manor farms, historical houses, etc.). In addition to that, the region intended to promote the cooperation among local receptive firms in order to increase the overall competitiveness of the destination. 


\section{Labour Market Qualifications}

With reference to the theme of training and education policies for the tourism sector, the authorities have recognised an evident gap between the offer of specialised training programmes financed by the region and the demand for specific skills coming from the tourism sector enterprises. In order to better address this issue, the Regional Department for Tourism identified a possible solution in the creation of a High Level Training School on tourism with the aim of supporting the growth of regional tourism SMEs The High Level Training School will work in close cooperation with Universities and the high school system in the region. This could represent an important progressive step to better link the training offer to the real needs of local entrepreneurs.

\section{Mobility and accessibility}

\section{$\underline{\text { Airlines }}$}

The network of airline routes is a very important issue for the development of tourism in Apulia. The region is a geographically peripheral area, and so the improvement of airline links - especially international routes to Central and Eastern Europe - could make an obvious contribution to expansion of tourism and the numbers of out-of-season visitors to the region.

From 2006-2008, in order to develop the network of airline routes of the Apulian airport system, the Regional Tourist Department promoted and financed co-marketing with "Aeroporti di Puglia", involving three communication campaigns to develop incoming tourism. These campaigns achieved strong results for Apulia: (a) consolidation of the German, British, Belgian, Swiss, French, Austrian and Italian markets, all traditionally linked to Apulia; (b) an improved image of Apulia on the original markets, and new potential tourist inflows; (c) development of incoming charter flights.

Over the three-year period, nine destinations were the object of co-marketing in 2006 and 2007, and eight destinations in 2008. The positive results of the communication campaign have been the incentive for a new co-marketing collaboration with Aeroporti di Puglia to promote the region on the main markets for low-cost flights already in operation, and for those about to be established. This will allow Apulia to further expand the network of destinations served by Bari and Brindisi Airports, with Ryanair as its privileged partner due to its prominent role in determining the travel choices of tourists in Europe.

Ryanair has committed to providing 10 new routes from Bari and five from Brindisi during 2010, which will add to the seven already operating from Bari and the five from Brindisi. In addition, the agreement is that Ryanair will use Bari as a new operative base, and will locate three Boeing 737/800s with 189 passenger seats there for five years, with the option of a further five years.

Apulia Region is making great efforts to expand the network of destinations served and this is indicative of the importance which the region gives to the issue of physical accessibility in the development of Apulian tourism.

Apulia is a narrow and long region, therefore it is important to implement actions to improve the internal mobility system in order to favour the creation of new itineraries to increase access make a better use of the multiple resources of the region in an integrated way. To achieve this, a better coordination with the transport policies is crucial in order to define integrated actions to improve the actual internal mobility system. 
With reference to the theme of infrastructure, Apulia is making a big effort to improve the regional system of tourist ports. Apulia has over $800 \mathrm{~km}$ of coastline and a natural vocation for sailing. For this reason, the region has recently commissioned a feasibility study on the regional tourist port system which has allowed the preparation of an organic development plan and programme of infrastructure work and functional improvements required for enhancement of the entire regional network. At present, the study's results have provided the basis for a series of preliminary discussions involving the Regional Ministry and the various Town and City Councils, aimed at defining the work needed to re-qualify tourist ports using European Union funds (ERDF).

\section{Fostering Policy Integration}

As noted earlier, the present structure of governance of tourism in Apulia is at the centre of a complex reform process which is aimed at redesigning regional tourism organisation and management.

The better integration of environmental, cultural and tourism policies is essential given their important role in a more general strategy of development aimed at making Apulia more competitive. The application of a policy of integration means selection and activation of "links" of interventions and environmental, cultural and tourism activities which are interdependent, functionally connected, mutually synergic and complementary, and also clearly directed towards unified developmental objectives at the territorial and sectoral levels. This method makes it possible to avoid fragmentation of projects or silo thinking and compartmentalisation.

For this purpose, the Regional Ministry for Tourism has been considering strategically important ways to systematically connect tourism policies with the interventions to valorise the vast historical and cultural heritage of the region and the spread of artistic and cultural activities. In this respect Apulia has moved from the stage of recovery and valorisation of the single "cultural and environmental emergencies" to the stage of valorisation of cultural and tourism "integrated systems". This was done at the regional level by activating a bottom up integration of the planning capacity of the territories in the context of a more general process of multi-funded coordination based on common objectives and procedures.

This has encouraged a positive process of territorial animation, connected with the common activities of "Aree Vaste", by setting up "territorial" negotiation instruments, and the start of integrated and efficient management ventures for territorial resources aimed at the implementation of "environmental and cultural systems" and "local tourism systems" (LTSs). The actions undertaken will ensure cost effectiveness and efficiency in the short term, and in the medium term it ensures the development of new territorial capacities and capabilities for competitiveness, cooperation and codevelopment within the "enlarged Euro-Mediterranean" area.

Regional action in the field of tourism, culture and the environment is directed towards the adoption of a strategy of "integration between systems" based on the valorisation of the "real" territory and connected with the planning and development processes of the ten "Aree Vaste". This takes concrete form with the creation of "system actions" to fulfil Axis IV of ERDF with the direct involvement of all its lines of intervention 4.1, 4.2, 4.3 and 4.4 of the Action Plan. Further integrations are defined with interventions included in Axis VII of the ERDF Apulia; with the actions identified in Vast Areas programming, admissible in Axis IV, and; with the strategies and interventions provided for in the framework of the LTSs and the interregional and national territorial valorisation programmes (the Interregional Operational Programme - InPO - "Cultural, natural and tourist attractions", Museum Poles). 
As far as tourism is specifically concerned, the regional strategy provides for accompaniment of "environmental and cultural systems" with the promotion of tourism products in keeping with the regional character and with its territorial potential, and this includes the creation of specialised "Local Tourism Systems" for themes and territories. It also includes the full involvement of the production sector, the exploitation of district economies, the generation of new entrepreneurial forms and publicprivate partnerships. More widely, the strategy also provides for the integration of Apulian tourism, cultural and environmental systems with the actions of (InPO) "Cultural, natural and tourist attractions", in particular concerning interregional enhancement and integration of the poles and their cultural, natural and landscape attractions, in coordination also with Ministry of Cultural Heritage and Activities and the Ministry of Environment.

On this basis, the Region intends to define a common working method in agreement with the territories starting from the negotiation process that has led to the approval of the transitional plans through an appropriate assessment of the coherence of the "Area Vasta" planning with the tools regional planning on the basis of an operational approach able to link the need for expenditure efficiency with strategic effectiveness of the interventions.

In parallel with the assessment of the transitional programme, the Region has launched a coordination process of regional and local project initiatives through the definition, in a partnership perspective, of a Plan of Actions (Piano di Interventi) based on a multi-funds approach (from the Interregional Operational Programme - POIn, within the 2007-13 European Structural Funds programming; and from the so called Interregional Implementation Programme - PAIn, within the national funds for "underdeveloped areas" - FAS). The Plan of Action allows the Region to act in favour of initiatives with a high financial leverage and a significant impact on the socio-economic development of the region. The definition of the plan is still ongoing through negotiation processes involving regional ministers, the "Aree Vaste" and main stakeholders. The plan should also cover the initiatives of the regional Government and its Departments.

For the plans mentioned above, besides reconciling the common requirements for cost effectiveness and efficiency, and favouring a significant bottom up partnership process with the main stakeholders of the territory, this stage is a preliminary to the identification and establishment of "Territorial and Cultural Systems (TAC)" and of "Territorial Tourist Systems". These can ensure unified, qualified and sustainable use of the environmental and cultural heritage of the region. The establishment of the TAC/TTS marks the fundamental transition from interventions designed to safeguard and protect, to local-scale activities of integrated enhancement and shared management of the territorial environment and culture, within the promotion of tourism at the national and international levels. In practice, there is a transition from planning and management of the single "emergencies" to an aggregated management of services and activities.

The TAC are based on a system of environmental and cultural resources, and the TTS are dedicated to creating a system for the promotion of tourism; both aim to achieve more efficient management and more regular and sustainable use of the territorial heritage. These are seen as the means to strengthen Apulia's position in the Euro-Mediterranean area, including the Euro-Adriatic region, and also to develop a new way to finance the territorial projects. The transition from the multifunded intervention plans to the adoption of tourist, environmental and cultural systems requires organisation and the conviction to promote advanced processes of regional attractiveness which also recognise the importance of tourism in order to promote the socio-economic development and international regional cooperation. 



\section{CHALLENGES AND REQUIREMENTS FOR ESTABLISHING AN INTEGRATED TOURISM DEVELOPMENT POLICY IN APULIA}

\section{Introduction}

In recent years, the Apulian authorities, the Regional Giunta and Council, have started to design and implement a strategy for increasing the tourism development at the regional level. Before this, tourism development policies were managed at local and/or provincial levels, with quite uneven performances, and if some specific sights were already attracting many visitors, most of the tourist flows were linked with traditional seaside activities. Tourism issues are not new for Apulia, and as noted earlier in this report, the tourism industries contribution to the regional GDP is close to the national average but, compared with some other Italian regions, it has until now played a less significant role in the local economy.

Apulia is actually a large and quite diverse region, with a dense network of cities and towns and many micro-regions endowed with specific features, in spite of a common historic background and cultural identity. The range of regional tourist assets reflects this diversity and richness. However this situation is not providing the region with a clear and unique image, especially at international level, and this makes the design and development of a regional policy a challenging task.

Initiatives, taken by the regional authorities to reinforce and diversify tourism activities in Apulia, and to promote the entire region as a tourist destination, have clearly met with some initial successes. However it seems obvious for regional decision-makers, as it is for external experts, that there is still much work to be done if the objective is to develop tourism in Apulia to a similar level as that achieved in neighbouring Italian regions such as Campania or Sicily.

Efforts should be carried on and intensified in order to consolidate the current growth, and to produce even greater results while avoiding the negative consequences of over intensive peak period tourist flows. Besides specific challenges related to enhancing education and training, as well as policy evaluation, which will be developed hereafter, five strategic issues merit specific focus:

4. a full integration of tourism in the overall development strategy and the incorporation of tourism goals in the other regional development strategies;

1. a greater awareness - and participation - among local public and private decision-makers but also amongst the wider public of the importance of tourism development;

2. a clearer definition and promotion of Apulia's competitive assets, compared with other tourist destinations in the central part of the Mediterranean Sea;

3. a better segmentation of tourism targets according to specific tourist characteristics, their backgrounds and expectations; and as a consequence,

4. a more targeted branding of Apulia. 


\title{
Fully integrating Tourism in the overall development strategy
}

\section{Importance of considering Tourism as an integrated part of local development}

\author{
Tourism is a horizontal domain, which encompasses many different policy fields
}

The need for a better and more effective definition and implementation of local and regional development strategies is a crucial issue for both the concerned territories and the European Union. This concern has been at the core of political debates and regional studies at national and European level, at least since the time when the European cohesion policy was created. The issue is obviously all the more important for regions covered by the convergence objective and responsibilities to the EU.

The importance of the challenges faced by the European model in the globalized world, and the constantly growing demand for an effective use of a relatively scarce public resource, are clearly the major reasons backing this demand. But another important reason lies in the progress of a new conception of local development, based on principles associated with sustainability. This means designing policies not merely to tackle particular issues individually but rather by considering them as a whole, and especially taking into account their potential interaction and the combined or contradictory effects coming from the different initiatives to be implemented.

This has led to the development of the concept of integrated local development, which has been considered as the reference method at European level in recent years and is promoted to be as relevant for small communities (neighbourhoods) as well as for wider areas and regions. This implies developing a comprehensive definition of policy goals, and a clear vision of the outcomes expected from the interaction between them. However, achieving an effective integration of policy dimensions such as research and development, urban regeneration and transport for example is a complex challenge conceptually as well as in practice.

There are nevertheless some policy domains for which a constituting element can be more easily found than in many other policy fields. Tourism is one of these domains; it is concerned directly or indirectly with various policy dimensions. Domains as different as education, public transport, infrastructure (road), environment, construction, local services (including hotels, restaurants and cafes as well as retail), sport and culture are all impacted directly by implementation of an integrated tourist policy.

\section{Tourism can help reveal local riches, even for local people}

History shows that tourists (at least pioneering ones) have often been the first people to understand - and even sometimes simply to "see" - the assets of a region, which were not recognised as such by local people. That is true for cultural resources; Egypt and Greece are perfect examples, but some parts of France, Spain or Italy have also been discovered in this way. That can even be the case with natural resources and landscapes; for example, the first tourists discovering the beauty of the Alps in the late $18^{\text {th }}$ century changed the previous perception of the area as a terrible desert.

Tourist flows can also contribute, in a decisive way, to revealing local riches previously underestimated by the majority of local people. For most local people, the fact tourists are coming is changing their perception of the area in which they are living: this new attention and demand lifts the quality of the daily environment or at least raises the level of interest in such issues often previously underestimated. This is what happened in some remote rural areas, like western Ireland and the highlands of Scotland for instance or in old industrial regions, such as the "Ruhr basin" or the canal bank cities of the north of England such as Manchester. 
Such changes in local people's thinking can contribute decisively to enhance their commitment to the place and engender their "civic pride", which in turns helps develop the involvement of citizens in the processes of local and regional development. This is particularly important in places where the transformation and regeneration challenges are greatest; where the weight of problems, the lack of positive image and the citizens' negative feeling about the area's future are likely to inhibit or curb the development process.

\section{$\underline{\text { Tourism can be an accelerator of projects, including those serving residents }}$}

Tourism exerts an indisputable influence on the provision of regional and local services. The fact that people visit from other regions and from other countries can obviously put more stress on the local services, especially when tourism is concentrated on a narrow peak season, as it is in the case for summer beach or winter sports resorts. But it can also have a clear booster effect to accelerate a range of projects that are likely to directly serve the local people, including projects that had previously been regarded as difficult to justify or carry out.

With the obvious exception of hotels and other types of accommodation, most of the services required by tourists are the same as the ones expected by local residents. The need to serve tourist demand can thus help to develop projects in various fields. This is the case with accessibility infrastructure: managing authorities of airports, ports, railway stations, and even of roads, can be induced to enlarge and improve these facilities to cope with this new demand to the benefit of all consumers and business development.

Tourism can have a direct effect on the investment capacity by local authorities and even the national government due to the contribution to tax returns. This can contribute to speed up the process of improving the public realm and developing public facilities, especially in health, culture and sport.

Private services are also likely to be developed thanks to the increases in consumer demand and consumption: medical and health services, sport and leisure, and obviously retail etc. This can even lead to an increase in the level of foreign direct investment, directly in the tourist activities, or indirectly in related services.

\section{Tourism, a constituent part of Apulia's current development strategy}

\section{Tourism as it appears in the regional strategies}

When reviewing the Regional programming documents, tourism is clearly appearing as a priority. Already mentioned as Priority 5 in the national strategic plan (2007), it is explicitly featuring in the main regional documents, and especially under Priority Axis 4 in the ERDF Operational Programme, entitled "Enhancement of natural and cultural resources for attraction and development". Natural and cultural assets are thus clearly considered as the main potential attractors.

The related action plan is clearly in line with this. As it has been described earlier in this report, a strong effort is devoted to the improvement of infrastructures, whether public (like ports) or private (accommodation) and to the marketing and promotion of the region.

However this Priority Axis 4 is by far the less well endowed one with funding among the seven operational priority axes; only Priority Axis 8, dealing with governance and institutional capacity, is allocated with less funding. 
With the exception, and to a certain extent, of Priority Axis 7, described as "Competitiveness and attractiveness of cities and urban systems", tourism is not clearly mentioned in other priorities, even if attractiveness appears also as a main objective in Priority Axis 3 "Social inclusion and services to enhance the quality of life and the attractiveness of the region". However most of the other priorities could easily include a tourism dimension, or at least help to develop projects directly contributing to the development of the tourist industry in Apulia.

\section{Regional programme for tourism development}

As it has already been mentioned, Regional authorities have for years issued a regional law on tourism, which has already been amended several times; this law testifies the strong commitment of the regional authorities and is providing a suitable framework for the support to the development of the tourist industry.

\section{Links between Tourism and local development}

Tourism is playing a large part in regional policies, and some Local Tourism Systems (LTS), like the one in the Low Salento, are very well developed and very active. However it seems that they are not all developed to the same level and Tourism has apparently not yet become a real priority for most of the local territories. The fact that the whole regional territory is covered by LTS and that most of them have exactly the same limits as the "aree vaste", in charge of the local development, is clearly very positive as it allows to a direct and easy integration of Tourism targets in the local development strategies.

\section{Suggestions for potential improvements}

\section{$\underline{\text { Developing a more original and more integrated conception of Tourism }}$}

Tourism has changed over the last 10-15 years; activities that used to be considered marginal tend now to be mainstream. In most European countries, the risk today relates rather to the limitations of the local services than to their quality as the standards of living tend to be harmonised between visitors and residents. In such a context, most tourists have developed a quite individualistic way of organising their stay, and they are now looking for experiences rather than traditional sight-seeing. It is therefore less easy to define what a tourist attraction is and to delineate tourism and non-tourism activities. A slightly different and more integrated conception of tourism is therefore needed, which encompasses most of the services - if not all - a tourist can experience during a visit or stay in the region.

\section{Including a tourism dimension in all regional thematic strategies}

As in many regions, tourism objectives and challenges could be better represented in other policy domains. This is particularly true with region-wide projects from transport to economic or cultural development; if tourism development is to be a priority, their impact on tourism should be considered and even evaluated. Also, projects more limited in size could also encompass a tourism dimension.

Transport is a particular policy area that has strong links with tourism development; transport provision involves not only improving the international access, which is crucial for tourism, but also developing internal mobility which is of major importance for improved valorisation of the region and its various tourism assets. It is clear that Apulia cannot develop specific transport systems for tourists; however it is vital to take account of tourists' needs when the regional transport system is designed and implemented. 
Social services and quality of life constitute another domain where tourists' demands should be better considered. The development of a tourism experience does not mean tourists will agree to face much bigger risks and accept a lower quality in services, especially for what concerns health, security and safety. Indeed, the direct opposite is the case for the vast majority, and for many North European tourists, Southern Italy is suffering from a poor image in this domain; a strong effort is thus required.

Other policy fields like energy and water supply are directly concerned with tourist's consumption. Increased pressures on environmental resources have to be managed in some places at a specific time because of tourists' concentration. But tourism can also have a positive impact, with the development of new forms of tourism more sustainable and respectful towards the environment.

Even Research \& Innovation can be considered as a relevant policy field, as boosting the tourism industry implies developing the capacity of creating new and innovative products and services and new managing instruments.

\section{Making the role of Tourism recognised everywhere in the local development}

Moving from local to regional promotion is progressive in general terms, but it is uncertain that this helps to develop the specific assets of some areas. The Salento, the Val d'Itria, and, to some extent the Gargano, are clearly areas experiencing important tourist developments.

But there are areas where tourism has to be boosted as it seems to still be underdeveloped compared with the potential; Taranto is probably one of the best examples. The regional capital is another place where an important effort should be made; Bari is the main gateway and transport hub in the region, but the tourist infrastructure is far from the required level expected for serving a major tourist destination.

\section{Mobilising regional resources towards tourism development}

\section{Importance of mobilising all regional forces for tourism development}

\section{Valorising Tourism as a field of activity, to improve the quality of Human Resources}

The image of Tourism as a professional activity is often far from positive among the general public. The tourist industry is frequently seen as providing little more than a set of low quality activities: high constraints, low qualification, weak social recognition and low salaries. This image is unhelpful and does not reflect the diversity of the jobs on offer; while it may still prevail in some parts of the casual and highly seasonal trade in the hotels, restaurants and café domain, it is certainly not the case in most of the other types of activities. However, the tourism domain as a whole is not creating many high technology, high prestige jobs and it goes against the general trend for the development of longer and more generalist higher education.

Having a pool of highly educated and qualified staff is regarded as the main way to develop employability in European countries, and is particularly important in regions where so many young people experience huge difficulties to enter the job market and thus remain in the region. Enhancing the reputation of tourism among the general public is therefore of major importance if the objective is to attract talented young people to this industry, which is a precondition for the development and improvement of the human resources. 


\section{All residents are ambassadors of their region}

The quality of welcome is a crucial issue in tourism development where the objective is not only to attract people once, but also to encourage them to stay longer and come again. This concerns first the people working directly or indirectly in the tourist industry. However it is far from being limited to domains where people have to take care of tourists on a daily basis. Every local person who comes into contact with tourists will contribute to the quality of welcome. Most of the time it is the quality of this informal welcome, which makes the difference in tourists' minds and contributes much to the positive or negative image of a region.

The issue is actually not only to develop a friendly attitude towards visitors but to ensure that people will give a positive image of their region and will even be enthusiastic about it. This means that people become proud of the place where they live, become well informed about what is likely to arouse tourists' interest and pleased to help them to discover regional/local "secret" assets. This also supposes that local people have at least a minimum awareness of tourists' specific needs/expectations, and, to some extent, of their habits and customs, according to their cultural background, in terms of food and drink for example.

\section{People in the tourism milieu are the best specialists of tourists' needs}

As they are in permanent and direct contact with tourists, people working in the tourist industry are probably the most relevant informers on their opinions and expectations. They know the expectations of tourists, what they like and dislike, problems they have been faced with, etc. And moreover what are they complaining about: what is missing, what is well or badly organised according to their standards and expectations. If their needs are likely to be quite dissimilar from those of local people, their appreciation of the effectiveness and quality of service can be quite different.

Recognising their competence is vital: there is a clear interest in valorising their expertise and using it in the design and implementation of public policies. Involvement in this process offers the additional advantage of making them the first supporters of the policy developed in that way.

\section{Interest of linking the promotion with the actual reality of the offer}

Involving tourism professionals is also of great importance for getting a better knowledge of the reality of the tourist offer. They are generally much better informed than public authorities regarding the reality of an offer of which they are the main providers.

A comprehensive consultation is likely to help in avoiding a mismatch between the claims of a marketing campaign and the reality of the offer, which is crucial, if the aim is to ensure tourists' satisfaction about their stay in Apulia.

The Tourism milieu must also be comfortable with the promotion policy in order to contribute to it and convey it confidently. If they think the promotion is relevant for what they have to offer, they will be more likely to reuse it in their own promotion, thus multiplying the effectiveness and impact.

\section{Importance of the "District system" in the economic development}

The economic performance of the Italian district system is famous all over the world. Analysis shows that in considering these districts, the focus should not be on just one type of activity but rather the economic and human system as a whole. This is clearly more difficult in the tourist industry than in many other domains, given its size and dispersed character. 
In this field, districts are facing some difficulties to develop on the basis of their own resources, as most of the businesses concerned are family ones characterised by a limited investment capacity, due to both scarce resource and a limited appetite for risk-taking.

Another important feature of these businesses is the fact that they often employ a significant number of non-professional staff members, which are working casually on a yearly or weekly part time basis. In such a context, it is extremely challenging to succeed in mobilising the human resources towards the development of quality standards and valorising their role in the tourism industry.

\section{Current situation}

\section{Local Tourism Systems}

As already mentioned, the mobilisation of local actors is mainly done through the organisation of the LTS. The fact that there are two types of LTSs, the TTSs, (quite institutional) and the PTSs (more operational), is likely to help bring together all local - direct as well as indirect - players in the tourism industry. This is obviously very positive and is providing opportunities for implementing more relevant and accurate local development projects..

To date however there have been more applications from TTSs than from PTS. This could tend to show that such instruments are considered more relevant as administrative governance tools than real means of involving all types of local players. In any case, their activity is directed towards the local development and they probably do not have much to propose as input into a regional vision.

\section{Mobilisation of tourism players}

An annual tourist Forum has been organised in Apulia for three years now. This two day event brings together public and private players in the field of tourism: local authorities, businesses, national agencies, associations and the regional authorities. Thematic working groups provide all people with the opportunity of expressing their opinions and concerns. This is a very positive initiative and a good start in the long-term process towards a full mobilisation of regional resources. However to date it appears to be a rather formal event, with limited input from fieldworkers, which is probably a consequence of the event format.

\section{The film commission}

By creating the commission, the regional authorities were aiming first to improve the international image of Apulia and second to develop the local cinema industry. However there are internal resulting effects that are not to be underestimated: first on the local recognition of the region's attractiveness, second on the "internationalisation" of local people.

\section{Suggestions for potential improvements}

\section{Developing effective participative mechanisms}

The promotion of tourism in Apulia should not be just directed to foreign or national audiences, but should have a regional dimension in order to mobilise all the local forces towards the common goal of tourism development. This objective implies that individuals involved directly in the tourism industry should share a common culture and perspective on tourism development in Apulia. This means that the strategy will gain in efficiency if designed through an effective participative process 
involving as many players as possible and certainly engaging the tourism milieu (entrepreneurs, trade unions, etc.).

The Forum and annual conference is a good start but cannot be enough to achieve this: direct and frequent contacts between regional decision-makers and tourism professionals are required. Regular meetings should be organised with representatives from the tourist industry, at both local and regional levels, as a first step in order to exchange information and develop an action agenda. As a second step, participants should hold debates on the main actions to be undertaken to improve the quality of the offer and the way these actions could be implemented more effectively and be sustained in future.

Thematic working groups - or committees - could be set up at regional level. If so, it is important that meetings are well organised on a regular basis and the same players are involved. Such groups could be charged with the preparation of contents to be discussed in the annual Forum.

\section{Promoting Tourism among citizens}

The promotion of the region should not concern only those individuals working directly in the tourism industry; a much wider mobilisation of the local society would be of major relevance. Interest towards tourism should be developed as much as possible among the general public, for ensuring a quality welcome first but also for encouraging the development of new ideas and new tourism projects. All potentially interested citizens of Apulia should be aware of the challenges and opportunities Apulia is facing in this field and should obviously know the regional strategy for tourism development.

This information process should use all the traditional media, but would benefit from more specific and practical forms of communication such as the ones described below.

- Competitions with prizes could be created in order to award innovative projects developed by individual players. This could be organised on an annual or biennial basis and be divided in different categories according to the theme (infrastructures, services, promotion tools, etc.) and the type of players involved (professionals, local authorities, associations, individuals).

- Campaigns in the regional press (including television) could be launched, especially out-ofseason, promoting the tourism development policy in general and the awarded initiatives in particular.

- Regional promotion of movies directed in Apulia should be organised with help from the film commission and could be done through premieres in Bari, an annual festival in another city and/or showing in the regional TV networks.

- Tourism Trade Fairs and exhibitions could be held on an annual basis in Bari. They would be directed to the professionals in principle, but open, at least partly, to the general public.

\section{Better defining and promoting Apulia's specific tourism assets}

\section{Importance of developing a clear vision of the competitive assets}

\section{$\underline{\text { A tough competition }}$}

The Mediterranean Sea is one of the major tourist destinations in Europe. This is due to the existence of obvious natural and cultural assets, but also to the presence of a domestic market and the 
proximity of an important, effective and affluent wider European market. This is based upon and developed from the importance and variety of the tourism offer. When considering the wider European context, a dozen Italian regions and some 15 in other countries (Spain, Greece, France, etc.) are competing to attract and secure the loyalty of the same tourists. This is tough competition: a random choice would give a probability of around just one visit in each of these regions in a lifetime!

In such a context, some regions have established themselves for a long time as major tourist destinations: Tuscany, Côte d'Azur, Balearic Islands, and part of Campania, for instance which have attracted tourist flows for more than a century. Other regions have experienced a huge growth in tourism development since the 1980s with, sometimes, unintended negative consequences as seen in the Costa Brava, Costa del Sol (in Spain) and some parts of Crete. A third category of regions concerns those, which still have an important unexploited tourism potential, and are implementing strong strategies to valorise it; Apulia fits in this category, within which it is one of the few regions from Western European countries. Most of regions in this category belong either to countries outside the EU (such as Croatia, Turkey, Tunisia, Morocco and Egypt) or from new member states (Cyprus, Malta, Bulgaria or Romania).

Some of these regions are likely - or have even started - to reproduce some of the mistakes made by their predecessors in accepting quick and non-sustainable forms of development. Some others, and Apulia is among them, have managed to retain a significant part of their natural and/or cultural assets unspoilt. Current environment concerns, and the resulting shift in consumption trends in Europe, show that these regions should soon directly benefit from this situation.

There are obviously different motivations for a tourist deciding to come to the Mediterranean regions; sun, sea, food and culture are probably the main ones. The cost of living, which was an important consideration for tourists from Northern Europe, is no longer so decisive for residents of prosperous European countries. However the order in which different considerations influence the destination choice will vary according to individual tastes and cultural backgrounds. That is the reason why common assets to all Mediterranean regions are to be valorised, but highlighting the specific ones is crucial. This is a major challenge for Apulia.

Defining the specific assets of Apulia in the Italian context is even more challenging. Among the main tourist attractors mentioned above, culture and food are generally recognised as Italy's main competitive assets. The same is true for Apulia. A better understanding and expression of what can be the "extra factor" (or unique value added) provided by the region is therefore a precondition for any decisive development of the regional tourist industry.

\section{Extending the tourism season supposes appropriate assets}

To date, tourism in Apulia has been based mainly on the traditional seaside activities with an important part emanating from the regional and domestic markets. It is clear that this type of tourism is heavily concentrated in a short peak season covering two to four summer months in the year. This presents a number of disadvantages including intense pressure on the environment during this peak period, pressure and disruption in the labour market, high stress at peak periods then under-use of infrastructure during the remaining - major - part of the year. The development of an "all seasons" tourism offering is thus a crucial objective for relieving stress and achieving more balanced and sustainable development in the region.

However developing out-of-summer season tourism implies the existence of a range of relevant factors including a variety of attractive activities and/or assets, ease of access to them for tourists, and their active promotion. Weather and climate are important and even in regions benefiting from a rather 
mild winter, the tourism offering cannot rely on outdoor activities only. Cultural and "urban" activities are thus playing an important role in this field. Also most out of season tourism will be comprised of short stays and urban tourism plays a significant part in this. This has been recognised with the formation of groups such as the European Cultural Cities Programme and some of the regional associations and initiatives profiled in Annex 1: International Case Studies.

\section{Importance of pointing out weaknesses}

No tourist destination is devoid of weaknesses: some weaknesses can limit the range of incoming tourists, while others are likely to constitute more serious difficulties and major disadvantages for the specific area. A clear understanding of these weaknesses and an honest evaluation of their potential negative impact are essential in developing an effective development strategy, whatever its intrinsic quality.

\section{Current situation}

\section{The assets identified in the marketing campaign}

In the marketing campaign developed by the Region, eight types of tourist attractors are appearing, which can be considered as the eight main identifying assets of Apulia. These are: sport, wellbeing \& spa, religion, traditions, nature, food \& wine, art \& history, the coast \& sea. As such, they are all indisputable attractions for tourists and they adequately reflect the riches and diversity of the region.

However, except for traditions and, to a certain extent, religion, it is not totally clear, for an international audience at least, exactly what assets are specifically distinctive to Apulia. Sport, nature, wellbeing and sea are common assets to many regions and Apulia has no specific or distinctive image to promote. Food and wine, and art and history are general assets for Italy and it is unclear, except for subtle connoisseurs, in what Apulia presents better - or even different assets - than other more illustrious and internationally known Italian regions.

This calls into question the relevance of all the identified assets for at least foreign tourists. The addition of various assets to form a long list without any clear hierarchy or prioritisation risks to weaken rather than to reinforce the promotion of the region as no clear coherent or global image of Apulia emerges.

\section{Enhancement of the (built) heritage}

Heritage, and especially the built heritage, was mentioned in many contacts as a specific asset of Apulia, and the current enhancement efforts were stressed as one of the most positive among the recent evolutions in the local development.

With two UNESCO world heritage sites, it is clear that the region is provided with an international visibility and the opportunity to generate consecutive visitor flows. The fact they represent two very different types of architecture (one very traditional, the "Trulli", the other highly sophisticated, "Castel del Monte") reflects the riches of the Apulian heritage. Romanesque cathedrals, medieval castles, baroque churches and "masserie", and the vernacular townscape in many towns are also clear assets for cultural tourism. 
This is all positive. However, in an international context, the region is not alone in this regard and the list of positive heritage sites is unlikely on its own to be enough to make the difference with other Italian regions, except for a rather limited public.

\section{Culture}

Another recent and positive evolution in the regional development mentioned in local contacts lies in the new role played by cultural activities and events. This is true for traditional/folk culture as well as for popular or more classical forms of cultural activities.

As with the heritage, culture is a clear asset which may be decisive for the domestic market but is probably not original enough at present to attract major international tourist flows. However some already existing cultural festivals could be developed in a way that elevates them to become international attractions.

\section{$\underline{\text { Imagel cinema }}$}

Cinema is a powerful potential vehicle for the promotion of a region like Apulia which is full of assets but lacks a clear international image. The film commission is therefore playing a very important role in revealing Apulia's assets. Talented directors are able to see - and reveal to the general public assets that would otherwise be missed. The positive but not complacent image that cinema can give to the region is clearly a more effective, albeit subtle, promotion instrument than an advertising campaign.

It is important to emphasise that it is an overall message of authenticity that appears to be delivered through most of the films directed in Apulia, at least through those which have reached a truly international audience. This image is clearly recognisable, and, as long as the link with Apulia is clear in the public's mind, this is undoubtedly a potential brand image to exploit.

\section{$\underline{\text { Main weaknesses }}$}

A number of weaknesses were mentioned in local contacts, some of them constituting real handicaps for a further growth of the tourist industry. These are:

- External accessibility is probably the main obstacle for the development of international tourism in Apulia. The region's location is central in the context of the Mediterranean Sea but rather remote in the national context and even more so when compared to the main international market (North West Europe). The limited number of international direct air connections makes travelling to Apulia longer and more awkward than to some of its competing regions. The domestic accessibility is highly dependant on air routes and the national company as the interregional train system is relatively slow, especially compared with the servicing running on the western coast of Italy.

- Internal mobility is another difficulty, mainly due to the geography of the region. Trains are neither frequent nor fast enough as noted above and the network is not developed sufficiently to serve all tourist attractions. This is significant as the tourist assets in Apulia are widely dispersed. This limits the possibility and ease of discovering the riches of the region using public transport, which means that people have no other option than to resort to car hire if they want to have the flexibility and freedom to move quickly and conveniently throughout Apulia. 
- The limited capacity of local entrepreneurs to develop their activities has been stressed often. This is particularly the case with regard to accommodation, but entrepreneurship levels appear to be low and often lacking in the whole tourism sector. There are various reasons for this but the effects are significant with lack of investment, lack of enterprise and consequent effects on local communities where relevant skills and confidence levels are also low or non existent.

- The weak attractiveness of the main gateway, Bari, constitutes a clear weakness. Bari is the main access point to Apulia through Palese airport but it is also, and naturally, the main transport hub for the whole region, and this position will grow in importance if the entire transport system is improved. This means that Bari should become a better place for tourists to access and have a pleasant stay. Indeed, the same situation and development requirements will apply to the second regional gateway, Brindisi.

\section{Suggestions for potential improvements}

\section{Improving accessibility}

This is a crucial issue and probably the one in which the region's room for manoeuvre is the most limited. The importance of international air connections has already been stressed, and initiatives are being taken to try to develop them. Ryanair has developed an intention to develop new international connections with both Bari and Brindisi since 2010. This brought more - and probably new tourists to Apulia, but will not on its own solve all accessibility problems. Other complementary initiatives and actions to expand the market reach will be required. For example, the development of business tourism and the need therefore to attract more international (European) companies should be a constant objective.

The improvement of the train connections with the North of Italy and with Naples should be at the forefront of the region's efforts to link with the national train company and potentially with other companies in the prospect of opening up the routes to competition. Regional trains are another important issue which is moreover included in the operational programme under priority 5 .

Maritime access to Apulia should not be forgotten, obviously with a quite different perspective. Two types of accessibility are particularly important, cruise terminals and tourist harbours, which have both proved to be a major local development tool.

\section{Developing the tourism infrastructure}

It is obvious that the tourist infrastructure in Apulia requires improvement. There are at least two main domains in which important progress is required as a priority: accommodation and facilities for business tourism.

Except in some of Apulia's seaside resorts, there is a clear shortage of accommodation suitable for the development of international tourism; that is the case for large hotels with international standards, and also for small B\&B. Most of traditional hotels offer little to attract tourists, and alternative forms of accommodation are underdeveloped, except with the quite recent conversion of traditional "masserie" into upper market accommodation. There is thus a real need for more accommodation and more original forms of accommodation in almost every category.

There is also a need to develop more convenient facilities for business MICE activities (Meeting, Incentive, Congress, Event) for both the national and the European/international markets. The 
refurbishment of "Fiera del Levante" could be the flagship for a strong effort towards the promotion of Apulia, and Bari in particular, as a major business tourism location.

\section{Encouraging product development}

Most tourists need to be helped and even led in making choices. Once their centres of interest are defined, they like to get suggestions and even already prepared packages, which they are free to follow or not.

Combinations of specific local products should be at the core of such packages (e.g. Tarantella, authentic food, crafts, etc.). The "route" (or "trail") concept has been implemented successfully for years in many European regions as shown in the international examples profiled in Annex 1. Apulia could follow their example by developing this type of route or trail themed tourism. Initial trails could be developed around traditional peasant civilisation or Frederic the second's route, for instance.

\section{Developing softer, more sustainable forms of tourism}

The general trend towards a more responsible attitude towards the environment is starting to have a significant impact on tourists' choices. Most tourists obviously still want their stay abroad to be a time to relax and to escape the daily stresses and constraints of routine living, but a growing number are looking for new forms of tourism; more "authentic" experiences and responsible tourism with a lower carbon footprint.

\section{Cooperating with the neighbouring regions}

Regions are not isolated and there is often greater advantage in linking with neighbouring regions, especially where complementarities will bring mutual advantages and economies. For example, it could be worthwhile for Apulia to establish strong promotion links with some neighbouring regions. This could be advantageous, especially with the neighbouring region of Basilicata, which is very close and for which Bari also functions as the international gateway. The two regions present complementary assets, notably because of the existence of UNESCO world heritage sites which are potential attractors for global tourism.

It could be also interesting to develop partnerships with the other side of the Adriatic Sea, making Apulia the main access to countries where tourism has yet to develop significantly, such as Albania or Montenegro. Historic connections to Greece could also be developed.

\section{Box 1. Manchester: developing an all season tourism destination}

Manchester, cradle and iconic city of the industrial revolution, faced a deep crisis in the 1970s with its mainly textile - industry losing all its competitiveness. In the early 1980 s the city had entered a spiral of decline and deprivation; it had lost any attractiveness and most of its centre was close to total dereliction. No one was imagining Manchester could be a tourist destination. Since then, Manchester has achieved a very impressive recovery. With around 1 million international visitors per year, Greater Manchester ranked $2^{\text {nd }}$ in 2006 among the most visited cities in England, thanks to a very impressive urban regeneration, but also due to a very effective tourism development policy.

Manchester was actually not provided with much tourism assets, but the local strategy made the proof that a huge tourist development can be based, in an early phase at least, on quite a limited number of specific tourists niches.

As potential tourist attractions, Manchester had only some - mainly industrial - heritage buildings, the prestigious Museum of Science and Industry, a rather small art gallery and a world famous football team and 
legendary stadium.

But what made Manchester become a real tourist destination was actually first the huge development of the popular music scene and the club culture. In the late 80 s and early 90 s, "Manchester" became - after London the favourite week-end destination for many British young people, attracted by legendary places such as the Haçienda, created by Factory records. Around the same time, pubs and clubs in Canal street became well known for their gay friendly attitude and the area was soon named the Gay village, popularised by the TV programme "Queer as folk". A few hundred meters further, The Northern quarter was offering a wide range of shops and stores providing second-hand and young designers clothes and accessories, creating a new street fashion.

The consecutive image of Manchester as capital of British counter culture arouse curiosity among people longing for novelty; the city became thus for them the place to be and this created a real craze for Manchester. Although a great part of the initial scene has now disappeared, tourists flows have increased from year to year since then.

At the start, this movement was not really encouraged by the local authorities which had obviously not planned it : they were primarily concerned with safety, security and health problems linked with this night life, and especially drugs and alcohol. However they understood very quickly all the benefit they could draw from this new image and attractiveness of Manchester. They however managed to turn it towards the development of more diversified tourists flows by creating MICE and more traditional cultural facilities.

More information: http://www.visitmanchester.com/; http://www.prideofmanchester.com

\section{Box 2. Rovaniemi (“Santa Claus home town”): creating a specific niche and marketing it worldwide}

Located in the very north of Finland, close to the arctic circle, the town of Rovaniemi, capital of Lapland, is not naturally provided with much tourism assets (except natural ones). The town is totally devoid of built heritage, as it was totally demolished during World War 2, and is obviously in a very remote location, even for Finland and Scandinavia. It nevertheless became an important tourist destination, based on the development of the simple idea that it was the place where Santa Claus was living.

For some years, thousands of tourists are coming every year to visit Santa Claus village, where everything is organised around the well-known character. Visitors can use the original - but official - post office, where mail can be sent all over the world with Santa Claus seal, and even meet Santa Claus himself. 500000 overnights were registered in Rovaniemi in 2008, around one half by foreign visitors (British, Russian, French, German, etc.) A new Santa park opened in 1998 and, in spite of some initial difficulties, is now reinforcing the town attractiveness and helping extend tourists stay in the place.

This example illustrates the possibility of creating almost ex nihilo a tourist niche, should there be a serious and consistent investment from the local authorities and obviously some link with something or someone already known.

In spite of the name, there is obviously no direct link between St Nicholas and Santa Claus; the latter is to be understood as the fabled red-jacketed old man with its reindeers sleigh. However if this fiction character has been dominating children's imagination for decades, it has not totally erased the figure of St Nicholas, who is still very popular as gift bringer in countries such as the Netherlands, Germany, Belgium, North and East of France, etc. In this context, Apulia could probably better benefit from the presence of St Nicholas in Bari and develop its attractiveness among this potential public.

More information: http://www.visitrovaniemi.fi/ 


\section{Defining tourist targets: new products for specific niches}

\section{Importance of diversifying tourist activities}

\section{Tourism is no longer a unique thing}

Tourism has experienced a considerable growth in Europe during recent decades. But this development has been accompanied by an ever-growing trend towards more diversification of practices and products. And this evolution is likely to increase further in the coming years.

The first important change is concerning the length and time of holidays. Whether by personal choice or resulting from work constraints or incentives, more and more people, especially in Northern Europe, are no longer concentrating their annual holiday in a long summer leave. If they keep taking summer holidays, employees are also dividing their annual paid holiday into shorter periods, especially in winter (Christmas) and in spring (Easter) times. Moreover, they have developed a practice of very short holidays, often linked with traditional feasts (bank holidays) allowing for longer weekends. The rise of low cost flights has in recent years allowed many people, especially from Northern Europe, to spend these weekends in foreign countries, especially in those where the cost of living, especially food and drinks, is lower (not always with totally positive consequences for the host countries).

The second important change concerns the way people organise their holidays, at least in European countries. More and more people plan their holidays directly on their own and they buy less and less ready-made full packages, except for specific types of leisure (cruises, spas, etc.).

Tourism is tending to become more and more individualistic and it is easy for most to access a wide variety of the most diversified offers around the world through the Internet which is obviously playing a decisive role in this development.

Another trend, which has been observed in recent years, is the growing mobility of tourists. Except for short stays, more and more people no longer spend the full holyday in the same place and/or type of accommodation; they tend to move from place to place and experience different types of accommodation.

The rise of business tourism is also an important trend in Europe. MICE activities have been experiencing a constant growth over recent decades, and one can even speak of an explosion in the growth of the congress industry. Traditional, central destinations, such as political or economic capitals, have been the first to benefit from this tendency, but new, more original or cheaper, places have then successfully developed this activity. This is particularly important as a business tourist is reputed to spend on average three times more in a day than other types of tourists.

The most important change is the general evolution of the public expectations, which is turning the tourist industry from an offer oriented to a demand led activity.

\section{Tourists have various expectations}

If all tourists have some basic common demands (in term of quality of welcome and information, access to transport and facilities, use of their language in particular) their expectations are highly dependant on the types of tourism experience they are looking for. 
It is relatively easy to respond to the long established types of tourism and the tourist industry and local authorities are responding well to demands clearly identified, those for example coming from people looking for traditional sea/sun activities, or from heritage sight-seeing "consumers".

In many places, facilities and services have also been developed to respond to the quite different requirements expressed by tourists looking for sport and outdoor activities or coming for quite specific purposes, like historic and/or religious pilgrimages.

But tourism professionals and local authorities are often less well equipped with the relevant responses to emerging trends. This is especially the case with Eco- and Ethno- tourism, where people are looking for real life experiences, and are de facto refusing to acknowledge the obvious paradox of their demand: they are tourists but don't want tourism products but, in principle at least, the opportunity of taking part in "authentic" activities that are not designed for tourists and therefore mainly attended by local people.

To some extent the same trend can be observed with other types of tourism. Cultural tourism is one example: people want to get access to cultural events (festivals, shows, exhibitions, etc.) which are not supposed to be designed for tourists but from which local people increasingly tend to be excluded due to the tourist flows. The same can be said for urban tourism: trendy bars, restaurants and nightclubs tend to lose most of their exclusiveness, as soon as they are attended by large numbers of tourists.

Business tourists have quite different expectations: they usually look for standardised quality facilities and services, somehow independently from the place to where they come and stay. In this type of tourism, local customs and picturesque locations can obviously be competitive assets but only once the excellence is provided in services and facilities.

\section{Tourists also have various needs}

Tourists' demands are also highly dependant on their specific basic needs. It is clear that people travel in a variety of groupings: as individuals, as a family, with pets, in couples or in larger groups etc. As a consequence, the accommodation and even leisure needs differ; providing a unique type of product as a single response would inevitably lead to major dissatisfaction.

Tourism is also characterised by a growing diversity in age and this is leading to the development of very different needs. The ageing population is a common issue in Europe, but aged people are nowadays generally enjoying a much better health and a higher income level compared to previous generations. As a consequence, more and more retired people are travelling abroad. However many are likely to require some specific care on occasions and cannot be expected to use the same services as young people. The same issue could be raised with disabled people who are more and more inclined to decide to have a life as "normal" as possible, and are therefore touring and seeking new experiences.

Another important aspect which has to be taken into account is the cultural differences which can exist in considering the way of life according to social and national differences; quality of food, best time for meals, comfort in rooms, etc. can receive quite different appreciations depending upon the origin, orientation and background of tourists.

\section{Attracting and securing the loyalty of tourists}

This is the actual objective of any effective tourism development strategy. But if attracting people is first a matter of effective marketing policy, making them come again is the result of a more complex 
and diverse alchemy. There is always an important subjective dimension in people's choice to come back and therefore the margin of uncertainty is an important consideration in this field.

However some decisive factors can clearly be identified: The first one is obviously the overall quality of tourism products, and the second one, directly linked with it, is their adaptation to the demand, which supposes a relevant assessment of this demand and a sufficient quantity and diversity of the offer provision.

These quantity and diversity is likely to prompt people to come again as they cannot discover in just one stay all the region's riches in keeping with their main centre(s) of interest. For some people the diversity can even be an opportunity to alter their centres of interests and to decide to try something unusual with some limited risk, as there will be enough on offer to meet their ordinary tastes and to satisfy them should the changed experience be deemed unsuitable to their taste.

It is worth stressing that the "little extras" that attract people back again often relate further to the quality and diversity of products; in the quality of welcome from local people and their overall attitude towards visitors.

\section{Current situation}

\section{Diversity of tourists flows}

As it has already been stressed, Apulia is currently quite important as a tourist destination. However tourism activities appear to be rather traditional, and tourist' flows are clearly segmented. The most important tourist grouping in terms of numbers comprises mainly domestic summertime tourists, who are primarily going to the region for the 3Ss (Sun, Sea and Sand.) whereas a more limited number of tourists appear to be going to Apulia for its cultural riches.

An additional and significant flow of tourists go to Apulia for religious purposes, mainly to Padre Pio's sanctuary, but the traditional pilgrimage to St Nicholas in Bari is also still very popular. Some other forms of tourism have been growing in development importance in recent years, especially cultural, sport, and nature tourism.

This is encouraging however there are apparently too few tourists who go to Apulia for such a variety of reasons and most appear unprepared to diversify their centres of interest. This has so far limited the development of mixed activities, which could yet be an interesting way of developing tourism from the existing customer base.

\section{International tourists but for very short stays}

An interesting aspect of the current tourist activity in Apulia is its international dimension. Some European tourists, from Germany or France for instance, have for some time now discovered Apulia's assets as a summer holiday destination or as an area full of cultural riches. However probably more important for future development is the fact that some tourists are coming from outside the EU. Religious and UNESCO sites are important attractions for these tourists. Some people travel from Asia or North America to discover the UNESCO sites and Bari is attracting a number of Russian tourists given the link with their patron saint St Nicholas. On average, such tourists have a higher purchasing power than European ones, but they also expect higher standards and quality of services. The vast majority of the tourists from distant origins are however coming to Apulia for a very short stay. Keeping them a few days more could be of major addition to the tourist economy, especially as these tourists are not specifically coming in summer. 


\section{Importance and diversity of assets but a limited diversity of products}

While Apulia benefits from having a wide range of tourism assets, it seems that the diversity of products is rather limited and does not reflect the importance of Apulia's potential for tourism development. As stressed above, helping potential tourists to make choices or establishing thematic itineraries is of real importance for assets to be turned into active and productive tourist attractions. If such products already exist, information about them is not easily available and this needs to be addressed.

\section{Lack of international imagel fame of Apulia}

In spite of the riches in the region and probably mainly due to their diversity and fragmentation, Apulia does not benefit from a clear image abroad (except to a certain extent in the Germanic countries). Some specific features of the region are well known but are not always associated with Apulia. The case of the Tarantella could be a good example. This has gained a strong interest for the last years among music lovers, but links with the city of Taranto and the fact this city is located in Apulia rather than in another southern Italian region is generally unknown abroad. And the same could be said from the UNESCO sites which are associated with Southern Italy rather than Apulia.

\section{Marketing and the limited quality of international information}

Apulia has a marketing problem. The lack of international recognition is reflected, reason or consequence, in the limited amount and quality of the available information and the overall lack of a strong regional brand. Destination marketing is vital and provision, promotion and dissemination of information on the area and its assets is a basic pre-requisite to attracting international visitors.

There are few specific guidebooks on Apulia published in foreign languages, with the exception of German. Influential international guidebook collections most frequently describe Apulia within a chapter or guide to "Southern Italy". In addition, most official tourist web sites are available in only three languages (Italian, English And German.). This can limit the access and thus the interest from the other major audiences such as French speaking (who account for the largest group of cultural and short stay tourists in Italy) and Spanish, Russian or Japanese.

\section{Suggestions for potential improvements}

\section{Targeting short stay travellers}

The development of out of season tourism being a main challenge, it is clear that the short stay travellers should constitute a priority target. Low cost flights users are probably the most significant influence on short stay travellers. Low cost flights are now used by a diverse range of people including families, retired couples, groups of friends, business travellers and independent travellers. The common feature of such travellers is generally the fact that they devote a limited budget to travel, are travelling with limited luggage and for short stays. They expect an easy and quick access to accommodation and their main centres of interest or purpose of visit which is mostly linked with urban tourism.

- Bari and to a lesser extent Brindisi are Apulia's gateways for these tourists. It is therefore important that these cities can meet the requirements of such tourists. This can be mainly defined a mix of café-restaurant-night life facilities, shopping opportunities and/or cultural events. The two cities should also be considered not only as gateways but also as hubs for the 
whole region. Accessibility from them to the main regional sites should be made as easy as possible.

\section{Developing Business tourism}

Business tourism is one of the most profitable parts of tourism. Business tourists spend more, and are in a way easier to satisfy as they are much more predictable in their needs than other tourists. Another important advantage of business tourism is that it is mainly developed in Autumn and Spring, which means it can help maintain an all year activity in accommodation facilities. With selective additional investment, business tourism could be further developed quite easily in Bari on the basis of the city's existing assets.

- La Fiera del Levante, the historic fair of Bari, should benefit from the current improvement of its facilities. It could quite easily gain a new vitality with the planned construction of a new congress hall. Unfortunately little information appears to be available about this project, which should be the flagship of business tourism in the Region. In any case achieving and opening this congress hall should be considered as a priority.

- The Mediterranean and eastern expansion of the EU has presented Apulia with new strategic geographical advantages as an east-west meeting point. EU enlargement to include the Balkan countries and islands such as Malta and Cyprus, as well as further potential future enlargement to Turkey and Ukraine, gives Apulia a pivotal role as a location between East and West. This could lead to an important development of professional tourism, if sufficient initiative and investment is committed.

\section{Developing yachting}

Yachting has been a booming activity in the Mediterranean in recent years. With the end of the war in the former Yugoslavia, the Adriatic Sea has become one of the favourite areas for this activity, and the Dalmatian coast is a prestige celebrity destination. Apulia's located half the way between this area and the more traditional Greek islands could naturally benefit from this trend. This supposes the development of tourism oriented port infrastructure and related services to a public endowed with a high purchasing power.

\section{Experiencing and not (only) sight seeing:}

- Authentic life is without doubt one of Apulia's main assets: there exist many examples of the survival of traditional events and preservation of customs and life style. This form of real life tourism is very popular and continues to grow. Apulia is well placed to capitalise on this and show how traditional values and culture can be sustained.

- Eco tourism is another niche which could very easily be developed. Some efforts have already been made in this field especially with the natural parks, but there is clearly still a huge potential for this type of tourism.

\section{Developing "Slow tourism"}

Italy is the cradle of the increasingly popular "slow food" movement. Apulia could use this trend to develop a slow tourism movement which could encompass the authentic life and eco-tourism in a new category including quality of food and accommodation. 


\section{More diversified communications}

Trying to develop new forms of tourism supposes a new, more targeted, approach to communication; this can mean developing new communication tools but also adapting the existing ones. People interested in new forms of tourism are most of the time not using travel agencies but preparing their travel arrangements by themselves, sometimes months in advance; they thus tend to expect a more detailed and more tailor made information set, easily available in their own country, with all functionalities - including interactivity - expected from the use of new ICT. Adapting institutional communication to such a context is clearly an important challenge, but some straightforward initiatives can been taken. For example:

- Increasing the language diversity on web sites; if English is widely accepted as the language of the Internet, there are very uneven levels of understanding and practical use across countries. For example, while people in the Nordic countries consider English as an essential communication tool, this is not the case in other countries. Presenting guide books and other information in the national language of target country markets is valuable not only for practical reasons but also as a sign that they are valued and will receive a specific welcome in Apulia. This is particularly important for large markets such as Russia and Japan.

- Turning the regional tourism web site into the tourist portal of Apulia. Managing and maintaining reliable updated information on a single site in different languages is a challenge. However basic information should be present on the official site with links to a wide range of different more specialised sites providing more detailed tourist information about Apulia. Protocols and standards can be set within regional network and tourism association rules.

- Publishing articles in the specialised press; individuals with specific interests tend to look for information more in specialised media than in tourism sources. Trusted and apparently independent sources are considered more accurate and reliable as a guide to decision making. Supporting the production of articles by journalists and/or experts about what Apulia can offer in the relevant domain can be an effective way of attracting new potential tourists.

- Encouraging publication and diffusion of information can be done in various ways including:

- Profiling Apulia's riches. In bookshops and main tourism sites in Apulia, a quite abundant tourist literature is available in different languages. This is especially the case for food and the cultural heritage. Unfortunately these often high quality (guide) books are considered more as souvenirs than as tourism development tools. Encouraging a better international diffusion of pre visit guides should be a priority.

- Sponsoring publication of generalist/specialised guide books in foreign languages. As noted earlier, except for the German speaking public, the availability of specific guidebooks in foreign languages is very limited and there are few guides specifically on Apulia available internationally. One of the most popular French guide publishers has not even published a French version of the guide of Apulia it has made in Italian. Encouraging the edition of guides by foreign publishers in existing well known series should play in important role in the development of international tourism. 


\section{Box 3. The Ruhr area: Route der Indutriekultur (industrial heritage trail). Developing specific and original tourism assets}

The Ruhr area is the main industrial region in Europe and the largest conurbation in Germany The area has been dramatically transformed by 150 years of heavy industry development (mainly steel and coal) and severely damaged during World War 2. , but has managed to preserve a number of monuments (some being on the UNESCO World Heritage list), most of them being former industrial sites. However there are actually quite few other centres of interest in the area for people coming from outside, and in any case the image of the Ruhr area is so deeply linked with heavy industry that any attempt to promote any other asset would probably be useless.

In this perspective, regional authorities decided in 1989 to implement for 10 years an ambitious redevelopment programme called IBA Emscherpark. Among the many initiative developed in this frame featured the idea to open up the industrial heritage to visitors by creating a network of the main existing sites and developing a trail to link them. Today, there exist $400 \mathrm{~km}$ route with 25 "anchor points", and 25 thematic routes that attract a significant number of tourists, including foreign visitors. The initial promotion included campaigns in national news magazines showing photos of blastfurnaces, with the slogan: "This, we are the only ones to have it!"

However, diversification of tourist assets has started from long and the main city Essen has been chosen as European capital of culture for 2010 and the Ruhr 2010 agenda is based on many other assets than just industrial heritage ones.

More information: http://www.route-industriekultur.de; http://www.metropoleruhr.de; http://www.essen-fuerdas-ruhrgebiet.ruhr2010.de

\section{Energizing the region's branding}

\section{The need for a more diversified strategy}

\section{International and national perceptions of Apulia}

Except for some worldwide known regions, and even then only to a certain extent, the perception of an area is usually quite different for national rather than for international potential tourists. Even if the region is not a traditional tourist destination and suffers from a lack of tourism image, people living in the same country will always know something about the region where they are likely to come and spend their holidays. This image is obviously not only made of the region's assets but is also fed in by sources such as the "news in brief" from TV channels and newspapers. It can also often be out of date, no longer correspond to the current situation or even comprise standardised clichés, but in any case it will be primarily based on what are supposed to be the specific features of the region, compared with other ones in the country.

Most people from abroad will have a different perception and approach, as they will primarily come to the country, Italy, and not necessarily to a region like Apulia, the local specificities of which they will often consider irrelevant. When coming, they will often be principally interested by what is different in Italy from their own country and are thus not sensitive to, or at least minimising, regional characteristics. The focus is more likely on what the region has in common with the rest of the country; most tourists usually don't know much about internal cultural differences within a country and will be unaware of what is truly authentic to particular regions or locations.

In this context, it should not be assumed that there is a similar basic knowledge of the regions tourism assets in the mind of both national and foreign citizens; proposing the same marketing strategy 
towards Italian and international potential tourists will always be less effective than developing a more diversified approach to communicate with different sub markets of tourists with varying degrees of knowledge.

\section{Lack of clear image at international level}

As it has already been stressed, even if there are world famous sights and/or specialities in the region (Castel del Monte, Trulli, Tarantella, etc.), Apulia lacks a clear international image and distinctive identity. If the objective is to develop the region in its entirety as a tourist destination, any marketing campaign emphasising Apulia's diversity and riches must also reveal its regional identity and differences with other competing regions if it is to be effective and successful.

\section{Current situation}

\section{The eight themes mosaic and emotion. Interesting but clear enough?}

The communication campaign, which has been developed by the regional authorities for the promotion of tourism in Apulia, is based on the clear message that Apulia is a region where tourists can experience a wide range of various emotions. It is divided into the eight main domains already mentioned as Apulia's main resources for tourism development. For each of them, a collage of some 50 images aims to show the variety of the region's assets in respect of the selected domain. It is obviously difficult to identify any of these photos but this is clearly not the objective; the priority is given to the overall message and further information can be found on the official website.

The general impression is really positive: images are well chosen and the lay out is creative and original as well as being clear enough for the message to be easily understood. The result is pleasant and the campaign on the whole adequately reflects Apulia's main tourism assets. The problem is that it does not give a specific image of Apulia for people who do not already know the region. No clear identity emerges and it is not evident which assets are specific to Apulia; the terms, mosaic and emotion, themselves do not specifically evoke Apulia, even for people who already know the region. When considering the images, one must recognise that for non specialists, they could also represent some other Mediterranean destinations such as Sicily or Campania or even Dalmatia, Cyprus or Malta. The location of the region is not even mentioned, at least in the Italian version, where it is actually not as necessary as it is in other language versions.

The general impression is that the communication has moved on to a second step whereas the objectives of a first one were not totally achieved. It is clear that tourists expect nowadays that a communication strategy will tell them a story about their future holidays and not only speak of the place's identity; however this supposes that this identity is already clear in their minds, as clear as the reasons why they would choose Apulia for their holidays rather than any other area in the central part of the Mediterranean basin. This is probably the case for most Italian tourists, but certainly not for the majority of international ones. In the current situation, the issue of the region's specific identity should remain for them the first concern in any communication campaign.

Another aspect, which seems to be underdeveloped in the campaign lies in the need - and ability - to propose an "all seasons" offer, which also means this offer can meet with all type of stay duration.

\section{Suggestions for potential improvements}

It is obviously not an easy task to attempt to define the tourist identity of a region as vast and rich as Apulia. It would be inappropriate to give a definitive and immediate answer to a question, which 
has been pending for decades. However, from the analysis above, two basic principles are emerging: the first one is the importance of making a distinction between the national and the international audiences; the second one is the need to highlight the competitive advantages of Apulia compared with other neighbouring tourist destinations.

From these two principles, certain suggestions emerge for further discussion.

\section{For the national audience:}

Apulia is already known but probably not as well as it should be and the impression outdated; the region is in a relatively remote situation and access is highly dependant on air traffic. As in most of the regions of southern Italy, potential Italian tourists in Apulia are of two kinds. The first ones are inhabitants of the region, or people from the region who have moved to the North, and they are unlikely to be highly influenced by marketing campaigns, and the second ones are people coming from the North and the Centre of the country. For what concerns the latter making an attempt to reverse this situation could perhaps be worth trying. Some suggested themes include:

- The North of the South. This could be the kind of message that a national campaign should suggest. It is true that in geographical terms this is not strictly correct, however the main argument, to be used with care, could be that Apulia, even if its economic situation is not totally dissimilar from other southern regions, is not suffering as much as from social and structural difficulties; tourists are therefore unlikely to be confronted with these potential problems in Apulia. It is obvious that this should be done in a positive way and very tactfully.

- The region of the quality of life and/or the quality of food. This is a much less controversial message, and it is corresponding to an already existing positive image of the region. With the relative decline of the traditional Italian way of life in some northern regions, Apulia could trade on preserving the traditions and heritage of keeping alive of the art of fine cooking and eating. The historic international connections also present a wider sophistication of influences that make the region a "Curious Corner" of, not just Italy but, the Mediterranean thus widening the regional appeal.

\section{For the international audience:}

As has already been stressed, international tourists in Apulia have long been attracted by the seaside, summer resources and, to a lesser extent by the cultural riches of the region. However the lack of a clear identity and specific image could be interesting as a marketing angle for Apulia to attract people who want to spend time in Italy, and Italy as such not in a specific city or region.

A priority target could thus be people who already know Italy; people who like the Italian way of life and are no longer finding what they are looking for in more traditional destinations, like Tuscany or Sicily. This could present Apulia as a place to find "Italy at its best". This should be directly linked with the niches proposed in the previous section and whilst mainly concerning holiday tourism, could be quite easily adapted for the development of business tourism, , and even probably to "urban" tourism. Some suggested themes include:

- The secret Italy. This type of message should be directed to people who are primarily interested in cultural heritage, traditions, and who like to consider themselves as pioneers, or at least first comers. 
- Italy for connoisseurs. Far from mass tourism, this could be directed to a rather discerning public, interested in the quality of food, wine and other elements of the dolce vita, those who would appreciate the idea of slow tourism.

- The authentic Italy. This could be tailored for people with eco and/or ethno concerns, which are mainly looking for traditional living experiences.

\section{Box 4. Lille 2004: giving a positive image to a city-region and revealing its assets}

Lille and its city-region share a wide number of features with Manchester: similar industrial past, huge decay in the 1970s and recovery from the early 1990s on; both cities have therefore been faced with the same set of prejudices and loss of attractiveness in their country. However the national cultural/political contexts but also local opportunities differ quite extensively from one city to the other. Lille is for example endowed with a much more prestigious past and ancient (XV' to XVIII' centuries) heritage and with major cultural institutions, but has not much benefited yet from the development of popular music /club culture.

In a context of deep economic and social crisis, local authorities in the Greater Lille area have implemented for more than 30 years a cultural development strategy that has managed to turn a post industrial city into what can be considered as the most thriving cultural centre in France after Paris. The first evidence of this transformation was given in 2004 when Lille was European capital of Culture. However since then many events have been organised in order to keep the momentum, the only exhibition in France of large parts of the François Pinault's collection before it is transferred to Venice, being one example.

This cultural development strategy was actually not primarily geared towards tourist development: the main objective was to change the image of the area not only for potential new comers but also for residents and to develop their civic pride, self-esteem and sense of belonging to the place.

The success of Lille 2004 resulted in a huge local participation but is also due to this popular enthusiasm; 18 000 local "ambassadors" committed themselves to promote the events programme and deliver information towards the local, national and/or international audience. Participation was very important: 9 million individual participations in the programme events and 2.8 million tickets sold. However the true success of Lille 2004 was to manage to achieve a real mix between popular participation and the most advanced contemporary creation. It became clear that coming to Lille for cultural events was meaning experiencing and even participating in these events with local people and not just attending an artist' performance.

This obviously draught much attention both nationally and internationally and strongly improved the fame of the city region, which was even qualified as "European city of the Future" by a British news magazine.

However, due to Lille localisation and the easy connection with neighboring countries, this led first rather to a strong increase of day-trips than to an actual explosion of tourists flows, but, especially foreign, visitors high level of satisfaction should result in the development of longer stays. Lille has also strongly increased the Business tourism since 2004.

More information: http://www.lille3000.eu 


\section{TRAINING AND EDUCATION POLICIES NEEDS IN THE TOURISM SECTOR}

\section{Introduction}

Tourism is a human activity and involves a series of personal perception processes. These processes are individualistic yet capable of being gathered to identify generic components of successful experiences. Human experience and sensory satisfaction are at the core of the tourism process as individuals seek to maximise their value obtained from leisure and learning time. This consideration of learning and part of tourism experience is becoming an increasingly important consideration, especially with the upper end of the market where passive tourism experiences have become largely superseded by a desire for more involved learning experiences. This is an important consideration for the industry as a whole and specifically for the authorities in Apulia as they seek to establish the optimum position of the region to encourage sustainable development into the future.

Tourism is relatively easy to develop in one form or another and high value niche markets are often driven by pioneering consumers rather than mass promotions. As in most industries, some of the best ideas and innovations actually originate from customers who literally vote with their feet by going repeatedly to places that meet their desires and expectations. All countries and regions - even at an early stage of development - can develop successful tourism sectors relatively easily around existing natural resources and local attractions, albeit in a very competitive sector. Sustaining the patronage is a more difficult task especially as economic and market conditions change as is inevitable.

Tourists usually express demand for four main types of goods and services: transportation, food and drink, entertainment and accommodation. These services are mostly labour intensive; hence tourism leads to the creation of many jobs that are primarily low-skilled. This does not mean low quality; training and standards are essential as it is the quality of the greeting and welcome that so often determines the success of the tourism offering.

The ability to extract economic benefit from tourism and in particular to generate return visits for longer periods and spending more money in the local economy is the key to success. Tourism is a labour intensive industry and one of its key advantages is the employment "ripple effect" with jobs being created in a wide range of support industries as a result of tourism expansion and the development of multi job income streams for local people.

For many small countries and regions, tourism is the single most important and influential sector of the economy. This creates tremendous opportunities for development relatively easily as noted above, however it also has a potential downside, as tourism demand can be both seasonal and highly volatile; areas that become dependent on tourism are susceptible to negative exogenous shocks that can have a severe impact on the entire economy. The current downturn in the global economy, changing consumer patterns and currency fluctuations illustrates the perils of over-dependence on tourism. This raises the importance of public sector involvement and support to nurture a balanced tourism development strategy that recognises the dependence of many local areas on tourism for jobs and income. 
In Apulia the authorities have begun this process and now need to accelerate it. This will be challenging for the local tourism "sector" to make appropriate representation and raise awareness in central and regional government, and amongst national decision makers in other sectors. This concerted effort is essential to raise awareness and gain strong commitment to the industry from a recognition of the contribution that tourism makes to local livelihoods, and how best to develop joint strategies and initiatives that will increase regional and local economic development as well as reducing poverty and peripherality. The role for skills and training is central to the development of a sustainable and strong tourism sector and to the regeneration of confidence in local communities.

\section{Links between tourism skills training and regional development}

As far back as 1999, the OECD ${ }^{5}$ in its Tourism and regional development Round Table explained that Tourism and Regional Development are closely linked:

"Tourism policy, which is a tool for economic development and job creation, is becoming an instrument for territorial development and for enhancing and preserving an area's heritage. In many regions, the tourism industry is one of the greatest sources of economic growth and job creation. Tourism, through active promotion policies, can also become a tool for integrating less developed regions or giving them equal access to the fruits of growth. One of the first major challenges consists of setting up mechanisms to improve the competitiveness and quality of tourism at regional and local levels in order to ensure the sustainable and balanced development of tourism at national levels, improve the industry's performance and make tourism areas more competitive at regional, national and international levels. A second challenge consists of reconciling local tourism development with the preservation and renewal of tourism resources."

Over many years, tourism has contributed significantly to the domestic economic growth of many countries, including Italy, whilst emerging as a major factor for regional economic development (as shown clearly also in many diverse countries including France, Greece, Ireland and the United States). Whether international or national in nature, tourism has a major economic and social impact at regional and local levels in the areas where the tourism activities take place. Tourism, measured at regional levels, is an activity that is complex and multi-faceted, much like regions themselves. Tourism also helps to finance the infrastructure necessary for the economic development of an area and can give it a distinctive image and identity that will benefit all its economic activities.

Tourism has been highly beneficial to certain types of regions. These regions include, for example, coastal (such as Emilia-Romagna in Italy), mountainous (Valais in Switzerland), urban and historic (Ile-de-France in France) or regions with exceptional natural resources (Quebec in Canada, Arizona in the United States); but regions with different profiles can also benefit from the growth of tourism. This is a reason for Apulia to be confident about the future development potential. Predominantly rural regions can be successful in promoting green tourism, leisure and nature activities (Queensland in Australia), as can very remote regions, (Greenland) or regions undergoing industrial restructuring (Nord-Pas-de-Calais in France). In all these regions, appropriate tourism strategies have been implemented by public and private decision-makers in order to maximise the benefits that the local economy can derive from tourism and to minimise negative spillovers, particularly for the environment. This again will become central to success in developing tourism in Apulia.

\footnotetext{
${ }^{5}$ See http://www.oecd.org/dataoecd/10/32/1902552.pdf
} 
These strategies can also contribute to broader goals, such as spreading activities more evenly over time and space, and co-ordinating "inter-sectoral" policies. Skills and human resource training will be at the core of the approach to developing a sustainable tourism sector in Apulia.

The regional development of tourism in Apulia, could under the right circumstances, trigger general economic growth by creating a new dynamic and engine for expansion of activity and wealth creation. It could also contribute to better land use planning by countering over rapid concentration or urbanisation in the most developed areas and by attracting populations to new regions where tourism could be developed. Some framework for development already exists in the region and further more specific tourism related guidelines for development must be laid down in order to preserve natural resources and ensure complementarities between areas.

Apulia has a range of natural attractions and potential new development opportunities that could become major international attractions. Many regions across Europe have used European Structural Funds to improve their tourism product, with a view to bringing visitors and visitor spend into an area. There have been some considerable successes (such as the Eden Project which became a major visitor attraction and engine for new growth in the economy of south west England, UK), but, as is often the case, the failures or mistakes are worth noting to ensure that lessons are learned from them.

It is often difficult to know why some areas generate initiatives and specific tourism projects that "hit the spot" while others simply fail to innovate or indeed make best use of the resources and attractions that exist naturally. It is clear that a balanced and analytical approach to tourism is essential in Apulia to promote successful campaigns with the necessary blend of design, marketing, communications, location and intangible factors, notably the role of local people. Like all areas, Apulia will require a well trained workforce and an enterprising attitude amongst the local business community to become successful.

We know how to define and measure the weight of tourism in national economies with increasing accuracy. This is far less true at regional and local levels, although much work has been carried out in this area in recent years (often conducted by the OECD and their expert advisors) through the development of sophisticated evaluation frameworks. Improving knowledge of the economic weight of tourism at regional levels is a challenge for policymakers, but a necessary condition for implementing optimum development strategies.

Skills levels, job opportunities and income levels are central. A specific aim of regional policies is to reduce inequalities between regions in order to increase a country's economic and social cohesion. However co-operation between regions is "not always satisfactory" ${ }^{6}$. Regions often choose competitive development, even though they could develop complementary tourism products. Potential lonks between Apulia and neighbouring regions were mentioned in the previous chapter, including the links to other Mediterranean locations beyond Italy. In this regard, a clusters approach makes sense in the Mediterranean and in Apulia region.

In order for tourism to grow and to create jobs, the competitiveness and productivity of the industry does need to be improved continually. The challenge, of course, is that visitor value is determined by numerous interactions, mostly with people. Tourism is a highly personalised industry and human resources are critical to unlocking visitor value. It is recognised that tourism human resource development is often not effectively addressed in tourism strategies, and the more popular functions of marketing and promotion often receive the bulk of attention. While marketing and promotion are indeed priorities for the region, the importance of the skills, education and training

${ }^{6}$ ibid 
agenda is recognised in Apulia and must now be addressed as a central element of improvements in the region.

\section{The Importance of Human Resource Development: International Experiences}

Skills and training as part of continuous human resource development is absolutely crucial to people based activities such as tourism. This has been recognised around the world and re-iterated on many occasions at international events and knowledge sharing conferences. Many countries and regions have identified tourism as the major industry for development and economic growth and the competition is increasing constantly as more developing countries and regions emerge to offer distinctly competitive products. They also recognise the importance of education and skills development, and more broadly, the necessity for an adequate level of human resources development. The lack of this becomes a critical constraint to achieving and sustaining a positive rate of economic growth rate

For example, the regions of Africa are emerging as competitive and attractive tourism locations and there is a tremendous effort in creating the facilities as well as the services to claim a share of the global tourism market. Major sporting events such as the Africa Cup of Nations held in Angola and the 2010 World Cup in South Africa have provided a major showcase for promoting Africa and tourism in Africa to the world. The success in generating follow on tourism on the back of such major events is all part of the strategy.

The skills issues go beyond the specifics of international events. Here too skills are recognised as vital and there is much to be learned from knowledge sharing. In a symposium in South Africa in $2006^{7} \mathrm{Mr}$ Marcel Leijzer of the WTO, in a discussion on international best practice in skills development for the tourism industry, highlighted the following key human resource challenges and success factors:

- The need for human resource (HR) information, knowledge and tracking systems;

- The importance of clear HR strategies;

- Training delivery must be flexible and demand led;

- The tourism industry is made up of a large number of small and medium sized enterprises (SMEs) and micro businesses in particular;

- Co-ordination and a commitment to partnerships among public and private sectors are critical elements of a successful HR development strategy;

- Excellent and continuous communication is essential;

- Uncomplicated administrative systems and procedures.

In addition to these factors, he also highlighted critical considerations that are relevant to all locations seeking to develop practical initiatives for regional tourism development. These include:

- The provision of practical, easily accessible training resources;

\footnotetext{
${ }^{7}$ See http://www.tourismskillsinitiative.co.za/pdfs/NBIConferenceReport.pdf
} 
- Providing SMEs with appropriate training support and assistance;

- Developing flexible and relevant training systems;

- Growing a tourism culture:

- Recognise the critical role of HR development in tourism;

- Work towards pooled resources and a shared commitment;

- Follow a demand driven approach;

- Training priorities should be in support of the destination positioning and branding;

- While the implementation of the training system and policy, (including quality assurance and certification) is crucially important, addressing key HR "levers" - i.e. those interventions that could make an immediate impact - should be tackled as a matter of priority.

South Africa is one of many countries that recognise the need to improve skills, training and education in tourism. As a result of the 2006 conference, several high level priorities were agreed and each has a series of action tasks with clear roles and responsibilities for individual parties in order to:

- Improve skills co-ordination;

- Improve the knowledge base;

- Improve curriculum development and participation in education and training

- Develop Small and Medium Sized Enterprise (SME) and community participation in education and training.

Apulia must consider the need to address these considerations and ensure that initiatives are implemented to address the real practical challenges facing the development of tourism in the region. Skills, education, training and labour market issues all must be profiled, analysed and tackled.

National, regional and local measures have been developed in various European countries to support the needs of their respective hospitality and tourism industries. Some of these are profiled below with regard to particular issues being faced in each country that illustrate examples and potential learning for future initiatives in Apulia.

The countries chosen are not profiled in detail; rather a specific aspect of the tourism development agenda is highlighted. For example, in the UK there has been a recent emphasis on support structures and network systems whilst in Portugal, the initiative with village tourism is highlighted. These examples are all chosen with relevance to the specific context, challenges and opportunities in Apulia rather than as generic learning. In this way, the knowledge and experience from other locations can be transferred more readily to the practical developments recommended for Apulia.

The examples shown below are augmented by further case studies in Annex 1; International Examples. 
People $1^{\text {st }}$

Across the UK (including the devolved administrations of Scotland, Wales and Northern Ireland), People 1st is the sector skills council for hospitality, leisure travel and tourism. There are 25 sector skills councils in total, covering approximately $85 \%$ of the UK workforce, and representing the skills and training interests of small to large businesses.

People 1st cover the 14 industries that make up the hospitality, leisure, travel and tourism sector:

1. Contract food service providers

3. Events

5. Gambling

7. Holiday parks

9. Hospitality services

11. Hostels

13. Hotels
2. Membership clubs

4. Pubs, bars and nightclubs

6. Restaurants

8. Self catering accommodation

10. Tourist services

12. Travel services

14. Visitor attractions

They offer a variety of business solutions to help employers, including: training brokerage, particularly for training trainers; a website that brings together information on careers, job opportunities, qualifications, employers, colleges and funding for the sector; packages offering free online documents designed to help small and medium sized food businesses to grow and develop; online tools to support small businesses with human resources and food specifications; Preemployment Training - a two-week flexible programme, designed to provide job-seekers with relevant industry knowledge and skills; and an initiative to support women working in the sector and empower the female leaders of tomorrow.

People 1st are also responsible for ensuring that qualifications in the sector are fit for purpose. Their research has shown that there are currently over 400 industry-related qualifications across the UK, but employers and employees do not understand their relevance to careers in the industry. Although two thirds of employers are actively engaged in some form of training, only three percent of this currently results in a recognised qualification. A comprehensive qualification reform and rationalisation programme, is therefore currently underway, examining a complete evaluation of all qualifications as well as reviewing the National Occupational Standards for the industries.

Research commissioned by People $1^{\text {st }}$ found that employers in the sector are facing a number of skill gaps and shortages; particularly for managers, craft occupations and in customer service. This type of finding is not unusual and is indeed prevalent in many regions, and is likely to be directly relevant in Apulia. In the UK, the research revealed that:

- employers do not understand the range or purpose of the qualifications available;

- qualifications to aid workforce development are seen as too big and cumbersome; 
- employers tend to recruit on attributes and experience, rather than qualifications;

- some existing qualifications (particularly pre-entry) are not appropriate and are 'surplus to requirements';

- employers are unaware of the value of qualifications over and above in-house training; and

- qualifications are too expensive; particularly for micro businesses which represent $76 \%$ of sector businesses in the UK.

\section{National Skills Academy for Hospitality}

The National Skills Academy for Hospitality was established in England in 2008, backed by leading sector employers, with the remit to identify, endorse and promote qualifications and learning opportunities delivered to national standards. The Academy's mission is principally to develop a brand which is universally trusted as the benchmark for excellence in hospitality training. Delivery takes place in local universities, colleges of further education, employer businesses and dedicated hospitality schools. The role of the Academy is also to:

- focus on the areas related to management and leadership, customer service and craft skills which are central to addressing the industry challenges;

- innovate and provide franchise solutions (to training and skills development); and,

- ensure that funding is available where needed to support excellence in hospitality training.

These are all issues relevant in Apulia.

\section{Tourism Skills Networks}

England also has Tourism Skills Networks (with People $1^{\text {st }}$ playing a partnership role with the Regional Development Agencies, Local Economic Partnerships and regional tourist boards) aimed at increasing the productivity and competitiveness of the tourism economy in each of the English regions. Their role is to:

- Develop a funding and delivery framework to support tourism skills development activity throughout the region

- Increase the engagement of the sector in relevant and effective training leading to the development of a skilled workforce

- Identify the skills needs of the sector and work closely with education and training providers to meet those needs

- Support "Destination Management Organisations" (DMOs) in the development of workforce development plans which meet the skills needs of local tourism and hospitality businesses

For instance, the Tourism Skills Network South $\mathrm{West}^{8}$ have recently developed a vision called Tourism Skills 2015, which will be delivered through four key priorities; Regional skills policy,

\footnotetext{
${ }^{8}$ See http://www.tourismskillsnetwork.org.uk
} 
Regional skills development programme, Regional research and education; and Local skills delivery through partnership with DMOs. Further information on this is shown in Annex 1.

\section{Scotland}

In November 2009 People $1^{\text {st }}$ published their Sector Qualifications Strategy Action Plan for the hospitality, leisure, travel and tourism sector in Scotland. ${ }^{9}$ The key priority areas they have identified include examining:

- Labour market information [that is of high quality and fit for purpose]

- Delivery and maintenance of fit for purpose, demand led qualifications.

- Attracting talent

- Promoting the industry

- Provision of specialist careers advice and work experience programmes.

- Creation of pre-employment routeways for the sector.

- Training and Development

- Management and Leadership skills

- Craft / Chefs Skills

- Continuous Professional Development of the sector

- Delivery of a robust marketing and communications policy on skills

In Scotland, workforce development is increasingly recognised as a vital component of improving business performance, as the competitiveness of tourism businesses can often rest on the quality and skills of employees. It is recognised that effective training may be crucial when hiring new recruits or when changing business practices or adding new products. As a business grows, the skills needed for it to remain successful may change. Help is provided by public agencies to:

- Develop skills including entrepreneurial, leadership and managerial and service skills.

- Support tourism businesses in the development of good employment practice that improves retention and performance of staff.

- Ensure that the route through training and development is simple, straightforward and appealing.

Help is also available for entrepreneurs and established businesses through specific development initiatives including the following.

\footnotetext{
${ }^{9}$ See Sector Qualifications Strategy Action Plan for the hospitality, leisure, travel and tourism sector in Scotland: The Blueprint for Action 2008 - 2011 People 1st (November 2009)
} 
This programme is delivered by private sector providers but is owned and co-ordinated by the regional economic development agencies, Highlands and Islands Enterprise and Scottish Enterprise.

The course is designed to help tourism and hospitality businesses achieve better results through focusing on:

- Developing and delivering customer service;

- Achieving excellent performance through great leadership;

- Continuous improvement based on customer feedback.

100k Welcomes consists of three courses:

1. Tourism Leadership - for owners, managers, supervisors and those with responsibility for recruiting, training and developing staff;

5. Tourism Operations - for front-line staff;

6. Tourism Stars - for 'Stars' of the front line and/or managers of the future

\section{Hospitality Assured}

The Hospitality Assured programme is based on the concept of 'very best practice' and can help answer these key questions and more importantly provide a tool to improve the performance and competitiveness of a business. Support is also available for tourism employers and people working in the tourism industry through generic skills programmes.

\section{The Hospitality Assured online self assessment}

This online assessment comprises 10 key steps against which to measure a tourism/hospitality business. This assessment, when completed, shows how well a business is performing and helps the owners/managers understand the things they do well as well as identify where improvement is needed.

\section{Northern Ireland}

The Hospitality and Tourism industry has been identified as an area of particular economic significance for Northern Ireland by their Department for Employment and Learning, regularly citing challenges in relation to skills gaps and shortages. As a result the Northern Irish Assembly published their Hospitality and Tourism Future Skills Action Plan in November $2009^{10}$ in conjunction with People $1^{\text {st }}$.

The plan is structured around three thematic areas:

1. Skills provision;

7. Sector attractiveness; and

\footnotetext{
${ }^{10} \mathrm{See}$ http://www.delni.gov.uk/future_skills_action_plan_with_grid_attached.pdf
} 


\section{Coordination and communication.}

Under each thematic area, key issues and associated actions are outlined and accompanied by specific targets.

\section{Theme 1-Skills provision}

Like the rest of the UK, Northern Ireland identified that there was a critical need to improve the management and leadership skills of the Hospitality and Tourism sector and committed themselves to the development and delivery of a Hospitality Educators Programme across the Further Education and training provider network in order to improve the skills of those in senior positions in the sector.

They also noted a need to increase the number of chefs coming into the industry and have developed and piloted a fast track conversion programme which will enable suitable applicants to complete the Professional Cookery Diploma over six months with an additional three month placement, which will supply suitably qualified chefs into professional kitchens within a shorter timeframe. Furthermore they are extending their "Junior Chefs" Academy" which offers young people the chance to discover a passion for cooking which will increase the likelihood of them considering it as a career.

Following the success of a pilot Professional Cookery Diploma, they have supported the rollout of this Diploma across three more Further Education colleges in the region. They also continue to encourage employers in the sector to use the Modern Apprenticeship programme to upskill their staff.

Recognising that there is a need to increase the number of people in the workforce with customer service qualifications, they have commissioned their Further Education colleges to develop and run sector specific customer services qualifications aimed at those people already in the industry. Northern Ireland's Department for Employment and Learning will work with one employer in the sector to ascertain their skills needs and put in place a solution for a minimum of 10 employees.

\section{Theme 2 - Sector Attractiveness}

The Northern Ireland Government also recognised a need to encourage more people into the sector and is developing a Tourism Awareness Programme as an educational resource for teachers to use in schools. This will be linked in with the curriculum and will aim to improve the attractiveness of the tourism industry as a valid career pathway. They have also developed an Ambassadors Programme to put in place a network of ambassadors from the industry that will participate in promotional activities and careers events and enhance the appeal of tourism as a source of good quality employment opportunities in Northern Ireland.

\section{Theme 3-Coordination and Communication}

They also identified a series of actions to coordinate new and existing work with that being taken forward by other agencies and partners and communicate these actions to stakeholders.

\section{Republic of Ireland}

Fáilte Ireland ${ }^{11}$ provides strategic and practical support to develop and sustain Ireland as a highquality and competitive tourist destination. They work with the tourism industry in areas including

\footnotetext{
${ }^{11}$ See http://www.failteireland.ie
} 
business support, enterprise development, training and education, research, marketing and regional development. Fáilte Ireland works in partnership with Tourism Ireland (who promote Ireland as a holiday destination to overseas markets) and the Northern Ireland Tourist Board (responsible for tourism development and marketing in Northern Ireland).

There are a number of strands to their work:

- Business promotion: Marketing products with an extensive annual calendar of in-Ireland and overseas promotions, workshops and networking events.

- Journalist Familiarisation trips: Fáilte Ireland's publicity department welcomes journalists, photographers, television and radio crews from all over the world every year.

- Tour Operation Familiarisation trips: Fáilte Ireland supports industry partners in marketing and promoting Irish tourism products at home and abroad

- National Tourism Database: they administer Ireland's national database for tourism content, including details of Irish accommodation, activities, attractions and events.

- Discover Ireland campaign: a comprehensive media campaign for home holidays featuring a wealth of choice in inclusive package holidays for long or short breaks

- Regional Support for businesses in the industry: local support from Fáilte Ireland in three key areas: organisation development and staff management; product and market development; and enterprise development.

Fáilte Ireland also runs a network of branded training centres. Fáilte Ireland programmes are of "the highest international standard" and are available all over Ireland. They provide the first step on the road to a career in the tourism and hospitality industry and are specially designed to appeal to all who want to enter the industry on either a full or part-time basis.

\section{Portugal}

Tourism is one of the most important sectors of the Portuguese economy, responsible for about $8 \%$ of the national product and around $10 \%$ of the total employment.

In addition, the receipts from tourism contribute substantially in financing the current account deficit of the balance of payments in Portugal. Current revenues from tourism represent 6.3 billion Euros, equivalent to $11 \%$ of the nation's GDP ${ }^{12}$.

Although tourism figures have grown over recent years, Portugal has lost market share at international level and is currently highly dependent on four international markets - the UK, Spain, Germany and France, which make up $60 \%$ of international visitors and $67 \%$ of revenues. The country offers a number of interesting insights on how to tackle the challenges of tourism, including seasonality, fragmentation and linking local, regional and national offerings in a way that is relevant to local communities and businesses.

Like Apulia, Portugal has an attractive coastal character for mass tourism and an intriguing traditional internal network of villages and cultural attractions that are often overshadowed by the

\footnotetext{
${ }^{12} 2008$ figures. See, for instance, http://portugal.themovechannel.com/features/58c587f0-5748
} 
resort attractions. This imbalance can lead to pressures internally and competitiveness issues internationally.

The coastal areas of Portugal, such as the Algarve and Estoril, attract tourists with the lure of glorious sunshine, inviting beaches and numerous leisure options, such as great golf courses, healing health and wellness facilities and wonderful water-sport activities. These types of locations tend to suffer from seasonality, where they are extremely busy during the summer months, but quiet during the winter periods.

The major cities such as Lisbon and Porto have broader appeal and attract visitors all year round in various numbers as there is a strong market for visitors looking for a short city break. Such visitors tend to be more interested in the history, culture and architecture of a place.

However, as in all countries, the regions of Portugal offer a variety of such genuine culture based attractions albeit that they are harder to access. This has been addressed and the Portugese region of Aletenjo led a European Network of Village Tourism project and the lessons learned have formed a 2008 OECD study ${ }^{13}$. The region is characterised as an area of isolation, degradation of economic activities and a consequent increase in unemployment, as well as an aging population, and depopulation.

In order to address these characteristics and promote positive changes, the Aletenjo region, working alongside others with similar issues, promoted a raft of initiatives that contributed towards their sustainable development. These initiatives sought to tackle the problems and build around the strengths and opportunities of the region such as environmental preservation and the richness of their cultural and ethnographical heritage.

They devised the European Network of Village Tourism, using tourism as a catalyst for integration and sustainability, by promoting endogenous tourism led development in a number of selected villages. This led to a solid networking system with other regional villages at the international and also extending within the country at the regional and local level to produce a combined top down and bottom-up approach in the development of the initiatives and activities with the communities involved.

Local knowledge formed the basis for their plans and it was agreed that the formation of Village Plans (Local Development Plans) was essential for the establishment of the Network and all the activities to be developed in each village integrated into the network approach. Additionally, a tourism activity plan for the Network was developed to consolidate this new tourism product and shape an information and marketing strategy.

Another aspect considered important was the promotion of training and professional qualifications, in order to give local communities and their citizens the skills for improving their human capital. In this way, the project put together a local development plan, complemented by a training analysis, in order to provide the basis for a training plan as well as a tourism activity plan.

A branding identity and a range of tourism projects were developed which enhanced the distinctive image of the common project, and in turn led to the involvement, on a voluntary basis, of

\footnotetext{
${ }^{13}$ See European Network of Village Tourism (2008), "Networks in Rural Tourism and Their Impact on Sustainable Destination Development: European Network of Village Tourism”, Case study submitted to the OECD by the European Network of Village Tourism, Portugal.
} 
local communities in activities such as recreating historical events, booking excursions, organising the tourism offer and joint activities and exchanges with the other villages.

The European Network of Village Tourism project stimulated and mobilised public interest in another type of tourism; those seeking village tourism based on the traditions of a warm welcome, with regional products, and in a traditional cultural setting. The project won the Ulysses 2007 Award by the United Nations World Tourism Organization for innovation in tourism. The Network generated interest in other regions and five additional regions, from Italy, Belgium, Greece and Slovenia, became involved during 2009.

It is clear that many lessons can be drawn from the Portuguese experience and applied to Apulia given the similar cultural and geographic challenges.

\section{France}

Central government has encouraged comprehensive sustainable development in France since at least the mid 1980s, attempting to strike a balance between economic development (favouring retention and development of economic activity) and conservation of natural areas. ${ }^{14}$ Measures often link agriculture and the environment, or development, especially tourist development, and the environment.

An OECD paper from $20044^{15}$ noted that, "in France, tourism is one the few sectors still creating jobs. However, the highly seasonal nature of this activity generates constraints that tend to marginalise such jobs or make them less attractive, despite the fact that the quality of the welcome extended to tourists depends directly on the attractiveness and professionalism of jobs in the tourism sector."

Over the past few years novel legal and social provisions have been deployed with a view to narrowing the gap, in terms of the working environment and security and sustainability, between jobs in the tourism sector, particularly for seasonal workers, and those in other sectors of activity.

This has led to such measures as:

- the creation of a contract of employment tailored to periods of seasonal work;

- development of employers' groups;

- better access to training and recognition of acquired skills;

- changes to occupational medicine;

- access to various allocations and particularly housing benefits;

- organisation of a territorially-based environment for the protection of employees (European network of housing for seasonal workers, with union representation).

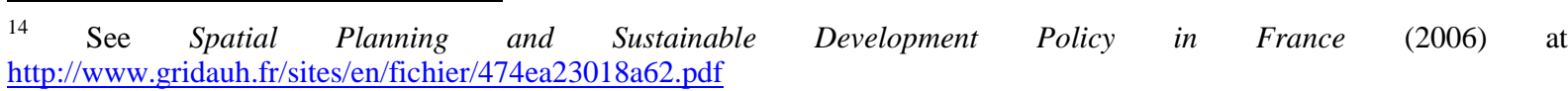

${ }^{15}$ See "The French Initiative for Innovation in Tourism: How to Rejuvenate supply and increase the productivity of the tourism sector" Guerin/OECD 2004 
A French Interministerial Tourism Committee added to this by insisting that a given percentage of new or renovated tourist accommodation, for which tax benefits have been granted, should be reserved for seasonal workers.

Professional assistance for tourism development is provided through a network of public agencies for business and commerce. There are 159 chambers of commerce and industry, as well as 20 regional chambers, and these bodies are grouped together in the assembly of French chambers of commerce and industry, the ACFCI. In 2001, the combined income of these chambers amounted to EUR 3.4 billion, primarily in the form of tax revenue. A process of re-organisation is on the way, and Regional chambers will soon play a leading role, local chambers becoming sub-delegations of them. These bodies have a very wide range of activities, including the management - directly or in partnership with local authorities, through joint ventures companies - of infrastructure such as ports, regional airports, conference facilities, etc. This often leaves them with few resources to devote to small and very small tourism firms. Nonetheless, they remain a genuine resource for the development of hotels and restaurants as well as the supply of leisure or tourism services.

\section{Learning from international experience}

The selection of international examples has highlighted how a range of initiatives and issues are being tackled. Many more can be developed to show that all across the developed and developing world, the tourism industry and related sectors is placing significant focus of resources and policy emphasis on the development of relevant and usable skills that will improve competitiveness and productivity for the future. Many countries recognise that their current educational programmes are not sufficiently aligned to industry needs. While a policy framework can be constructed and supply side initiatives promoted, it is essential that demand side drives development. In many countries, the tourism industry is not being involved significantly in developing the fundamental drivers of future skills provision including curriculum development and in providing routes to obtain structured and meaningful on-the-job practical experience of working in the industry.

There is also considerable evidence internationally that systems for tourism development and basic communications networking between practitioners and policy makers are insufficient and immature. In many countries there is a lack of government inter-departmental cooperation and cooperation between levels, from local to regional to national and international. In order to attract talented people to develop a career and businesses in tourism, it will be essential to engage young people from an early age and market the opportunities and rewards. As well as issues concerning recognition of the role that tourism plays in growing regional and local economies, particular concerns have been raised about the content of the curriculum in formal schooling and Further Education and Training colleges around tourism as there is often a disconnect between this training and the Higher Education offerings.

However, there are a number of specific examples of best practice that have emerged from this research which, if implemented successfully, could readily provide a solid foundation of core skills, a structured training regime that is valued and has currency within the industry. The best of this learning can be applied sensitively in Apulia to establish a competitive policy environment for development of tourism skills and continuous human capital up-grading in tourism, travel and leisure services, demanded by a modern tourism and hospitality industry. The specific learning points for application in Apulia are discussed further below. 


\section{Consistent, Targeted and Themed Marketing Initiatives}

\section{Developing an 'internal' marketing strategy}

It is essential for regions such as Apulia to develop a shared marketing strategy recognised and promoted by all internal partners involved in the region. This would help stress the requirement to have a consistent approach to tourism skills development and an approach that recognises its importance to regional development. Linking this approach across previously separate areas of responsibility and policymaking in different Departments and funding agencies (particularly those with a locus in skills development at school level, and also FE and HE levels) becomes an accepted way of working and a basis for performance assessment. Co-ordination of new and existing work with that being taken forward by others, and communicating these actions to stakeholders, is vital.

To encourage a future supply of skilled individuals into the hospitality and tourism industry in Apulia, work needs to be done to understand the issues clearly and address the attractiveness of the sector as a place to work. A marketing strategy, particularly aimed at young people to attract them to the sector, should be promoted once these issues are better understood.

\section{The need for underpinning efficient, effective structures}

Best results seem to come from organisations that have responsibility for a range of issues relevant to taking the industry forward as a vital component in the country or region's economic development mix. For example, the Fáilte Ireland model and the approach taken by Ireland in working with the tourism industry to provide business support, enterprise development, training and education, research and marketing appears to engender supportive links and partnerships with local industry and tourism boards. This has produced a range of benefits and deeper capacity building development benefits in a country with a strong national identity and a number of strong regional subidentities.

Marketing is essential and often difficult to coordinate effectively in countries with strong regional identities. Individual country media campaigns with all overseas marketing effort under one umbrella brand can work well when buy-in has been secured in advance and sufficient resources are made available. Furthermore, linking different elements of the industry promotion and regional features can produce excellent regional results with specific activities and attractions registering international prominence. It is also useful to link in specific skills sets aimed at a comprehensive promotion of an area by attracting journalists, photographers, television and radio, as well as tour operators with a view to marketing and promoting tourism products at home and abroad.

Promoting the warmth of welcome and the people skills of employees and ordinary residents in the region is becoming more and more important as tourists look for a deeper and more personal experience. Apulia has much to offer in this regard and positive profiles of local people can be very persuasive in securing commitment from within the community and attracting future employees to the tourism industry.

\section{Balancing supply and demand of skilled individuals}

Notwithstanding the above, there is no point in focusing efforts on the supply side alone. Ensuring there is specific demand for skilled individuals from industry is vital. Having a supply/demand mismatch, with too few or too many people with the right skills available at the right time, will impact on performance, wages and ultimately affect the competitiveness of the sector. Moreover, many small and micro businesses simply do not take up skills programmes, even when 
available, because they are stretched to stay in business and/or do not see the return from investing in skills.

This concept of the "free rider" is a persistent market failure and many regions have intervened to overcome this problem and demonstrate that training is a worthwhile business investment. The development of regional tourism clusters has brought this issue to the surface and collaboration in practice has shown how more can be gained if local businesses work together to build community competitiveness rather than continue with a narrow short term perspective.

An awareness campaign aimed at business, providing evidence of benefit to the bottom line that investing in the skills of their core assets - people - at every level of the organisation, will always help to address this issue. Improving demand for skilled people within industry, as well as ensuring effective utilisation of skills within the workplace, is notoriously difficult (contrasting with "supply push" models) but new thinking has emerged in several countries in recent years - particularly in countries such as Australia, New Zealand, Ireland and Scotland. Apulia can benefit from these developments by drawing on the lessons learned and applying best practices in developing tourism skills in the region.

\section{$\underline{\text { Tools for business }}$}

As seen in Scotland and New Zealand for example, the provision of tools for use by business can be an excellent way of engaging and nurturing a deeper involvement from the demand side. Use of the internet and digital technologies allow efficient and continuous involvement and facilitate networking within the industry. Simple online survey and assessment tools comprising a series of diagnostic questions from which a measurement can be drawn on how well a tourism/hospitality business is doing is an excellent way to engage with businesses and for business to understand and to access support - particularly those 'hard to reach' small and micro businesses, where time is seen as a premium and 'time out' from the business by busy owners is seen as impossible. Signposting tourism businesses to support in areas where they perceive themselves to be weak is recognised as a good way of stimulating demand for upskilling and business development, it can also strengthen the cluster and assist businesses to make connections that drive themselves, individually and collectively, up the value chain.

\section{Tourism Skills Academies}

Best practice in England, Ireland and elsewhere suggests that a network of branded local providers of training, delivering a blend of courses from introductory and craft level all the way up to graduate level and beyond could enhance human capital and the subsequent spin off benefits. After a review and (perhaps) rationalisation of the number and type of qualifications on offer in Apulia, the next logical step would be to assess the potential to develop a regional tourism academy, similar in scope to the National Skills Academy for England with the remit to identify, endorse and promote qualifications and learning opportunities delivered to national or regional standards. These academies could be developed with neighbouring regions to secure a critical mass of activities and a national centre of excellence, possibly securing funding from the EU.

Industry should perform a leading role by having a significant stake in the operation but, as in England, this delivery could take place in local universities, colleges of further education, employer businesses and dedicated hospitality schools. Consistency of quality of training provision and methods utilised could be protected through a 'social franchise' model which would only provide branding and accreditation to a local centre if standards were met and upheld regularly. Industry trust would stem 
from delivering courses that are valued by, and demanded by, industry, and which have a demonstrable impact upon increased productivity and/or license to operate.

Some examples of the type of provision that could be offered are:

\section{Chef/Culinary skills}

A shortage of quality, skilled chefs seems to be a recurring theme across many countries and it is fundamental that a supply of skilled and competent professionals is available to a successful tourism offering. It is absolutely critical, however, not to downplay the importance of traditional methods of cooking and preparation which will, in all likelihood have been passed down through generations and not through formal education.

Culinary tourism will undoubtedly form a vital component of the marketing mix of the region. Encouraging those with traditional skills to act as tutors for apprentice and journeyman cooks and chefs could act as a mechanism for encouraging buy-in from local people, engender pride in their culinary tradition, and form an additional layer of protection from cultural homogenisation and loss of traditional skills in Apulia.

\section{$\underline{\text { Junior Chef }}$}

Encouraging the next generation of tourism professionals is vital. The hospitality industry offers many opportunities to retain young people in employment in local areas and maintain the specific traditional skills of the area. Providing access to showcase opportunities, such as becoming a traditional chef, is an important part of this process. In addition to featuring in the schools educational curriculum, there are a number of ways to promote the industry as a career choice. Running a series of "taster sessions" for young people of school age to gain experience of a working kitchen and stimulate interest in the profession as a valid career choice for young people can be a very successful way of engaging and promoting the attractions of a career in tourism and related sectors.

\section{$\underline{\text { Tourism Awareness Programme }}$}

Linked to Junior Chef, perhaps through utilising a network of local industry ambassadors, a Tourism Awareness Programme could be a valuable educational resource for teachers to use in schools, linked to the curriculum, aimed at improving the image of the tourism industry in Apulia as a valid career choice, and raising awareness of the qualifications, availability and range of jobs on offer.

\section{Customer Service}

Given that the tourism industry is one where the customer interface is immediate and highly personalised, there is a need for sector specific customer service training and qualifications aimed at those people already in the industry in Apulia. Developing and delivering customer service, achieving excellent performance through great leadership and continuous improvement based on customer feedback are all important areas vital for concentrated effort and the development of hospitality skills courses locally.

\section{Management and Leadership skills}

There is an overwhelming consensus on the need to improve the management and leadership skills in the hospitality and tourism sector, worldwide not just in Apulia. A similar programme of work to that of Northern Ireland's Hospitality Educators Programme, with the support of the colleges and 
universities and the development of a network of private training providers could be considered to improve the skills of those in senior positions in the sector. This would also provide a Continual Professional Development (CPD) pathway for senior professionals, ensuring that skills are kept updated and informed by best practice from around the region and internationally.

\section{Cultural and environmental tourism}

The tourism market is changing rapidly to reflect more diversified tastes and refined requirements desired by individuals seeking different social, environmental and cultural experiences. Mass tourism resorts are also subject to more price sensitive and experience aware holidaymakers. These market trends all point to demand for a richer experience generally, increased quality and an offering that extends beyond the confines of the hotel or resort holiday. There is market advantage and repeat business to be secured in Apulia by enabling clients to enrich their experience and thus potential for increasing the local economic benefit.

The concept of environmental tourism, where individuals become more engaged with the ecological and socio-cultural concerns of an area through firsthand experience, evolved in the late 1980s alongside a growing consumer awareness of issues surrounding conservation and consumption.

Environmental tourism is a valuable and genuine opportunity to expand tourism into areas where jobs are scarce and economies are struggling. However, whilst the objectives of environmental tourism are often well intended, there are consequences that arise from the practice: when people travel to places that have historically been disparately inhabited, the presence of increased and new populations inevitably impacts upon the environment and the culture of the location.

In an effort to more effectively achieve the goals of environmental tourism, a focus on responsible and sustainable tourism has been added to the concept. To this end, more regulation for developers has been implemented; education is encouraged for travellers; and growth management is employed. Where these measures are undertaken successfully, local communities can have control over the conservation of their surroundings and culture, while continuing to reap the benefits of environmental tourism.

"A quality tourism product has to be compatible with environmental values and the preservation of cultural heritage, as well as balanced spatial planning. The traditions of regions and nations must be seen as a competitive advantage for the emerging tourist destinations." 16

It is important for Apulia to explore the potential for capitalising, in a sustainable and appropriate manner, on the current trend for environmental tourism and utilise the unique historical, archaeological and natural significance of the region, stimulating national and international interest in the particular culture, food and arts of the region. The European Network of Village Tourism, which started in Aletenjo region, Portugal, offers potential as a route to apply lessons learned from there, and from the other regions that have taken part in such initiatives.

\section{Market access for local providers}

International experience tells us that extending responsible business practices beyond the environmental agenda to address wider economic and social aspects builds reputation, particularly for those regions, organisations and companies which establish a leadership role. Developing the involvement of local residents in this agenda through skills and training is so important as is

\footnotetext{
${ }^{16}$ See Council of Europe (2006) at http://assembly.coe.int/Documents/WorkingDocs/Doc06/EDOC11069.pdf
} 
engagement of local traders as an authentic source. All this works together to produce a credible context for tourism growth.

Tourism development provides attractive opportunities for a number of providers of goods and services, especially in rural areas. For instance ${ }^{17}$, hotels and resorts can contribute and secure commercial advantage by working with local communities and SMEs to encourage the development of the diversity of local tourism services and products. Local economic development and the reduction of poverty are achieved where hotels and resorts:

- maximise their employment of local labour and through management and training interventions, by investing in people and ensuring that increasingly senior posts go to local employees;

- work with local communities and micro enterprises to ensure supplies of food and beverages, soft furnishings, maintenance, arts and crafts, transportation and entertainment are sourced locally.

The development of such local linkages requires that the challenges of quality, quantity and continuity of supply at a fair market price are understood and met competitively in the community. The key asset of human resources will always be central to success and creating a sustainable environment for tourism to develop commercially.

Hotels and resorts can contribute to this destination enrichment by providing market access for the communities and micro-enterprises that can provide these goods and services. Commercial advantage and risk management favour cooperation, especially where a cluster approach is part of the regional development process and businesses of all sizes are engaged actively with support from the public agencies. In adopting these approaches the hotel or resort is encouraging their clients to spend money in the local economy on complementary products by providing market access. Traditionally hotels and resorts have done this by entering into contracts with the local formal sector industry. There is commercial advantage to be gained by widening the range of goods and services available to guests and in the process a far more significant contribution can be made to the local economy by enhancing market access.

\section{Conclusion}

Tourism is a major source of employment and a vital driver of local development. There are limits to the extent that tourism can carry an entire economy forward however the integration of a diversified tourism offering with a wider economic development plan for the region can produce significant and sustainable additional benefits to business and communities. It is reasonable to expect that diminishing returns will eventually set in, putting a limit to the extent that the tourism sector can contribute but this further emphasises the importance of an integrated approach as part of wider regional and local development strategies.

Basic economics will affect the competitiveness of the tourism offerings as, for example, the impact of labour costs will emerge: as an economy based heavily upon tourism develops, wages rise and this leads to an increase in the price of tourism services, which are mostly labour intensive. At the same time, other countries continue to develop their own tourism sectors, many starting from a lower

\footnotetext{
${ }^{17}$ See Tourism and Local Economic Development: How can businesses in travel and tourism increase the contribution of the industry to local economic development and pro-poor growth? The International Centre for Responsible Tourism (Dr Harold Goodwin) and Scott Wilson Business Consultancy (Stuart Robson and Sam Higton), August 2004.
} 
point of development than Apulia and offering alternative products at a lower price. Thus a country or region specialising in tourism will become less competitive as it becomes richer unless the offering is diversified, enhanced and productivity and competitiveness continually improved within a growing total tourism market. This mechanical process appears to be consistent with casual empirical observation. For example, traditional Mediterranean destinations such as Spain, Greece, and Cyprus now face tough competition from relatively new mass tourism locations such as Croatia, Turkey, and Egypt. ${ }^{18}$

One approach to counter competition and limits to growth from existing and established products is to actively pursue a progressive policy which embraces specialist, upmarket or "boutique" type tourism targeting higher spend visitors as part of the distinctive regional offering. This is a crowded market and difficult, but not impossible, to achieve from a standing start - particularly if a robust and ambitious strategy is armed with a steady supply of capital, entrepreneurs, fresh ideas and a willingness to innovate, and a skilled and committed workforce.

\footnotetext{
${ }^{18} \mathrm{See}$ http://www.rcfea.org/RePEc/pdf/wp41_09.pdf
} 


\section{AN EVALUATION FRAMEWORK FOR TOURISM DEVELOPMENT IN APULIA}

\section{The importance of a strategic evaluation framework}

Evaluation is a critical component of policy making in all sectors and at all levels. Evaluation allows informed design and modification of policies and programmes, to increase effectiveness and efficiency. Even where this positive recognition is less strong there is a basic motivation to evaluate as the most defensible method of answering the fundamental questions:

- are we doing the right things; and,

- $\quad$ are we doing things right?

With accurate and reliable information, evaluation provides local authorities, governments, development managers and other interested parties with the means to learn from experience, including the experience of others. It serves the dual function of providing a basis for improving the quality of policy and programming, and a means to verify achievements against intended results. In particular, for funding organisations and responsible owners of initiatives at all levels, evaluation provides a basis for the allocation of resources and demonstration of results as part of accountability to key stakeholders. This shows accountability and achievements in a positive way around performance using recognised decision making processes and competency frameworks rather than a negative way that marks success or failure with reward and blame.

In a cultural sense, evaluation is a very powerful and positive method for promoting professionalism and a focus on demonstrably sustainable development at all levels of society and in all policy areas. It is not an option or a bureaucratic tick box exercise to release funds from central authorities.

\section{The context for Apulia}

An evaluation framework for Apulia Strategy for Tourism Development should have a clearly outlined set of indicators to be measured, identified data sources underlying these, and specific targets, rationale and baseline for each of the agreed development objectives. In addition, it will be appropriate to provide guidance for the investment impact assessment of existing and emerging activities, attractions and experiences, including suggestions of appropriate sources of evidence. This will take time and careful consideration involving partners from the private and public sectors. The framework suggested at this stage will be capable of development in this interactive way locally.

The Framework should be set around the vision for Apulia and the specific set of objectives including:

- To enhance the Apulia brand in order to consolidate perception of Apulia as a destination able to offer an integrated range of experiences for 365 days a year. 
- To encourage promotional policies offering a coordinated image of Apulia, to include collaboration between the Region and specific areas, recognising the central role of the Territorial Tourism Systems and the involvement of businesses in the promotion and marketing of Apulia.

- To invest more and better in defining an integrated tourism-culture-environment- transport policy and this facilitate the integration of different policies which influence the attractiveness of Apulia.

- To encourage greater specialisation towards market niches, through carefully considered policies. This will aim to enhance the potential of the different forms of "tourism" which can be introduced to Apulia, mostly through the Product Tourism Systems.

- To make important investments in improving the training of personnel working in the tourism industry and increasing communication and coordination between the requirements of the industry for skills and know-how and the professional qualifications on offer.

- To invest heavily in improving the tourist facilities and accommodation in the region, including a rigorous quality policy concerning the non-hotel accommodation $(\mathrm{B} \& \mathrm{~B}$, trulli, agritourism, farmsteads etc.), including seals of quality.

- To continue improving the quality of destinations in Apulia by investing in forms of slow mobility, tourist signs, information services at entry points (ports, airports) and the main tourist attractions.

A set of indicators can be developed within the evaluation framework, relating to these objectives, covering number and profile of visitors and expenditure as well as customer satisfaction and investment.

The consultations indicate that the framework should be structured around the priority strategic theme headings. The following headings can be seen as themes which can be developed in more detail in the framework:

- Economic

- Social

- Physical

- Profile and perceptions

- Capacity building.

The evidence to populate the framework can be built from the bottom up by gathering data on the effects from specific interventions in Apulia. This can also be checked by reference to a top down approach monitoring changes in the economy and environment. 


\section{Examples from Other Countries}

The suggested approach to the evaluation framework has been applied in many countries and regions in recent years. A number of these examples are shown below briefly before suggesting a framework for Apulia.

\section{UK, England: North East England Tourism Strategy 2005-10}

The North East of England is a region with a population of 4 million inhabitants and a diverse base for tourism and cultural events and activities. The area has undergone significant economic restructuring in recent decades and has sought to regenerate itself and modernise the economic base. Tourism is a key component of the region's economy supporting over 10\% of jobs. The North East's Regional Economic Strategy highlights the key contribution that the tourism sector can play in boosting prosperity. Given the inter-relationships between the different elements of the tourism economy in the North East (which range from heritage to hospitality) the leaders in the Region recognised that in order to strengthen the sector the private and public sectors must work very closely together.

The strategy and action plans to guide these efforts also aimed to bring substantial social benefits to the region. The logical thinking argued that more jobs and wealth alongside improved regional pride will bring better prospects for the environment, health, employment, education and social cohesion, resulting in a better quality of life for the resident population.

The area captured less than $4 \%$ of tourism expenditure in Britain, well below the per capita levels that could be expected. Addressing this was one of 10 objectives set for the Region ion the tourism development strategy: the objectives are shown below:

1. Attract more domestic and overseas tourists to the region

2. Increase visitors' average spend and increase day visitor spend

3. Increase visits throughout the year, not solely in the main holiday season

4. Increase employment in tourism, and tourism related businesses

5. Improve the productivity of the regional tourism economy

6. Accelerate the rate of investment in the tourism product

7. Improve the quality of the tourism product

8. Improve the skills of the tourism workforce

9. Improve levels of visitor satisfaction in the North East

10. Enhance and conserve the region's natural, heritage and cultural assets

The approach to measuring progress towards each of these objectives was set out in an Evaluation Framework. Objectives 1 - 6 are directly concerned with the economic impact of tourism and Objectives 7 - 10 relate to the quality of the visitor experience, including physical product, skills and the environment. 
The framework recognised the linkages between the objectives - for example, raising the quality of the visitor experience will play a major part in attracting new visitors and improving productivity. The framework used a template with a series of standard headings for assessing each objective as illustrated for objective 1 below.

Table 2. Objective 1: Attract more domestic and international visitors to the region

\begin{tabular}{ll}
\hline Measures & $\begin{array}{l}\text { Number of visits by UK residents } \\
\text { Number of visits by International Visitors }\end{array}$ \\
Instruments & $\begin{array}{l}\text { UK Tourism Survey } \\
\text { International Passenger Survey } \\
\text { Economic Impact study }\end{array}$ \\
Targets & $\begin{array}{l}\text { Increase market share to } 5 \% \text { of domestic visits and } 3 \% \text { of international visits by 2010. Based on } \\
\text { international visits. }\end{array}$ \\
\hline Rationale & $\begin{array}{l}\text { Of all the English regions, the North East attracts the smallest number of visitors. It also has the } \\
\text { lowest number of trips per head of population in England (1.9, compared with an England } \\
\text { average of } 2.5) . \text { As visitor numbers are subject to significant external influences, it is more } \\
\text { meaningful to link targets to market share rather than absolute numbers. }\end{array}$ \\
\hline Baseline & 4\% of domestic visits and $2 \%$ of international visits (2003) \\
\hline
\end{tabular}

This structure was followed for each objective and specific targets set including levels of occupancy rates for accommodation, increase in spend per visitor, quality of attractions and standard of accommodation, achievement of training qualifications, increase in tourism related employment. An action plan was agreed between the partners to ensure responsibilities for implementing the framework and gathering the evidence from surveys and other sources was in place and conducted at agreed reporting intervals.

\section{UK, Scotland: Fife Tourism Strategy 2007-15}

The tourism strategy for Scotland, "Scottish Tourism - The Next Decade - A Tourism Framework for Change" sets the challenging target of increasing the value of Scottish tourism by $50 \%$ by the year 2015 .

Sub regions within Scotland seek to grow within this overall strategy and build on their natural competitive advantages, nationally and internationally.

Fife is a successful tourism destination whose appeal centres on its natural environment, particularly its coastline, and includes some world class locations such as St Andrews, the home of golf. Tourism employment represents almost $9 \%$ of the workforce showing that it is an important and growing sector for the region.

In order to continue to grow and prosper, the region recognised that the tourism sector needed to focus more succinctly on the area's genuine key strengths and to consolidate industry and public sector activity to ensure that the economic benefit of existing and potential tourism strengths are maximised. The strategy for Fife recognized a series of challenges to be addressed including: 
- Environmental Concerns

- Declining Domestic Market

- Major City Effect

- Resistance to Embrace Change

- Poor Communication

- Duplication/Co-ordination

- Sustainable Tourism Development

- Cross-Sector Linkages

- Innovation

Partners in the region recognized the way forward required closer working relationships and a clear vision for the regional tourism offering. As a result, a series of regional workshop events and discussions produced a set of themes and new initiatives to increase growth and prosperity. This included diversification into new and innovative ways to promote the region as well as trading on its strengths including local scenery, the coast, historical attractions, religious significance sites and culinary skills around local food and prestige restaurants. Developing out these themes required a clear set of actions and promotions around new coordinated investments as well as collaboration on existing and planned initiatives with budgets. The resultant evaluation framework presented a series of headline and supporting indicators for measurement. These are shown below.

Table 3. Fife Headline Indicators

\begin{tabular}{|c|c|c|c|c|}
\hline Indicator & Source & Baseline & Year & Aspiration \\
\hline Visitor Expenditure & Survey & $£ 218 \mathrm{~m}$ & 2005 & Grow by $50 \%$ to $£ 327 \mathrm{~m}$ in 2015 \\
\hline Visitor Numbers & & & & \\
\hline $\begin{array}{l}\text { Seasonality } \\
\text { Total Employment }\end{array}$ & Survey & 5.8 million & 2005 & Grow by $20 \%$ to 7.0 million in 2015 \\
\hline
\end{tabular}

\section{Other Indicators included:}

- Annual Average Occupancy Levels in Hotel Accommodation

- Annual Average Occupancy Levels in Guest House/B\&B Accommodation

- Annual Average Occupancy Levels in Self-Catering Accommodation

- Average Spend Per Visitor Per Night

- Numbers Participating in Quality Assurance Schemes

- Average Star Rating Establishments

- Numbers Participating in Green Tourism Schemes 


\section{New Zealand: ASEAN Tourism Clusters}

New Zealand has refined various approaches to tourism strategy development from national campaigns for international promotion to internal marketing initiatives. One notable area of cooperation is with ASEAN countries in the development of a clusters approach to tourism. This identified four cluster initiatives using Michael Porter's approach to competitiveness, including creating the conditions for growth and markets to develop through competition. The monitoring and evaluation of such approaches also required a framework to be developed with performance measures against which implementation of the strategy could be tracked and assessed. The resultant framework required a range of representative indicators, guidance on how they should be measured and from what sources (such as surveys), how frequently they should be measured and how to track the distance travelled from an identified base line position and year. This logical approach is similar to many others, included the ones noted above, and can be used to inform the suggested framework for Apulia.

\section{Draft Apulia Tourism Evaluation Framework}

On the basis of the lessons learned and best practices from other countries and regions, it is recommended that a logical linear form of evaluation framework matrix is applied to assess progress. The framework matrix has the following advantages:

- It brings together in one place a statement of all the key components of the tourism initiatives over a defined time period.

- It presents them in a systematic way that shows the logic of how the initiatives are expected to work.

- It helps to ensure that the sequence of events is sensible and practical as well as true to the main development objectives for Apulia.

- It clarifies the relationships which will work together to deliver an integrated set of initiatives.

- It identifies the main factors that will determine successful change in the regional tourism offering.

- It encourages engagement with all partners in the regional tourism system across the private, public and community sectors.

As with all such frameworks, the chosen indicators must be capable of measurement, quantitatively or qualitatively, at reasonable cost. An example of a quantitative indicator is the volume of output from a new marketing initiative; an example of a qualitative judgment is the assessment that the majority of tourism operators have understood the messages and implemented complementary quality improvements. In some cases proxy assessments may be required and all assumptions on the use and relevance of the indicator should be stated in reporting.

Sources of information must be identified and made accessible for every verifiable indicator that will be quantified or assessed. The availability and reliability of data, and the practicability and cost of collecting them, must be carefully considered both in identifying suitable indicators and in determining the most cost-effective way of measuring them.

In a dynamic sector such as tourism where incremental progress is being measured the framework should include the following: 
- the baseline position

- choice of metric for each indicator

- means of measuring the metric

- interval for measurement, and

- means of benchmarking for each and with other regions.

The following page shows a suggested layout for the framework matrix for Apulia.

For this to progress in practice, extensive consultations and workshops should be conducted before drafting a detailed evaluation strategy and practical measurement framework. Prior to developing an approach or evaluation framework assessment must cover practicalities on the ground and address a number of questions including:

- Who currently provides what data?

- How is this collected?

- Is this fit for our framework purposes?

- Can this be aggregated to the higher level and benchmarked with other regions in Italy and elsewhere?

Partner workshops and practical working groups organised around each objective can be a good way of engaging effectively and developing a shared sense of purpose in implementing the tourism development initiatives. Proposals should also be developed for interim evaluation reports and possible amendments to the framework in the light of practical experience. 
Table 4. Evaluation framework matrix for Apulia

\begin{tabular}{|c|c|c|c|c|c|}
\hline Policy Objective & Input & Activity & Output & Outcome & Impact \\
\hline $\begin{array}{l}\text { 1. Broaden the tourism } \\
\text { season to } 365 \text { days a year }\end{array}$ & $\begin{array}{l}\text { Investment in } \\
\text { tourism initiatives }\end{array}$ & $\begin{array}{l}\text { Provision of attractions, marketing } \\
\text { materials and coordinated } \\
\text { promotion of initiatives }\end{array}$ & Rate of industry growth & $\begin{array}{l}\text { Provision of year round } \\
\text { tourism offering by all } \\
\text { partners }\end{array}$ & $\begin{array}{l}\text { Economic } \\
\text { benefit in GDP }\end{array}$ \\
\hline Verifiable Indicator(s) & \begin{tabular}{|l} 
Euros invested, \\
Time commitments
\end{tabular} & $\begin{array}{l}\text { Number of initiatives, promotions } \\
\text { and joint events }\end{array}$ & $\begin{array}{l}\text { Increased financial and } \\
\text { economic value of outputs } \\
\text { from initiatives }\end{array}$ & $\begin{array}{l}\text { Economic activity levels, } \\
\text { increase in new investment } \\
\text { into Apulia }\end{array}$ & GDP \\
\hline \multicolumn{6}{|l|}{ Source: } \\
\hline Frequency: & Annual & Quarterly & Annual & Annual & Annual \\
\hline Benchmark: & & Baseline & & & \\
\hline $\begin{array}{l}\text { 2. Favourable environment } \\
\text { for business and visiting }\end{array}$ & $\begin{array}{l}\text { Planning and } \\
\text { supporting } \\
\text { infrastructure }\end{array}$ & $\begin{array}{l}\text { Integrated transport solutions and } \\
\text { investments }\end{array}$ & $\begin{array}{l}\text { Reduction in travel time to } \\
\text { and within Apulia }\end{array}$ & $\begin{array}{l}\text { Increased flows of tourism in } \\
\text { Apulia }\end{array}$ & $\begin{array}{l}\text { Economic } \\
\text { growth }\end{array}$ \\
\hline Verifiable Indicator(s) & $\begin{array}{l}\text { Euros, time and } \\
\text { policy commitments }\end{array}$ & $\begin{array}{l}\text { Km roadways, timetable } \\
\text { enhancements for rail, bus and air } \\
\text { travel, new operators active }\end{array}$ & $\begin{array}{l}\text { Journey times and increased } \\
\text { efficient travel patterns }\end{array}$ & $\begin{array}{l}\text { Productivity increases in the } \\
\text { tourism and travel sector in } \\
\text { Apulia }\end{array}$ & GDP \\
\hline Source: & $\begin{array}{l}\begin{array}{l}\text { Ministry and } \\
\text { authorities }\end{array} \\
\end{array}$ & Local authorities & Periodic actual measurement & Specific surveys & $\begin{array}{l}\text { Published } \\
\text { reports }\end{array}$ \\
\hline Frequency: & Annual & Annual & Annual & Annual & Annual \\
\hline Benchmark: & & Baseline & & & \\
\hline $\begin{array}{l}\text { 3. Training, skills and } \\
\text { educational improvement }\end{array}$ & $\begin{array}{l}\text { Investment in health } \\
\text { training and } \\
\text { development } \\
\text { facilities }\end{array}$ & $\begin{array}{l}\text { Education of employers on } \\
\text { benefits of training and career } \\
\text { promotion }\end{array}$ & $\begin{array}{l}\text { Provision of time to train for } \\
\text { workers and courses from } \\
\text { new initiatives }\end{array}$ & $\begin{array}{l}\text { Improvements in } \\
\text { productivity, decrease in } \\
\text { skills emigration, increased } \\
\text { wages }\end{array}$ & GDP \\
\hline Verifiable Indicator(s) & $\begin{array}{l}\text { Euros and time } \\
\text { invested }\end{array}$ & $\begin{array}{l}\text { Companies contacted and } \\
\text { involved actively }\end{array}$ & $\begin{array}{l}\text { No. of companies with } \\
\text { Skills development and } \\
\text { training initiatives, links to } \\
\text { public sector course and } \\
\text { facilities provision }\end{array}$ & $\begin{array}{l}\text { Productivity increase: skills } \\
\text { surveys, educational } \\
\text { attainment and career } \\
\text { choice statistics }\end{array}$ & GDP \\
\hline \multicolumn{6}{|l|}{ Source: } \\
\hline Frequency: & Quarterly & Quarterly & Annual & Annual & Annual \\
\hline Benchmark & & & & & \\
\hline
\end{tabular}




\begin{tabular}{|c|c|c|c|c|c|}
\hline $\begin{array}{l}\text { 4. Improvements in Apulia } \\
\text { tourist accommodation }\end{array}$ & $\begin{array}{l}\text { Encourage } \\
\text { diversification and } \\
\text { new investment }\end{array}$ & $\begin{array}{l}\text { Regional accommodation } \\
\text { investment programme }\end{array}$ & $\begin{array}{l}\text { Innovative enterprises, } \\
\text { increased investment and } \\
\text { increased visitor stays }\end{array}$ & $\begin{array}{l}\text { Increased confidence in } \\
\text { private sector operators and } \\
\text { investors }\end{array}$ & GDP \\
\hline Verifiable Indicator(s) & Euros and time & $\begin{array}{l}\text { Number of operators and facilities } \\
\text { participating }\end{array}$ & $\begin{array}{l}\text { New accommodation and } \\
\text { investment, visitors and } \\
\text { length of stay }\end{array}$ & $\begin{array}{l}\text { Improvements in } \\
\text { productivity; increased } \\
\text { market share for Apulia }\end{array}$ & GDP \\
\hline \multicolumn{6}{|l|}{ Source: } \\
\hline Frequency: & Quarterly & Quarterly & Quarterly & Annual & Annual \\
\hline \multicolumn{6}{|l|}{ Benchmark } \\
\hline Verifiable Indicator(s) & Euros and time & $\begin{array}{l}\text { Take up of grant provision, } \\
\text { number. of new facilities }\end{array}$ & $\begin{array}{l}\text { People movement statistics } \\
\text { into and intra Apulia } \\
\text { attractions }\end{array}$ & $\begin{array}{l}\text { Increases in satisfaction and } \\
\text { customer surveys }\end{array}$ & GDP \\
\hline Source: & $\begin{array}{l}\text { Ministry and local } \\
\text { authorities }\end{array}$ & Ministry and local authorities & Transport facilities surveys & Surveys & \\
\hline Frequency: & Quarterly & Quarterly & Quarterly & Annual & Annual \\
\hline Benchmark & & & & & \\
\hline
\end{tabular}




\section{SUMMARY OF ANALYSIS, RECOMMENDATIONS AND SUGGESTED ACTIONS}

\section{Introduction}

Apulia is a large region and although there is a common historic background and cultural identity as part of Southern Italy, it is a quite diverse region, with a dense network of cities and towns and many "micro-regions" endowed with specific features.. The range of regional tourist assets reflects this diversity and richness. This situation makes the design and development of a comprehensive regional policy for tourism development a more challenging task since it does not facilitate the provision of a clear and unique image, especially at international level.

In recent years, the Apulia government has started to design and implement a strategy for tourism with the aim to reinforce and diversify tourism activities in Apulia and to promote the entire region as a tourist destination. Some initial successes have been achieved. However more work need to be done if the objective is to consolidate the current growth and to produce greater results while avoiding the negative consequences of over intensive peak period tourist flows.

In the next paragraphs of this document a summary of strengths, weaknesses, opportunities and threats (SWOT) to tourism development in Apulia is presented, based on the analysis jointly undertaken by the OECD and the regional government. Flowing from the SWOT and the OECD analysis, preliminary recommendations and suggested actions are also provided, which could help to better focus the key policy and operational challenges that the region has to face in order to develop further a successful, sustainable and integrated "regional tourism development strategy".

\section{SWOT Summary}

The table below summarises many of the considerations debated within the implementation of the project. This recognises the breadth and depth of the challenges as well as the various positive aspects of tourism in Apulia and provides a platform for further development.

Table 5. SWOT analysis

\section{STRENGHTS}

- Commitment to further improve regional planning and coordination

- Significant awareness of "Apulia" brand in Italy;

- Facilities, including two international airports;

- Traditional hospitality of local population;

- International quality "beach" tourism;

- Historic town centres and attractions with great cultural, religious, architectural and environmental quality;

- Showpiece "major events" (Night of the Taranta, Itria

\section{WEAKNESSES}

- Lack of performance-oriented development culture at all levels of government.

- Total tourist visits, especially international, very seasonal;

- Short average stays and low average expenditure;

- Dependence on the national Italian market;

- Limited and highly concentrated numbers of foreign tourists from specific countries;

- High concentration of tourists in beach resorts;

- Low levels of gross rates of occupation in hotels;

- Lack of distinctive character and some urban and 
Valley Festival) promote Apulia;

- Film and media use of Apulia locations for dramatic productions;

- Important natural environment and quality local resources, especially food and wine;

- A well-developed tourism website (www.viaggiareinapulia.it) to promote the sector and co-ordination;

- Positive experiences of cooperation between the Region and local administrations;

- Growing awareness of tourism potential locally and appreciation of environmental sustainability;

- Three universities committed to supporting the development of tourism in the region through research and training;

- Access to EU funding sources.

environmental decay in locations;

- Unbalanced awareness of tourism opportunities

- External accessibility and internal mobility (weak regional public transport network);

- Poor links and access between Bari and Brindisi airports and main resorts, especially in the Salento;

- Impact of the tourism industry on the economy underappreciated in comparison to the significant identified potential;

- Lack of co-ordination of events and activities between local areas and Apulia as a whole;

- Inadequate infrastructure for telecommunications and new technologies;

- Small average size and average quality of accommodation facilities;

- Lack of clearly defined international offering;

- Persistent difficulties of hospitality in terms of specific skills, sign-posting for tourists, and management of information about the region;

- Ports and harbour infrastructure facilities limited;

- Insufficient integration of beach tourism with hinterland tourism resources (environment, natural heritage, culture, cuisine).

- Lack of performance-oriented development culture at all levels of government.

\section{OPPORTUNITIES}

\section{THREATS}

- Increasing interest in Apulia;

- Tremendous potential to enhance "tourisms" of Apulia (religious, culinary, cultural, health, sporting, etc);

- Business and event tourism, national and international;

- Growing importance of tourist experiences linked to authenticity of regional resources;

- Potential of regional tourist attractions to be clustered and bring coast and hinterland closer together;

- Ability to marshal efforts to enhance an international brand and competitive market offering;

- Individuals, associations, and bodies working more closely to protect and enhance the cultural heritage;

- Potential to create a destination product able to diversify its offer and attract out-of-season tourism;

- Cooperation with neighbouring regions (in Italy and across the Adriatic sea)

- Some traditional "authentic" local accommodation facilities emerging;

- Thermal spa resort (Santa Cesarea Terme) in a good geographical location to encourage integrated "beach - wellness" tourism;
- Intense international competition for beach tourism and alternative development upgrading in other countries;

- Intense competition of other destinations in south Italy for local tourists;

- Tourist trends indicate likely further reduction in the average length of stays;

- Loss of identity of local place and product brands;

- Congestion of coastal beach resort areas in very short high season;

- Gradual neglect and deterioration of many natural and cultural resources;

- Excessive identification of Apulia with the "beach" and lack of recognizable diverse offering;

- Difficulties in achieving inter-business collaboration to promote regional competitiveness;

- Difficult economic climate in the main reference markets (national and international);

- Lack of initiatives to attract funding for major new developments, especially infrastructure to improve access and mobility; 
- Support from the Region, with EU funds, for improvements to competitiveness of Apulia's tourism businesses;

- Increased activity to attract investments from outside the region;

- Suitable conditions to move Apulia towards the definition of an integrated vision of a tourism region
- Lack of highly skilled, qualified and motivated staff locally;

- Lack of international tourism players;

- Infrastructure inadequacies and lack of quality accommodation choices deter tourism growth; mixed messages on branding and USP of the region rather than specific attractions, destinations or events.

The SWOT analysis has highlighted the range of important influences, risks and issues to be addressed if Apulia has to further develop a comprehensive and competitive tourism offer. This chapter outlines challenges and suggested actions that the region may undertake to strengthen its tourism development strategy.

Tourism has certainly produced satisfactory results in Apulia in recent years, but these highlight the need for continued investment in the sector. This is required both in terms of financial resources, and also in terms of the Regional Government's commitment to define suitable development policies in view of significant potential which has yet to be realized.

From the analysis, a real disparity emerged between Apulia's natural and cultural resources, and the inherent capacity of the region to attract tourists. Apulia seems to have attractions which the region has not been able to fully exploit yet. The combination of nature and culture is a high potential growth factor for international and out-of-season tourism in Apulia; however this needs to be better defined and structured within an overall strategy of re-positioning the traditional (beach) tourism segment and diversifying the range of other segments quoted on tourists' reasons for visiting Apulia.

In fact, the traditional position of Apulia based on medium-quality beach tourism may constitute a limit to further tourism growth in the region because of increased international competition and changing holiday styles. Apulia has struggled to compete successfully with other Mediterranean countries (Greece, Croatia, Montenegro etc.) for beach tourism because it has not yet improved the quality of its services, and the region's specific resources do not always justify the prices tourists find. In addition, the average length of stay is increasingly short and there is a progressive reduction in the incidence of summer holidays on the total of annual holiday periods; this is leading to tourism based on short breaks.

In such a scenario, it is essential for Apulia to improve its beach holiday tourism offer, still vital for tourism in the Region, so that it can compete with emerging destinations where good quality services are found together with good value for money. At the same time however, it is necessary to continue to enhance resources unconnected with beach tourism so that these become new factors of competitiveness for tourism in the region.

This process is under way, but it needs to be better structured, and above all, accompanied by specific policies to improve, for example, standards of accommodation, tourism infrastructures, regional connectivity and human resources in tourism. The following is a list of suggested areas of improvement in terms of priority policy interventions that Apulia will need to address.

\section{Better integrating tourism in the overall development strategy of the region}

The need for a better and more effective definition and implementation of local and regional development strategies has been at the core of political debates and studies for many years. This means designing policies not merely to tackle particular issues individually but rather by considering them as 
a whole, and especially taking into account their potential interaction and the combined or contradictory effects coming from the different initiatives to be implemented. This has led to the development of the concept of integrated local development, that implies developing a comprehensive definition of policy goals, and a clear vision of the outcomes expected from the interaction between them.

This is even more valid for tourism that is a very horizontal domain which encompasses many different policy fields, such as, for example, education, public transport, infrastructure, environment, construction, local services, sport and culture.

As it seems from the regional strategies and programming documents tourism is clearly appearing as a priority in Apulia and it constitutes an important part of Apulia's development strategy. Mentioned as Priority 5 in the national strategic plan (2007), it is explicitly featuring in the main regional documents, and especially under Priority Axis 4 in the ERDF Operational Programme, entitled "Enhancement of natural and cultural resources for attraction and development". Natural and cultural assets are thus clearly considered as the main potential attractors. However with the exception, to a certain extent, of Priority Axis 7, described as "Competitiveness and attractiveness of cities and urban systems", tourism is not clearly mentioned in other priorities, even if attractiveness appears also as a main objective in Priority Axis 3 "Social inclusion and services to enhance the quality of life and the attractiveness of the region".

\section{Considerations for Apulia}

Tourism concerns and objectives should be better represented in other policy domains. This is particularly true with region-wide projects from transport to economic or cultural development; if tourism development is to be a priority, their impact on tourism should be considered and even evaluated. For example:

Transport is a particular policy area that links to tourism development; transport provision not only improves the international access which is crucial for tourism but it also develops internal mobility which is of major importance for improved valorisation of the region and its various tourism assets. It is clear that Apulia can hardly develop specific transport systems for tourists; however it is vital to take account of tourists' needs when the regional transport system is designed and implemented.

Social services and quality of life constitute another domain where tourists' demands should be better considered. The development of a tourism experience does not mean tourists will agree to face much bigger risks and accept a lower quality in services, especially for what concerns health and safety. Indeed, the opposite it is the case for the vast majority.

Other policy fields like energy and water supply are directly concerned with tourist's consumption. Increased pressures on environmental resources have to be managed in some places at a specific time because of tourists' concentration. But tourism can also have a positive impact, with the development of new forms of tourism more sustainable and respectful towards the environment. Even research \& innovation can be considered as a relevant policy field, as boosting the tourism industry implies developing the capacity of creating new and innovative products and services and new managing instruments. 


\section{Suggestions:}

- Include a tourism dimension in all regional thematic strategies and invest more and better in defining an integrated tourism-culture-environment-transport policy.

- More can be also done to promote tourism as a growth sector in all parts of the Region and to integrate the different policies which influence the attractiveness of Apulia, so to develop a more original and more integrated conception of tourism, which encompasses most of the services - if not all - a tourist can experience during a visit or stay in the region.

\section{Raising participation of local citizens and private decision makers in tourism development}

The economic performance of the Italian district system is famous all over the world. In tourist field, districts are facing some difficulties to develop on the basis of their own resources, as most of the businesses concerned are family ones characterised by a limited investment capacity, due to both scarce resource and a limited appetite for risk-taking. Also, they often employ a significant number of non-professional staff members, which are working casually on a yearly or weekly part time basis. In such a context, it is extremely challenging to succeed in mobilizing the human resources towards the development of quality standards and valorising their role in the tourism industry.

This is also due to the common image of tourism as a professional activity often far from being positive among the general public. This image obviously does not reflect the diversity of the jobs on offer. Valorising tourism and its reputation as a field of activity among the general public is therefore of major importance if the objective is to attract talented young people to this industry, which is a precondition for the development and improvement of human resources and services.

Further, valorising the expertise of people working in the tourism milieu is vital. They should be the best specialists of tourist offers and tourists' needs and should be used in the design and implementation of public policies, thus recognising their competence. Involving them in this process also offers the additional advantage of making them the first supporters of the policy developed in that way. Finally, also local residents should have at least a minimum awareness of tourists' specific needs and should be involved in the implementation of tourism policy as "ambassadors" of their region. The issue is to ensure that people will give a positive image of their region (i.e. quality of welcome, etc.).

\section{Considerations for Apulia}

The promotion of tourism in Apulia should not be just directed to foreign or national audiences, but should have a regional dimension in order to mobilise the local forces towards the common goal of tourism development. This objective implies that individuals involved directly in the tourism industry should share a common culture and perspective on tourism development in Apulia.

\section{$>$ Suggestions:}

- Develop effective participative mechanisms. This means that the strategy will gain in efficiency if designed through an effective participative process involving as many players as possible and certainly engaging the tourism milieu (entrepreneurs, trade unions, etc.).

- Encourage promotional policies offering a coordinated image of Apulia, to include collaboration between the Region and specific areas within. Here the role of the Territorial Tourism Systems may become important. In addition, involvement of businesses in promotion and marketing of Apulia should be fostered. 
- Promote tourism among citizens. The promotion of the region should not concern only those individuals working directly in the tourism industry; a much wider mobilisation of the local society would be of major relevance. Interest towards tourism should be developed as much as possible among the general public, for ensuring a quality welcome first but also for encouraging the development of new ideas and new tourism projects.

\section{Better defining and promoting Apulia competitive tourism assets}

Tourism is a sector exposed to very tough competition. The Mediterranean Sea is one of the major tourist destinations in Europe. This is due to the existence of many natural and cultural assets and the importance and variety of the tourism offer. There are obviously different motivations for a tourist deciding to go to the Mediterranean regions; common assets to all Mediterranean regions are to be valorised, but highlighting the specific ones is crucial. Further, no tourist destination is devoid of weaknesses: some just tend to limit the range of incoming tourists, while others are likely to constitute major disadvantages for the specific area. A clear understanding of these weaknesses and a correct evaluation of their potential negative impact are essential in developing an effective development strategy, whatever its intrinsic quality.

In such a context, some regions have established themselves for a long time as major tourist destinations. Other regions have experienced a huge tourist development since the 1980s with, sometimes, unintended negative consequences. A third category of regions is those which have an important unexploited tourism potential, and are implementing strong strategies to valorise it. Apulia may fit in this category. This is a challenge for Apulia. Further, defining the specific assets of Apulia in the Italian context is even more challenging.

\section{Considerations for Apulia}

To date, tourism in Apulia has been mainly based on the traditional seaside activities. It is clear that this type of tourism is heavily concentrated in a short peak season covering two to four summer months in the year. This presents a number of disadvantages including intense pressure on the environment during this peak period, pressure and disruption in the labour market, stress at peak periods then under-use of infrastructure during the remaining major part of the year.

The development of an "all seasons" tourism offering is thus a crucial objective for relieving stress and achieving more balanced and sustainable development in the region. However developing out-of-summer season implies the existence of a range of relevant factors including a variety of attractive activities and/or assets, ease of access to them for tourists, and their active promotion. Weather and climate are important and the tourism offering cannot rely on outdoor activities only. Cultural and "urban" activities are thus playing an important role in this field. Also most out of season tourism will comprise of short stays and urban tourism plays a significant part in this.

The assets identified in Apulia marketing campaigns developed by the region concern: sport, wellbeing \& spa, religion, traditions, nature, food $\&$ wine, art $\&$ history, the coast $\&$ sea. As such, they are all indisputable attractions for tourists and they adequately reflect the riches and diversity of Apulia. However, except for traditions and, to a certain extent, religion, it is not totally clear, for an international audience at least, what assets are specifically distinctive to Apulia. Further, the addition of various assets without any clear hierarchy risks to weaken rather than to reinforce the promotion, as no clear global/coherent image of Apulia is appearing.

In fact, although Apulia cannot count on major outstanding attractions which draw tourists to the region (such as for example Pompei for Campania), it possesses a rich variety of complementary 
resources which can encourage year-round tourism in its territory. Apulia's resources are made up of a widespread heritage which needs to be organised into a system and enjoyed as an integrated network.

The search for a development model based on enhancement of cultural and natural resources for tourism to support the competitiveness of Apulia as a year-round tourist destination demands improvements to the entire hospitality sector, as well as it demands specific integrated policies to tackle a number of weaknesses identified as potential handicaps for further growth of the tourist industry. These include: a) external accessibility and internal mobility; b) capacity of local entrepreneurs; c) the limited attractiveness of the main gateways of Bari and Brindisi. (These issues will be described below and in subsequent sections of this chapter).

\section{Suggestions:}

- Keep improving the quality of destinations in Apulia by investing in forms of slow mobility, tourist signage, information services at entry points (ports, airports) and the main tourist attractions. The general trend of a more responsible attitude towards the environment is starting to have an impact on tourists' choices. A growing number of tourists are looking for new forms of tourism, more "authentic" experiences and with a lower carbon footprint. It is appropriate to develop softer, more sustainable forms of tourism.

- Improve tourism infrastructure. There are at least two main domains in which important progress is required as a priority: accommodation and facilities for business tourism. It is important to invest more in improving tourist facilities and accommodation in the region, supporting the modernisation of existing hotels, the development of new services and the definition of new forms of integration between the beach destination - where the hotels are and the inland places which have the cultural and natural resources. It is particularly important to formulate a rigorous quality policy concerning the non-hotel accommodation $(\mathrm{B} \& \mathrm{~B}$, trulli, agritourism, farmsteads etc.), including seals of quality

- Improve cooperation with the neighbouring regions. Regions are not isolated and there is often greater advantage in linking with neighbouring regions, especially where complementarities will bring mutual advantages and economies of scale.

\section{Improving internal mobility and external accessibility}

External accessibility and internal mobility are probably the main obstacles for the development of international tourism in a given territory.

\section{Considerations for Apulia}

Apulia's location is central in the Mediterranean Sea but rather remote in the national context and even more so when compared to its main international market (North West Europe). The limited number of international direct air connections makes travelling to Apulia longer and less comfortable than to some of its competing regions. The domestic accessibility is highly dependant on air routes and national train connections, as the interregional train system is slow, also compared with other Italian regions.

Apulia is making great efforts to expand the network of destinations served and this is indicative of the importance which the Region gives to the issue of physical accessibility in the development of Apulian tourism. However, a complementary theme to destination accessibility is that of internal mobility. Trains are neither frequent nor fast enough and the network is not developed as it should be 
to serve all tourist attractions. This has not been considered as a priority problem since Apulia has become comfortable hosting mid-level beach tourists who prefer to stay in one place rather than moving around the Region..

However, the new strategy to achieve a position in the cultural and/or naturalistic tourism sectors presupposes the ability to make Apulia accessible to travellers by means of an adequate transport system making all main destinations easily accessible. Existing gaps limit the possibility of discovering the riches of Apulia using public transport, which means that people have no other option than to resort to car hire if they want to have the freedom to move quickly and conveniently throughout the region. This is all the more important as tourist assets are widely dispersed.

\section{Suggestions:}

- Improve regional accessibility and internal mobility. This is a crucial issue and probably the one in which the region's room for manoeuvre is the most limited. However, the improvement of national and regional train and road connections should be at the forefront of the region's efforts. The importance of further developing international air connections has also to be stressed, even if initiatives in this field are already being taken by the regional government.

- Maritime access to Apulia should also be better valorised: two types of accessibility are particularly important, cruise terminals and tourist harbours, which have proved to be a major local development tool in other territories in the Mediterranean basin.

\section{Better defining tourist targets: new products for specific niches}

Tourism has experienced a considerable growth in Europe during recent decades. But this development has been accompanied by an ever-growing trend towards more diversification of practice and products. The first important change concerns the length and time of holidays. The second important change concerns the way people organise their holidays. Another trend, which has been observed in recent years, is the growing mobility of tourists. The rise of business tourism is another important trend in Europe. But what is actually the most important is the general evolution of the public expectations, which is turning the tourist industry from an offer oriented to a demand led activity.

If all tourists have some basic common demands in terms of the quality of welcome and information, access to transport and facilities and use of their language in particular. Their expectations are highly dependant on the types of tourism experience they are looking for and on their specific basic needs as individuals, as a family, with pets, in couples or in larger groups etc. Tourism is also more and more characterised by a growing diversity in age and cultural differences.

In this scenario, it is relatively easy to respond to the long established types of tourism. But tourism professionals and local authorities are often less well equipped with the relevant responses to emerging trends. This is especially the case with Eco- and Ethno- tourism, cultural tourism and urban tourism. On the contrary, business tourists have different expectations and usually require standardised facilities and services.

Thus, if attracting and securing the loyalty of tourists is the actual objective of any effective tourism development strategy, attracting people is normally a matter of effective marketing policy, while enticing them back again is the result of a more complex and diverse alchemy. Some decisive factors can clearly be identified: the first one is obviously the overall quality of tourism products, and 
the second one, directly linked with it, is their adaptation to the demand, which supposes a relevant assessment of this demand and a sufficient quantity and diversity of the offer provision.

\section{Considerations for Apulia}

Apulia is an important tourist destination. However tourism activities appears to be rather traditional, and tourist flows are clearly segmented. The most important tourist grouping in terms of numbers comprises mainly domestic summertime tourists, who are primarily going to the region for the 3 "S": Sun, Sea and Sand. A more limited number of tourists appear to be going to Apulia for its cultural riches. Another smaller but significant flow is made by tourists going to Apulia for religious reasons. However there are apparently few tourists who are going to Apulia for a "variety" of reasons. This has so far limited the development of mixed activities, which could yet be an interesting way of developing tourism on the basis of the existing flows.

Apart from the traditional seaside tourist offer, "authentic life" is with no doubt one of Apulia's main assets: there exist many examples of the survival of traditional events and preservation of customs and life style. This should be enough to satisfy the most exigent tourists. Eco tourism is another niche which could very easily be developed. Some efforts have already been made in this field especially in natural park areas, but there is clearly still a huge potential for this type of tourism.

Apulia also seems to suffer from a limited availability of quality international information. This lack of international recognition and identity is reflected (reason or consequence), in the limited amount and quality of the available information. There are few specific guidebooks in foreign languages. Official and most of tourist web sites are available in only three languages (Italian, English and German).

\section{Suggestions:}

- Target short stay travellers. As the development of out of season tourism is a main challenge, it is clear that the short stay travellers should constitute a priority target. Low cost flight users are probably the most significant part of this market, which can be focused on urban tourist centres such as Bari and to a lesser extent Brindisi whuch are Apulia's international gateways. It is therefore important that these cities can provide what such tourists are looking for. This can be mainly defined a mix of café-restaurant-night life facilities, shopping opportunities and/or cultural events. The two cities should also be considered not only as gateways but also as hubs for the whole region. Accessibility from them to the main regional sites should be made as easy as possible.

- Develop business tourism. Business tourism is one of the most profitable parts of tourism. Business tourists spend more, and are in a way easier to satisfy as they are much more predictable in their needs than other tourists. Business tourism could probably be quite easily further developed in Bari on the basis of the city's existing assets.

- Develop yachting. Yachting has been a booming activity for a few years, the development of which has just slowed down in the recent global financial crisis. Catering for this group presupposes the development of tourist ports infrastructure and related services to a public endowed with a high purchasing power.

- Develop "slow tourism". Italy is the cradle of the increasingly popular "slow food" movement. Apulia could use this trend to develop a slow tourism movement which could encompass the 
authentic life and eco-tourism in a new category including quality of food and accommodation.

- Diversify communication. Trying to develop new forms of tourism supposes a new, more targeted, approach to communication; this can mean developing new communication tools and adapting the existing ones. People interested in new forms of tourism are most of the time not using travel agencies but preparing their travel on their own; they thus tend to expect more detailed and more tailor made information, easily available in their own country. Adapting institutional communication to such a context is clearly quite an important challenge, but some initiatives can easily been taken. For example: increasing the language diversity in web sites; turning the regional tourist web site into the tourist portal of Apulia; publishing articles in the specialised press.

- Encouraging publishing and international diffusion of guides and books about Apulia's riches. Encouraging the edition of guides by foreign publishers in existing well known series should play in important role in the development of international tourism.

\section{Better branding Apulia}

In a highly competitive market for a tourist destination it is necessary to create a recognised brand. This brand should be well established and easy to identify. A tourist destination can turn its tourism image into a successful brand by the following stages: (a) identification; (b) shared internal and external recognition; (c) validation.

Often it is necessary to develop a diversified strategy according to target audiences. In fact, except perhaps for some worldwide known regions, the perception of an area is usually quite different for a national or an international potential tourist (most of tourists usually don't know much about internal cultural differences within a country). In this context, it should not be taken for granted that there is a similar basic knowledge of the regions tourism assets in the mind of both national and foreign citizens; proposing the same marketing strategy towards Italian and international potential tourists could be much less effective than developing a more diversified approach.

\section{Considerations for Apulia}

In the specific case of Apulia Region, the first stage in the process appears to have been completed with the development of the brand name (Apulia), and the logos and slogan ("Apulia for all Seasons"). The current communication campaign, which has been developed by the regional authorities for the promotion of tourism, is based on the clear message that Apulia is a region where tourists can experience a wide range of various emotions. The campaign in its entirety is adequately reflecting Apulia's main tourism assets. However, no clear identity seems to emerge and it is not always clear that specific assets mentioned assets are unique to Apulia. From this information, it is difficult for people who do not already know the region to form a specific image of Apulia.

It is clear that tourists today expect that a communication strategy will tell them a story about their future holidays that goes beyond mentioning the place's identity; however this presupposes that this identity is already clear in their minds. In spite of regional riches, and probably mainly due to their diversity, Apulia seems not to benefiting from a clear image abroad. Some specific features of Apulia are quite famous, but their association with Apulia is not always obvious except for well-informed members of the public. If the objective is developing the region in its entirety as a tourist destination, any marketing campaign insisting on Apulia's diversity and riches (rather than its identity or difference with regions competing on the same market) will hardly be able to deal with this goal in a 
totally effective way. Another aspect, which should be better developed, lies in the need for and ability to propose an "all seasons" offer, which also means this offer can meet with all type of stay duration.

Thus, the Apulia brand seems to exist in terms of a communication tool but it does not seem yet to express consciously its full "relational" nature. It functions to guide all operators (public and private) towards a single value proposition of Apulia as an out-of-season destination and land of hospitality, but it does not seem to have achieved the goal to act as an umbrella for the entire regional tourism system. This would require the conscious adoption of a destination branding strategy shared by all the agents of the Region through a process of collaboration, aimed at creating lasting relations with the internal target, operators and the host community, and also with the external business target (intermediary tourist operators) and tourists. This process would allow the Apulia Brand to actually guide tourists in their choice of destination, communicating the deeper intangible values of the offer and favouring the positioning of Apulia as a "unique and memorable destination".

\section{Suggestions:}

- Define the tourism identity of the region making a distinction between the national and the international audiences; there is a need to highlight the competitive advantages of Apulia compared with other neighbouring tourist destinations.

- Complete the enhancement of the Apulia brand in order to consolidate the positive customer perceptions and develop future customer perceptions of Apulia as a destination able to offer an integrated range of quality experiences for 365 days a year;

- Encourage greater specialisation towards market niches, through a more careful policy. The aim is to enhance the potential of the different forms of "tourisms" which are not yet present in Apulia in significant numbers. Here the tourism offer system may play an important role, mostly through the Product Tourism Systems.

\section{Fostering education and training for the tourism sector}

Skills and training as part of continuous human resource development is absolutely crucial to people based activities such as tourism. This has been recognised around the world. The industry is permanently in need of new competencies and skills to adjust to new tourism trends and to promote innovation and productivity improvements in tourism services in order to remain competitive in international and domestic markets.

Productivity in the tourism industry can be greatly enhanced by appropriate human resource strategies which take into account the development of entrepreneurial and social skills through education and vocational training, the transfer of knowledge from research institutions to practitioners and on the job training within the enterprise and in the destination.

Many countries recognise that their current educational programmes are not sufficiently aligned to industry needs and that the tourism industry is not being involved significantly in developing the fundamental drivers of future skills provision (including curriculum development and in providing routes to obtain structured and meaningful on-the-job practical experience of working in the industry). While a policy framework can be constructed and supply side initiatives promoted, it is essential that the demand side drives development. 


\section{Considerations for Apulia}

In order to attract talented people to develop a career and businesses in tourism, it will be essential to engage young people from an early age and market the opportunities and rewards.

Together with issues concerning recognition of the role that tourism plays in growing regional and local economies, particular concerns have been also raised about the content of the curriculum in formal schooling and in Further Education and Training colleges around tourism, as there is often a disconnect between this training and the Higher Education offerings.

There are a number of examples of best practice that have emerged from this research which, if implemented successfully, could readily provide a solid foundation of core skills, a structured training regime that is valued and has currency within the industry, and continuous human capital up-grading in tourism, travel and leisure services, demanded by a modern tourism and hospitality industry. This is summarised below.

\section{$>$ Suggestions:}

- Foster investments in improving the training of personnel working in the tourism industry. At present, when it comes to human resources, there is very little coordination between the requirements of the industry for skills and know-how and the professional qualifications on offer. This may be addressed in a number of ways: improving communication between public and private players in the region; providing practical, easily accessible training resources; providing SME's with appropriate training support and assistance; developing flexible and relevant training systems; growing a tourism culture that recognises the critical role of HR development in tourism; setting training priorities in support of the destination positioning and branding, following a demand driven approach.

- Develop an 'internal' marketing strategy (particularly aimed at young people) to address the attractiveness of the sector as a place to work so as to encourage a supply of skilled individuals into the hospitality and tourism industry.

- Ensure that there is specific demand for skilled individuals from industry and balance supply and demand of skilled individuals. Having a supply/demand mismatch, with too few or too many people with the right skills available at the right time, will impact on performance, wages and ultimately affect the competitiveness of the sector.

- Assess the potential to develop a regional tourism academy. A network of branded local providers of training, delivering a blend of courses from introductory and craft level all the way up to graduate level and beyond could enhance human capital and the subsequent spin off benefits. After a review and (perhaps) rationalisation of the number and type of qualifications on offer, there might be room to assess the potential to develop a regional tourism academy with the remit to identify, endorse and promote qualifications and learning opportunities delivered to national or regional standards.

- Local delivery and quality standards. Industry should perform a leading role by having a significant stake in the operation but this delivery could take place in local universities, colleges of further education, employer businesses and dedicated hospitality schools. Consistency of quality of training provision and methods utilised could be protected through a 'social franchise' model which would only provide branding and accreditation to a local centre if standards were met and upheld regularly. Industry trust would stem from delivering courses 
that are valued and demanded by industry, and which have a demonstrable impact upon increased productivity and/or license to operate.

\section{Developing an evaluation framework of tourism and local development policy}

In a cultural sense, evaluation is a very powerful and positive method for promoting professionalism and a focus on demonstrably sustainable development. It is not an option or a bureaucratic tick box exercise.

Evaluation is a critical component of policy making in all sectors and at all levels. Evaluation allows informed design and modification of policies and programmes and application of learning increases effectiveness and efficiency. Evaluation provides a basis for the allocation of resources and demonstration of results as part of accountability to key stakeholders. With accurate and reliable information, evaluation provides local authorities, governments, development managers and other interested parties with the means to learn from experience, including the experience of others. It serves the dual function of providing a basis for improving the quality of policy and programming, and a means to verify achievements against intended results. This shows accountability and achievements in a positive way around performance using recognised decision making processes and competency frameworks rather than a negative way that marks success or failure with reward and blame.

\section{Considerations for Apulia}

Limited attention seems to be currently devoted in Apulia to the assessment of the programmes and specific actions foreseen by the implemented policies. This results in a practical difficulty for the policy makers in gaining clear and reliable feedback following the implementation of actions in the region. This is a significant limitation.

\section{Suggestions:}

- Develop an evaluation framework for tourism and local development policy intervention. The Framework should be set around the vision for Apulia and the specific range of objectives set. An evaluation framework for Apulia Strategy for Tourism Development should have a clearly outlined set of indicators to be measured, identified data sources underlying these, and specific targets, rationale and baseline for each of the agreed development objectives. In addition, it will be appropriate to provide guidance for the investment impact assessment of existing and emerging activities, attractions and experiences, including suggestions of appropriate sources of evidence. This will take time and careful consideration involving partners from the private and public sectors.

\section{Concluding remarks}

This project on "Sustainable tourism and local development in Apulia region" aims to assist the Regional Ministry for Tourism of Apulia and its regional and sub-regional partners in reviewing policies and assets of the Region, so to:

- implement more effective sustainable tourism development strategies based on the valorisation of cultural, historical and natural regional assets with the aim to increase Apulia destination's competitiveness and facilitate the "seasonal adjustment" of the local tourism industry;

- strengthen the value of Apulia destination's sites proposition through the quality and the variety of tourism facilities; 
- foster skills and capacities at local level to develop sustainable tourism and local development in an integrated way.

The review has presented the assessment of these factors and identified a range of policy and operational initiatives to assist in overcoming barriers to valorisation and development as well as making the most of the assets and attractions in the region. It is clear that many positive steps have been taken and others are planned by way of bringing a more cohesive approach to tourism development in the region although much remains to be done on significant factors that will affect the long term success and sustainability of development across the region. This is especially the case for international success and the competitive attraction of new additional revenue from markets outside Italy as well as more high spending visitors.

The 365 day year round offering to the market will require co-ordination and commitment of resources (physical, personnel and intangible) in a planned manner to ensure that the basis for maximising the economic impact of tourism development is established and that the principles of sustainable development are embedded in every initiative. In this way, the quality of the offering will be maintained and the momentum established for self sustaining growth in the future.

A number of specific initiatives are possible in key areas such as marketing and branding, skills and education, infrastructure development, business and enterprise growth, inward investment and cluster development to link tourism with local communities and other development initiatives. A comprehensive and integrated approach also requires careful management and monitoring to allow for real time adjustment. Markets change and shocks can divert the best of strategic plans so it is vital to set out a clear monitoring and evaluation framework to capture progress and alert partners to the need for swift adjustment.

The range of partners in Apulia are more than sufficient to realise the potential of the region and to link localities into a regional market offering built around strengths and characteristics that will appeal to a wide range of tourists. The diversity of the regional assets, such as the natural environment and geography, and potential to exploit events and attractions means that a portfolio of themes can be developed within the regional approach. This can cover the competitive strengthening of existing tourism foci (such as beach resort holidays, film location marketing, festivals and events and historic buildings and places) and also extend to new under developed elements appealing to national and international visitors, (such as cultural, historical, religious, culinary, sporting and business conference and events tourism).

The next steps will involve all partners working together to gravitate efforts around the findings of this review and the enhanced strategy for tourism development in the region. Tourism does not exist in isolation and there are integral links with other policy agendas, including education, transport and business development. This linkage will be essential in developing the region in a practical way and in levering additional resources from national and EU funds as well as attracting private inward investment. 



\title{
ANNEX 1. INTERNATIONAL EXAMPLES
}

\begin{abstract}
Australia
Australia is a large country with many natural attractions and a climate that suits tourism development. The country has developed into a modern, sophisticated economy that attracts migrants and offers a high quality of life for residents and visitors. Many of the major cities and settlements on the coast are natural and vibrant tourist locations.
\end{abstract}

However the country covers a vast area is sparsely populated and the location in the southern hemisphere presents challenges in attracting tourists from the main markets in Asia, Europe and America. The regions, cities and national authorities have addressed the tourism development issues positively with active involvement of stakeholders and citizens at all levels. Tourism has been recognized as an important contributor to the economy and sustainable development of regional areas in Australia. Recent studies have shown the scale of the contribution of tourism with figures from December 2008, when 52\% of expenditure by domestic overnight visitors ( $\$ 23.2$ bn), 58\% of domestic day visitors $(\$ 8.2 \mathrm{bn})$ and $20 \%$ of international visitor expenditure ( $\$ 26.4 \mathrm{bn})$ went to regional areas of Australia.

The industry is seen as vital, providing a way to diversify regional economies and generate additional employment and income. The sector has also been recognised as an essential part of any case for wider development initiatives and improvement of investment in new infrastructure and facilities.

A team of researchers funded by the Sustainable Tourism Cooperative Research Centre (STCRC) of Australia produced a detailed evaluation in 2010 which identifies best practice principles and strategies for the sustainable planning, management, development and marketing of regional tourism destinations. This work produced examples of how to deliver best practices from different regions of Australia, locations varying in size, context and opportunity.

The report ("Sustainable Regional Tourism Destinations - Best Practice for Management, Development and Marketing, CRC Sustainable Tourism 2010) confirmed findings from elsewhere that best practice requires the following:

- regional destinations must have strong support from the national or territory governments;

- it is essential to nurture strong and cohesive regional and/or local tourism organisations;

- local governments, and local leaders must show leadership to foster and implement a shared vision for sustainable tourism across government;

- businesses and community stakeholders are drivers of innovation, competition and pressure to implement sustainable tourism best practice; 
- planning and implementing best practice for sustainable regional tourism destinations can contribute to regional economic development, conservation of natural, built and socio-cultural environments, community well-being, and exceptional visitor experiences.

The study findings presented best practice principles for sustainable destinations and detailed examples of where illustrative practices could be found across three categories of:

- $\quad$ planning and management (11 principles);

- development (4 principles) and;

- $\quad$ marketing (7 principles).

These three categories formed the basis of the research framework shown below.

Figure 1. Sustainable Regional Tourism Destination MAnagment Framework

\section{Sustainable Regional Tourism Destination Management Framework}

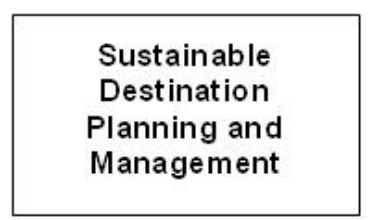

The pursuit of strategies and practices that facilitate balanced, sustainable administration and management of the destination



The pursuit of a type, style and level of tourism that contributes to the social, cultural, political and environmental sustainability of a place to live, to work and to visit



The promotion of tourism both within and outside a destination to attract and influence appropriate visitors

Source: Sustainable Regional Tourism Destinations - Best Practice for Management, Development and Marketing, CRC Sustainable Tourism 2010

The report is instructive as it identifies best practices and examples from across Australia against each of the principles identified within the three categories. 
For example, under destination Planning and Management, 11 principles were identified and for the first principle "to establish long-term strategic planning processes best practice regional destinations" the following best practices were identified:

- seek the support of local community champions or visionary leaders that have: technical, communication and facilitation skills, are well respected by the community, and that can effectively tap into local networks to lead the strategic planning process;

- engage experienced tourism consultants if tourism planning expertise is lacking at a destination level;

- seek the support of governments (local and state), industry (LTO, RTO, Business groups) and community stakeholder organisations;

- establish effective consultation processes to engage and consult with interested government, business, community and indigenous stakeholders across local, regional, state and national levels;

- engage the community in all stages of the planning process to ensure community ownership of the Plan;

- establish and communicate a shared vision for tourism amongst all stakeholders;

- undertake and utilise research to inform decision-making;

- undertake an assessment of the current and future market situation e.g. audits of existing tourist facilities, identification of tourists' preferences and behaviours, identification of competitor destinations and consideration of broader issues-changing environmental conditions and resources, airline capacity, visitor markets, sustainability, prediction of future trends;

- specify realistic time frames - short-term (1-3 years, medium-term 3-5 years and longer-term $5-10$ years);

- identify priority actions and identify implementation strategies (e.g. local government employment of a Tourism Officer, formation of a Reference Group);

- integrate with local and state government plans and policies, for example natural resource management, town and land use, social and cultural, economic development, infrastructure and risk management plans;

- establish a regular review framework (e.g. annually) to identify areas where strategies and actions need to change due to differing conditions; and

- facilitate learning amongst stakeholders about sustainable tourism.

This approach using the structure of a clear framework, principles and practices was followed and detailed real examples from within the regions of Australia and could be adapted for use by other countries and specific regions such as Apulia. 
Some regional examples from Australia offer particular learning for Apulia as there are some similarities in the bases for development and potential tourism clusters around themes such as food and drink, environment, culture and health. For example, the wine industry has emerged as a major economic sector for Australia and wine regions have enjoyed popularity as tourism attractions, especially with high spending overseas visitors. Barossa Valley is one such area which has developed with strong collaboration between the wine industry, tourism operators and local and regional councils. The Barossa Valley has become the largest wine processing region in Australia with an international reputation.

As noted in the Sustainable Tourism report, a strong integrated regional tourism structure has been developed successfully with regional winemakers, tourism operators, local government and other key players coming together to form the Barossa Wine and Tourism Association Inc. The association formed the industry body responsible for development, marketing and branding the Barossa Valley as Australia's premium wine tourism destination. A structure for the association from the report is shown below.

The wine and tourism interests have come together and accepted mutually reinforcing roles that have been successful for sustainable development. Tourism Barossa is responsible for marketing and positioning the Barossa as a premium tourism destination in national and international markets. Wine Barossa is funded by members (winemakers and grape growers who saw the benefits from collaboration and became the drivers of change) and provides representation on issues of environmental sustainability, viticulture research and development, and marketing and promotion of the Barossa Wine Brand. In total, over 300 members support marketing activities under the umbrella of Barossa Wine and Tourism and the partnerships have expanded to include formal agreements and funding contracts with local government and the food growing sector. This has led to greater coordination of wider investments and marketing in the area not just tourism or wine related.

Figure 2. Barossa Wine and Tourism: organisational structure

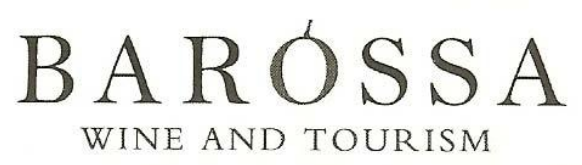

Organisational Structure

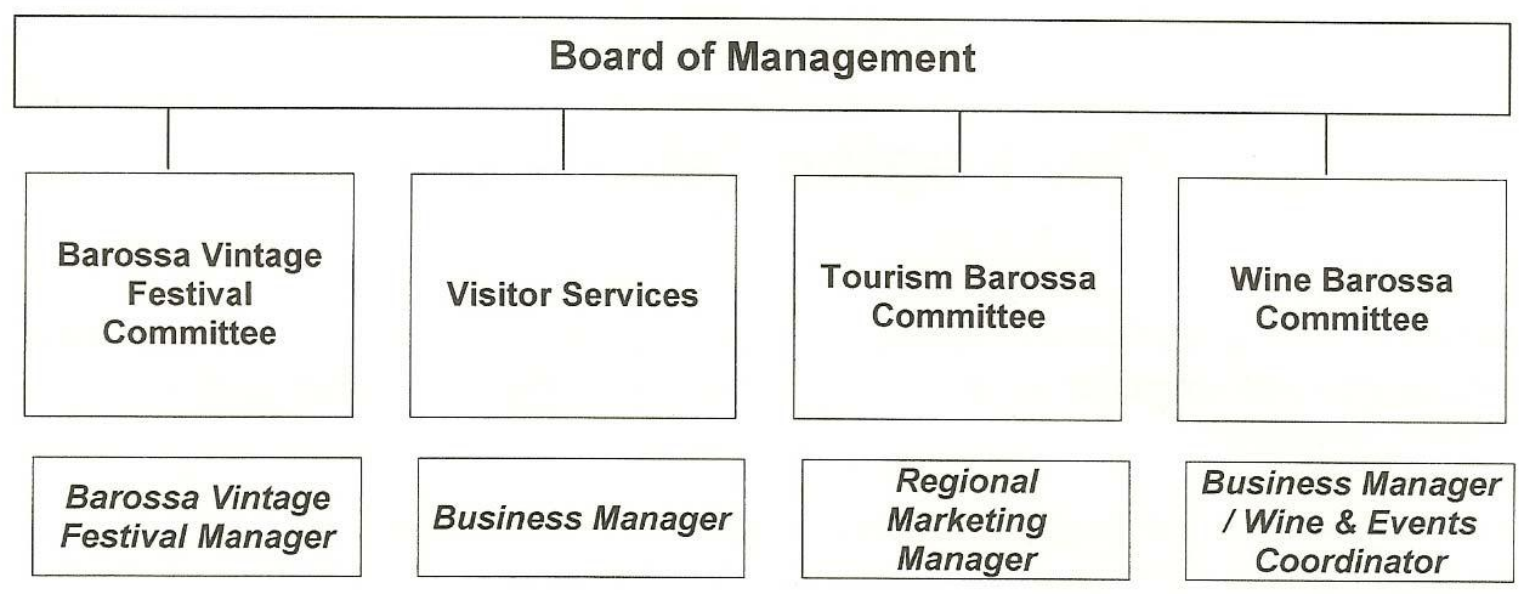


The dominant position has developed around the intrinsic strengths of the area, namely the infrastructure, the quality of produce, the range of festivals and events in the region, heritage and historic buildings, and the natural attractions of the region. Local festival of wine attracts over 50,000 visitors every two years and the area has also shown how to extend the attraction from wine into wider traditions of food with the increasing prominence of regional produce and the launch of Barossa Slow as the first slow food movement in Australia. Food and drink tourism trails have also been developed with complementary, quirky accommodation and local retail developments. This is a movement that is well known in Europe and Italy which Apulia could develop further alongside international food and drink branded identities.

Such developments and international recognition of the tourism product must be driven by a sense of belief, commitment and strong marketing from local investors and personalities over an extended period of time. It is also essential to develop a sustainable offering. Another region of Australia, Noosa, created such a plan and is pursuing this around a series of clusters to reduce dependency on any single offering such as beach tourism. The region is also seeking to spread the peak period for visiting and extend the season to attract year round visitors. An events programme has been designed to encourage this spread of visitors and the four clusters cover adventure, cuisine, culture and nature. All information is available and spread on the web through positive campaigns and promotion. Quality standards and awards schemes (for facilities and personnel training) also highlight the rising standards and on-going developments in the region with active participation from industry and stakeholders.

Branding and marketing of regions has become essential to for specific destinations within regions to position their products and experiences to their target markets. Advertising, promotional events, trade shows, internet and editorial placements are all part and parcel of the successful approach. Regional players coming together through a marketing group can accelerate and embed this process. Noosa Region did this and monitored marketing progress through surveys and benchmarking from a variety of sources.

\section{EU INTERREG IIIC Programme (case studies)}

In the early part of this century the EU funded European Cultural Tourism Network compiled a series of case studies on different aspects of regional tourism development. A number of these offer potential pointers for Apulia and practical learning on issues of implementation around key assets and traditional strengths of a region. A number of case studies from different regions and countries are presented in summary below.

\section{Republic of Ireland, County Laois Region}

This region of Ireland has a rich heritage and built environment with a number of museums. In the early years of this century, the museums were in varying stages of development and covering a range of cultural and social topics. These included the Irish Fly Fishing and Game Shooting Museum, Workhouse Museum, Steam Museum, Work Museum, Heritage House, People's Museum, Arts Collection and Poet's Cottage.

As part of the development strategy for the region, it was recognized that a new integrated approach was necessary to make the most of these built assets and the historical interest that would attract more tourists to individual facilities and to the region. In order to achieve this, a project was created which employed a facilitator to act as a museums expert and assist the museums in Laois both individually and collectively. The principle objective was to develop sustainable management 
strategies for each museum, to advise on medium and long-term sustainability and to provide specific advice and guidance.

The sustainability of each museum attraction was considered in terms of a review covering practical performance issues including effectiveness of exhibitions (programming of permanent and temporary exhibitions), audience numbers attracted, staffing resources employed, services provided and finance requirements to deliver. A range of other issues were also addressed, including the business strategy of each attraction, visitor services, identification of training capacity and needs, collection policy, advice on individual technical issues such as cataloguing, care and use of collections, child and family-friendly policies and marketing.

As part of this project, the Laois Museums Network was created, to provide support, training and advice for Laois Museums, to help them to work cooperatively for the long-term benefit of the whole sector in Laois. The tangible outputs from the work included:

- Interim Report

- Final Report on overall museums sector in Laois.

- Individual reports with sustainability plans and detailed recommendations for each museum

- Structure and preliminary Terms of Reference for Laois Museums Network

- Presentation at "Celebrating Laois Heritage" Conference.

This shows how a practical set of recommendations for improved performance and sustainable tourism attractions can be devised for a region.

\section{Hungary, Eger Municipality}

It was decided that in 2010, a Hungarian and a German town would be the European Capitals of Culture. In Hungary 11 towns applied in the first stage of the process and the city of Eger was one of the 7 candidate-towns, who made it into the second round of the process. As part of the preparation for the bid to become host city for Hungary, a Development Plan was prepared for Tourism Development in Eger City for the European Capital of Culture in 2010. This was an output from the EU project.

Eger is the tourism centre of the North Hungary region. Main tourism assets are cultural heritage (castle and Baroque city centre), wine, thermal bath, cultural events and the surrounding of the town. However many of the attractions were sub elements of the city which was renowned and perceived as a health spa and wine centre. More was required to raise the profile and perception of the city and surrounding environment. The different elements were assessed to identify various strengths to attract more visitors and develop a sustainable proposition for the European Capital of Culture and future years beyond the event in 2010 .

The city is relatively small with approximately 60,000 inhabitants but attracts over 1 million visitors a year as the third most popular destination in Hungary. The city-centre has a range of cultural monuments mostly with baroque buildings, palaces and churches. This Baroque city-centre with the fortress/castle is very important for the tourism of the city which has developed a sustainable plan for the range of attractions including:

- The Historical Town 
- The Cathedral of Eger

- Kepes Visual Centre

- The Dobó Square

- The City of Wines

- The Spa

- The City of Festival

- The Conference Centre

- The Centre of Knowledge

- Holy Trinity Church

- The Minaret

- Wellness centre and hotel

- The former Tobacco Fabric

- Adrenalin Park

Spain; Huelva County, Andalucía

The Local Development Area, County Council of Huelva, near Seville in Andalucía, south east Spain started a series of cultural and tourist initiatives in collaboration with the district councils, hotels, restaurants and other local tourism and community actors. The aim was to develop a tourism product around natural assets and attractions, such as a Castle Route, to reinvigorate rural areas through the promotion of the historical and cultural heritage.

\section{Castles Route}

The Castles Route was not only a tourism initiative but also a wider means to take special actions for the sustainable regeneration of localities in the region. It was a way to promote the real recovery and restoration of the ancient monuments and medieval heritage for tourist uses. The aim was to attract and satisfy a new type of tourist to the region through a more sophisticated and historically interesting series of attractions including:

- Castle visits

- Rural and urban environment

- Natural resources

- Historic and monumental heritage 
Ten local council authorities were involved in setting up the project which was highly participative in order to reach a consensus and shared vision for the sustainable tourism offering. A wide range of local enterprise players were also engaged early in the process to develop the regional partnership approach. The group identified the following steps to be taken:

- Conduct a feasibility study and produce a plan for the Castles Route

- Assess the extent of local agent involvement and areas where gaps exist

- Identify strategic themes and priorities

- Prepare a detailed action plan for the project identifying roles and responsibilities

A key output from this process was agreement on the need for the project to generate positive economic impacts on the areas involved, often fragile local economies needing to attract additional income to support wages and services. Thus the tourism offering was to be clear in market terms and a distinctive "product" offering compared to other areas or regions with historical attractions and a network of castles. The Huelva route was to be promoted as a castles trail with detailed information on the route to entice visits to all local areas and thus induce greater economic benefits locally.

Partnership working continued and regular meetings proposed to share information on progress, set standards for the quality of products and discuss new development proposals as well as celebrate successes. It was recognized that high quality offerings were essential for long term competitiveness and sustainability of the tourism industry in the region. A partnership committee was formed to guide this process and control enlargement of the network as other local authorities showed interest in joining the Castles Route. Strong and coordinated marketing plans were part of the overall approach

\section{Medieval Journeys of Cortegana}

This initiative originated in 1995 in order to create a different programme of tourist activities that would link to new projects including the Castles Route to rejuvenate summer tourism in the area. Medieval Days had become one of the most important events in the calendar giving a major boost to the host village and it was agreed to extend and connect the offerings. This acquired a reputation for the special characteristics of the medieval days which are:

- celebration in the middle of the village

- local inhabitants take part in the activities

- the use of ancient coinage as currency on the day (use the euromaravedi was a symbol of joining between the past and the European future)

- the meeting with other cultures which participate in the activities

Some of the activities that take place include:

- Handcrafts Market - artisans from all across Spain come to the Journeys and they sell souvenirs from the medieval ages as wood and leather cooking utensils, pottery, silverware, shoes, blankets, instruments, dry flowers, and street theatre that liven up the market. 
- Tournament - in the Middle Ages the main event was the Tournament or Trial by Ordeal. The Journeys celebrate it's own tournament of horsemanship and battle re-enactment with local teams supporting favoured colours

- Crowd events - includes street theatre, concerts, plays, juggling and demonstrations

- Medieval history forum -presentation of information and study material of the middle ages and the lives of ordinary people

- Medieval meals and banquets - traditional period food and drink as well as set events where participants enjoy a meal of the time wearing medieval clothes and enjoying entertainment from the period.

\section{The Interpretation Centre for Iberian Pork}

This Museum of Ham was created as an interpretation centre. It shows, in an educational way, information about the rearing of the Iberian pork and the production processes, illustrating the strong links between the local peoples, traditions and the environment. This is presented in a modern way through:

1. Graphic panels, DVD and film

2. Sculpture and artist's materials exposition

3. A trail through local Aracena mountain settlements, the heritage and traditions

4. The rich environment of the Natural Park of Aracena and grasslands for farming

5. The Iberian pork rearing, feeding and preparation, selection and slaughter, production

6. The quality processes and stamp of guarantee: "Jamon de Huelva"

7. A gastronomic exhibition and presentation of typical pork dishes and traditional recipes

8. Retail space for selling products and souvenirs

9. A rural authentic restaurant.

\section{$\underline{\text { Mycology Tourism }}$}

This initiative was carried out by the Regional Government and the town councils of Aracena, Jimena and Siles, in Andalucía with Information Points under the programme "Mycology Tourism". The Information Point of Mycology in Aracena is in the Ham Museum. This Point specialised in Mushrooms and Gastronomy due to the high predominance of traditional cuisine in the region.

Each Information Point across the Region had different emphasis reflecting:

1. Conservation Plan and Sustainable Use of Mushrooms and Truffles in Andalucía

2. The range of different kinds of Mushrooms that reflect the ecology and way of life in specific localities 
3. Economics and value add from Mushrooms

4. Environmental interests and conservation

5. Mycological biodiversity

6. Poisonous Mushrooms

\section{Mining Park of Riotinto}

The Thematic Park is sited at the Natural Park of Sierra de Aracena and Picos de Aroche. It covers a massive area of over $900 \mathrm{Ha}$ and it is the first park in Spain including such features with the main emphasis on tourism and culture. It features the most ancient mines in the world which remain functioning, in working order. The visitors were able to go back five centuries in the mining history and to look at a live working mine.

The area has a spectacular landscape of great natural beauty with a variety of wild plants and flowers, the tubular shapes, the ochre, violet, orange and red colours, These features could be experienced during the journey across the park landscape over a distance of $8 \mathrm{~km}$. This journey could also be done in another tourism attraction as a passenger on in a genuine mining wagon pulled by a steam engine that was made in the early years of the $20^{\text {th }}$ century. This train was restored and fitted out to a high standard, running parallel to the Tinto River which is a famous for its sophisticated ecosystem. The route was constructed in 1873 by the English company Rio Tinto Limited, now a part of the global multinational company RTZ. Rio Tinto developed and exploited the mines during the $20^{\text {th }}$ century before their closure in 1984 .

The Mining Museum was the first museum within the Iberian Peninsula devoted to Mining and Metallurgy. It was designed and developed to fit in the authentic setting of Bellavista where an English Neighbourhood and hospital was located. The museum is set within this larger settlement which covers an area of 1,600 square metres. The museum houses a vast array of artifacts from the period of production and shows what life was like in that mining region. The historical context for the English settlement covers life between late $19^{\text {th }}$ and early $20^{\text {th }}$ century when a sizeable English population worked in the mine. The architecture is traditional Victorian housing with stone walls, front and back surrounded the area which also had a Presbyterian Church, workers Social Club and the Council House (residence of the former General Manager). A notable feature dating from 1907 is Atalaya Open Pit which was the largest producer of iron pyrite in Europe. It was intended that visitors would be able to tour through the different cores of mineral extraction and treatment.

\section{International Film Festival of Islantilla}

This is a cultural initiative developed by partner organisations and business sponsors over a number of years. The Festival was created to gather resources in a forum to promote Islantilla as an international meeting point for small scale film productions. This was also seen as a way to promote the region and its attraction through the profile of film and an international film festival aimed at niche producers.

The organizers created a series of awards and categories to recognize achievements in the world of small scale film production. This included The Honour Chameleon which recognizes the contribution of different Spanish actresses and the Andalussian Film of the year. In addition special themed awards were developed around categories such as In Memorial (Orson Welles and others); 
World Culture (examining Islamic film for example); Special Projections (showcasing novel film projects). A series of complementary activities was also developed during the festival including:

- Round table Conferences

- 'Islantilla present: New cinema projects

- Films for Everyone. Special Projection for immigrant groups from around the world including the Magreb

- Film and cuisine, including sponsored tastings of typical local products (cured ham, wines, shellfish and other local delicacies and specialties of the area)

- Multiethnic night: film, cultural entertainment and food tasting of specialties from Magreb, Africa, the Middle East and Eastern Europe.

- Film and tourist guided visits to locations in the region

- Social inclusion activities involving different groups and ages including universities, women's associations, schools and different cultural organisations all participate regularly in the Festival.

- Exposition: La Tierra Herida, Carteles de Cine y Despierta, Cine Sin Barreras.

- Launching new promotional videos: Huelva, La Luz, del Patronato Provincial de Turismo de Huelva.

- Presentations and World Premiere of the short films, such as the first Spanish production done by disabled people.

The festival takes place each April and was initiated in 2000.

\section{Wales, United Kingdom}

The Wales Tourist Board, Welsh Food Directorate, Welsh food producers, tourism and hospitality businesses all came together to create an initiative called Food for Thought. This formed part of a wider regional Sense of Place initiative and toolkit developed to support cultural tourism development in Wales, a small country within the United Kingdom with a population of 2.3 million.

The Sense of Place initiative recognised that visitors are constantly seeking a distinctive and different experience. The importance of having a real "sense of place" embraces the distinctive sights, sounds and experiences that are rooted in a region or small country such as Wales. It was recognized that the special and memorable qualities and experiences in a region have benefits and appeal to local people as well as visitors. In order to build sustainable tourism in the region and reinforce the sense of place, the partners came together to encourage tourism businesses to introduce this concept in their business premises and to develop the theme to reinforce the character and appeal of individual towns and villages.

The Sense of Place Toolkit was designed to assist businesses in this process. It was aimed at providing practical steps for businesses to: 
- define their specific sense of place;

- build sense of place into their business by working with other organisations, and

- encourage visitors to participate in local community activities.

The toolkit comprised 9 self help leaflets which were written to assist individual businesses in creating their own distinctive offering as part of a wider sense of place initiative led by the Wales Tourist Board. Information was provided to businesses on:

- Getting started,

- Wales and its people,

- Working with the welsh language,

- Working with buildings (inside and out),

- Food \& Drink,

- Using creativity and the arts,

- The great outdoors.

A specialist business advisor was appointed to assist businesses in developing their own distinctive sense of place. This was also supported by regional cultural tourism events, workshops and seminars bringing together the cultural and tourism sectors to exchange information on best practice and identify mutually beneficial opportunities.

A specific 'Food for Thought' toolkit was developed as an additional module to support sense of place. This toolkit recognised the key role of food and drink as part of the visitor experience at a destination. The Food for Thought toolkit provides practical guidance on:

- Sourcing local foods combined with innovative menu suggestions and style of food presentations for a wide range of businesses.

- A guide to regional food and drink in North, Mid, South East and South West Wales.

- Important elements of good customer service.

- The skills required for excellent food service across different styles of business.

- How to deal with customer complaints.

- Creating ambience, atmosphere and Sense of Place. Factors to consider when looking at design and layout of premises.

- Where to go for further help, support and information.

Thousands of the toolkits have been distributed to businesses and partner organisations across Wales in recent years. 


\section{New Zealand}

The Creative Tourism New Zealand (CTNZ) initiative was piloted in 2004 and developed in phases with the aim to generate a more sustainable form of tourism that provides an authentic feel for a local culture through informal, hands-on workshops and creative experiences. The format was very intimate with workshops taking place in small groups at tutors' homes and places of work to allow visitors to explore their creativity while getting closer to indigenous people and their way of life.

The pilot phase back in 2004 involved:

- Management through an existing arts marketing trust.

- Programme of 29 workshops taught by 23 tutors took place in and around Nelson region on the South Island.

- Workshop bookings through a network of local tutors.

- Target marketing to baby boomers and backpackers.

- Subsistence grant and income support for participant organisations and tutors from sponsors tutor subscriptions, accommodation recommendations etc.

- Promotion through a bespoke website development and printed materials.

The next phase saw the creation of a new start business with supporting organisation and a fulltime Chief Executive to manage the further series of 15 workshops. This saw the CTNZ develop as a real organisation taking bookings and engaging in organised marketing such as 'The Interactive Traveler'. From this, the organisation developed further and re-defined its role:

- Find suitable tutors and encourage them to join.

- Help tutors set up and develop their workshops successfully.

- Promote workshops to overseas visitors and New Zealanders.

- Stimulate interest in Creative Tourism.

A network of 40 tutors was created with the target market being artisans, creative individuals, and small companies with niche products.

The EU report identified several lessons for Europe in terms of Creative Tourism's potential benefits which are:

- To showcase the creativity of any community.

- To add a distinctive, enjoyable tourist product.

- To provide a new income source for tutors.

- To do all this at relatively low cost. 
However the report also cautioned that the extent of demand for Creative Tourism is not yet clear so an advance investment approach is required and results in terms of impacts will take time to emerge. It was also emphasized that it is vital to have strong leadership and organizational commitment to such initiatives.

\section{European Network of Regional Culinary Heritage}

Many regions have recognized the value of local cuisine and natural produce as fundamental elements of regional competitiveness and as part of tourism clusters. Some regions do this individually; others do it as part of national strategies. In addition there are international networks with horizontal and or vertical linkages that bring members together.

There is a European Network with member regions all across Europe with the common goal to develop the member regions through the promotion of local and regional food. The network encourages increased production and use of regional food as a way to develop small scale business life and tourism in all the member regions. This can be effective in realizing the value of natural assets and talents in diverse regions.

The European Network of Regional Culinary Heritage (the network) has a website that lists restaurants, producers, farm shops and many other services and facilities in each region. Membership of the network promotes regions and their produce as an intrinsic part of their tourism offering. The local specialisms are promoted internationally to emphasize the origins of products from the regions and sell the regional characteristics.

Membership of the network has been open to regions throughout Europe that want to be or are already in the process of promoting regional foods and produce and culinary skills. The network seeks to add value to each region through a joint European Network for promoting regional foods. The network has a coordinator for membership, activities and training and typical member applicants are regional or local authorities.

The website highlights that member regions came together to share the following benefits:

- Membership of the European Culinary Heritage network.

- Participation in joint European activities.

- A licence to use the logo.

- The right to issue licences to businesses within the region.

- Published details on the official Culinary Heritage website which promotes both the region and each individual business member.

The European network is based on a common framework, which includes:

- Criteria and directions for participating regions.

- Criteria and directions for participating businesses.

- Directions for how to use the common logotype. 
The range of regions that have membership covered less well known regions of major tourist countries such as Galacia in Spain as well as Rivne in Ukraine. Such a network could be of major interest and value to Apulia in future.

\section{Balkans, South East Europe Cultural and Natural Heritage Routes}

In 2007 the Council for Europe devised a proposal to prepare the "Regional Programme for Cultural and Natural Heritage in South East Europe". This emerged from a desire to strengthen traditional links between regions in the area and assist them to create sustainable tourism and development plans that would benefit the stability and wealth of regions in several countries over the long term. Beneficiary countries were Albania, Bosnia and Herzegovina, Bulgaria, Croatia, Montenegro, Romania, Serbia, Macedonia and Kosovo.

Tourism routes and exchange were recognized as a means of promoting intercultural dialogue and mutual knowledge of the cultures and history of the South East European peoples. The Council set out to produce guidelines for defining and implementing projects that would revive the historic lifelines of South-East Europe constituting the lines of interaction between cultures spanning different territories, landscapes, settlements and traditions. The need for a "Detailed Action Plan" was based on the rationale that the apparent deterioration of the "cultural environment" must be addressed if sustainable development is to be achieved. This would act to counter destructive forces working against self expression of regional differences and cultural complexities.

Modern development processes were seen as having accelerated the deterioration of the social and physical environment, reducing the quality of living and social conditions of a growing number of people as well as making the development of sustainable tourism very difficult. The conflux of economic, environmental and identity problems, was seen as constituting "new poverties" constraining a growing proportion of people in Europe.

Sustainable regional tourism, seen as a process of renewal through creative contemporary development, can be a way of restoring pride and economic health to a region as well as connecting people to the past and present local customs and practices, allowing it to reassert its identify as well as retain population and income levels. Thus integrated tourism development initiatives demonstrate in real terms how dynamic, practical links can be made between cultural values and ideas turned to economic advantage for regions.

The Council paper of 2007 proposed a new integrated project to define an operational framework with parameters that identify existing nodes of development, projects, initiatives and personalities, and inspire them, together with the means for gathering information and resources, to develop a combined strategy. It constitutes a framework into which a common vision can be elaborated that can mobilise different strengths and stakeholders. The networking of many local communities that are responsible for their own development processes and capable of undertaking sustained efforts was identified as one outcome of the project.

The pilot project proposed to create a tool for intervention and development of territories which could be promoted by national, regional and local authorities. It is based on principles of sustainability and democratic improvement of the quality of life for citizens. Several stages were proposed which could form a basis for the next stage of development in Apulia:

- concept definition of regional, flows and routes;

- test, consult with stakeholders and gather data; 
- mapping resources, assets and territories;

- networking between organisations, priorities and pilots;

- conclusions and next steps on methods and resources;

- timetable for actions.

\section{European Commission}

These proposals for moving forward would accord with recent EU papers and proposals on tourism including Communication from the Commission to the European Parliament, the Council, the European Economic and Social Committee and the Committee of the Regions: Europe, the world's No 1 tourist destination - a new political framework for tourism in Europe.

This paper sets out a series of proposals for improving tourism and a list of actions to tackle challenges such as globalization of markets and seasonality of regional offerings. On initiative in support of this is CALYPSO, a preparatory action adopted by the European Parliament in 2008 for a three-year period with the objective of promoting partnerships between the public and private sectors an $\mathrm{d}$ the social economy, driven by the European Commission, with the main aim being out-of-season exchanges of tourists in four target groups (young and elderly people, people with reduced mobility and low-income families) under Calypso, at least between two Member States and/or candidate countries. An additional proposed action is to provide a voluntary tourism exchange mechanism between Member States enabling in particular certain key groups such as young or elderly people, people with reduced mobility and low-income families to travel, particularly during the low season.

The EU will continue to support economic diversification into tourism represents a priority for many areas, coastal and rural, where the decline in economic activities linked to agriculture, fisheries and shipbuilding in particular have led to a fall in incomes and increased unemployment threatening the sustainability of communities and the competitiveness of regions. Various support mechanisms are available including for the establishment of businesses active within rural tourism, the development and promotion of agri-tourism and capitalisation on the cultural and natural heritage of rural regions, including mountain areas. The Commission has stated that it will continue to promote and mobilize Community support instruments and programmes in favour of tourism. 